\title{
Post-Translational Modifications of G Protein-Coupled Receptors Control Cellular Signaling Dynamics in Space and Time
}

\author{
Anand Patwardhan, Norton Cheng, and (D) JoAnn Trejo \\ Department of Pharmacology and the Biomedical Sciences Graduate Program, School of Medicine, University of California, San Diego, \\ La Jolla, California
}

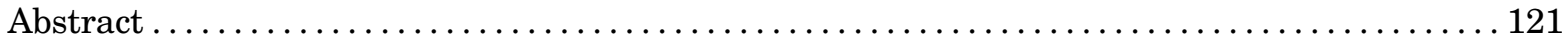

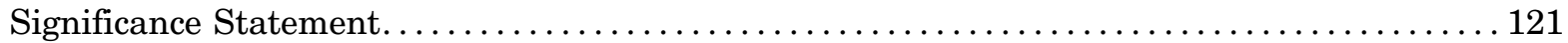

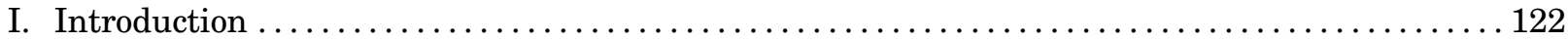

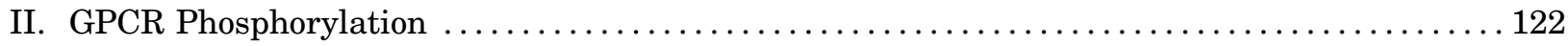

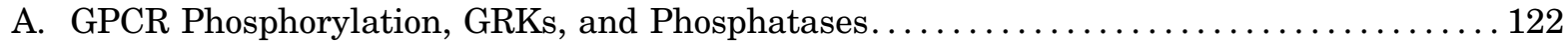

B. GPCR Phosphorylation, Desensitization, and Internalization ................... 124

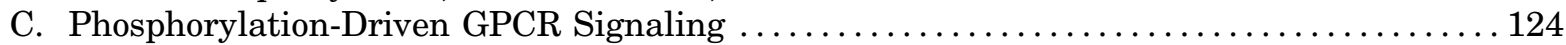

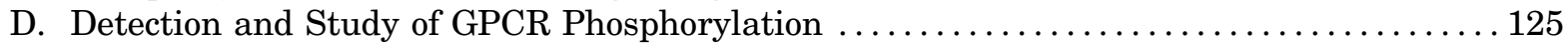

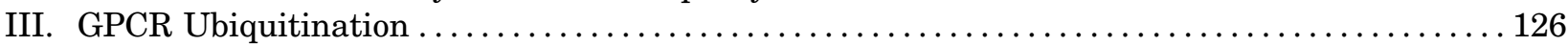

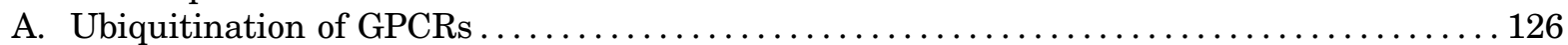

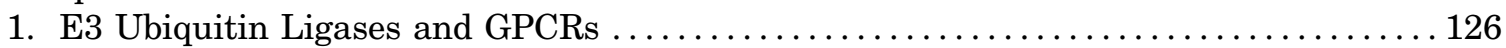

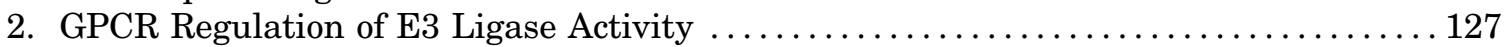

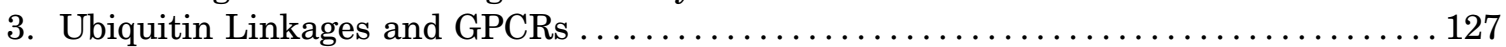

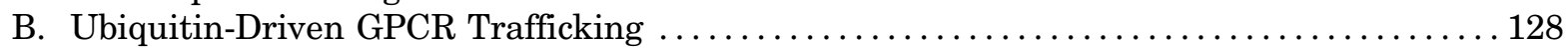

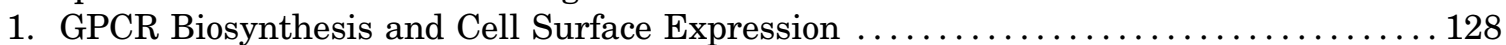

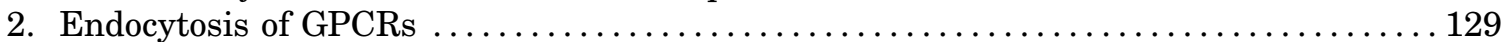

3. Lysosomal Sorting of GPCRs . . . . . . . . . . . . . . . . . . . . . . . . . . . 129

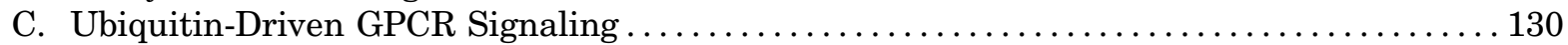

1. Ubiquitin and Plasma Membrane GPCR Signaling $\ldots \ldots \ldots \ldots \ldots \ldots \ldots \ldots \ldots \ldots \ldots \ldots$

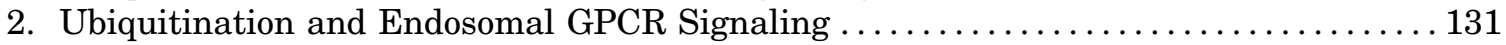

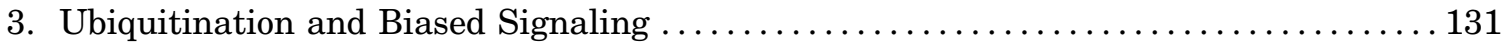

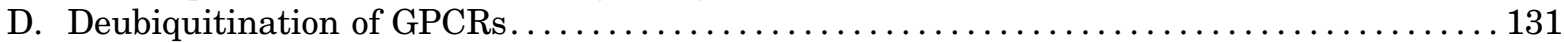

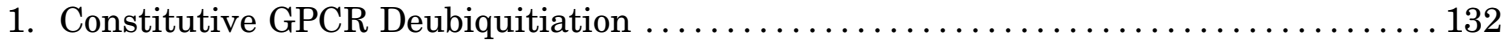

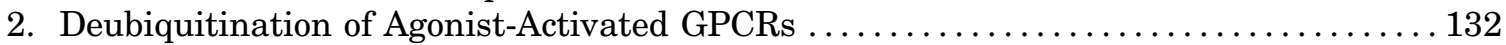

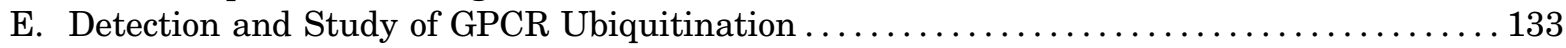

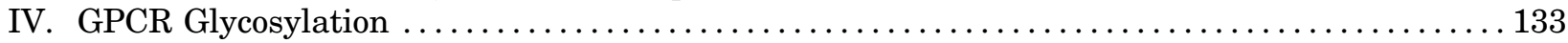

A. GPCRs and N-Linked and O-Linked Glycosylation .......................... 134

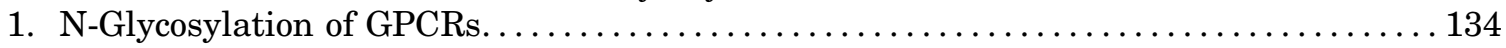

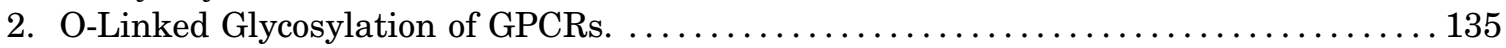

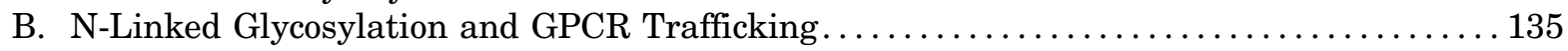

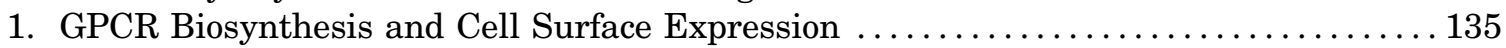

2. GPCR Plasma Membrane Compartmentalization and Internalization ............. 136

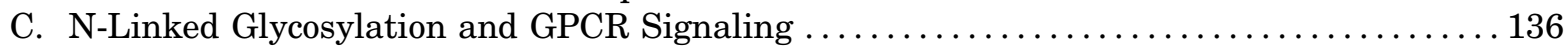

1. N-Glycosylation, Ligand Binding, and GPCR Signaling ................... 136

2. N-Linked Glycosylation and GPCR Biased Signaling..................... 137

\footnotetext{
Address correspondence to: Dr. JoAnn Trejo, Department of Pharmacology and the Biomedical Sciences Graduate Program, School of Medicine, University of California, San Diego, 9500 Gilman Drive, BSB 3044A, MC 0636, La Jolla, CA 92093-0636. E-mail: joanntrejo@ ucsd.edu

This work is supported by the National Institutes of Health National Institute of General Medical Sciences [Grants R35 GM GM127121, T32 GM007752] and the University of California, Tobacco-Related Disease Research Program Postdoctoral Award [T31FT1574].

https://doi.org/10.1124/pharmrev.120.000082.
} 
D. N-Linked Glycosylation and GPCR Dimerization......................... 137

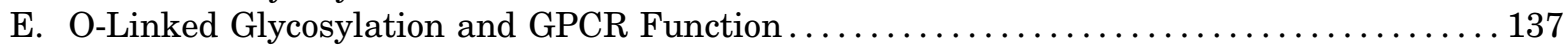

1. O-Glycosylation and GPCR Cell Surface Expression $\ldots \ldots \ldots \ldots \ldots \ldots \ldots \ldots \ldots \ldots \ldots$

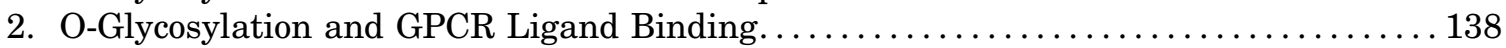

3. O-Glycosylation, GPCR N-Terminal Cleavage, and Signaling. $\ldots \ldots \ldots \ldots \ldots \ldots \ldots \ldots$

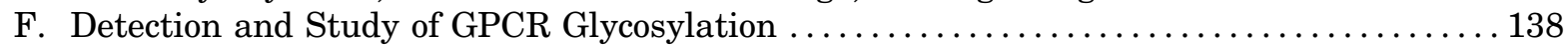

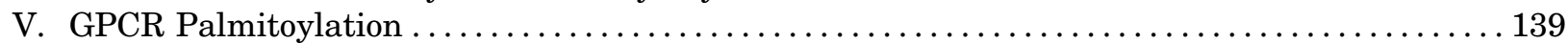

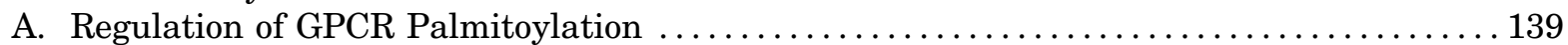

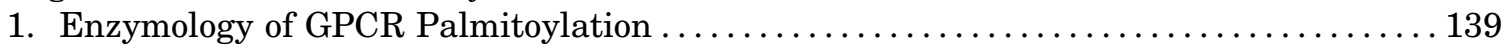

2. Basal and Agonist-Induced GPCR Palmitoylation....................... 140

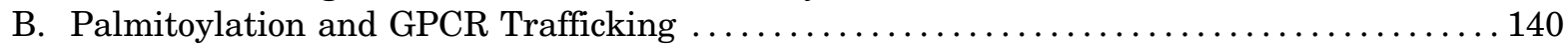

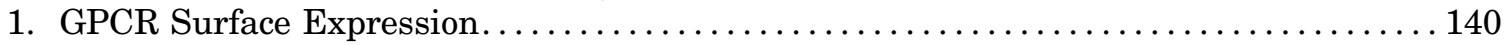

2. GPCR Dimerization and Lipid Rafts............................... 141

3. GPCR Internalization, Recycling, and Lysosomal Degradation $\ldots \ldots \ldots \ldots \ldots \ldots \ldots \ldots 1$

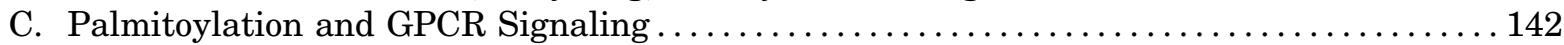

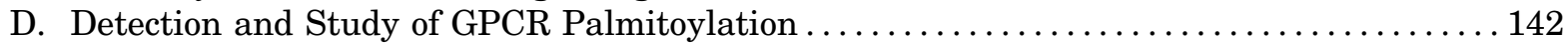

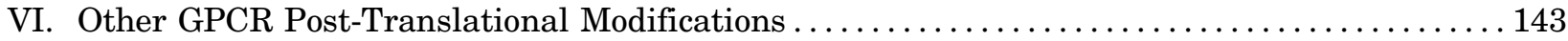

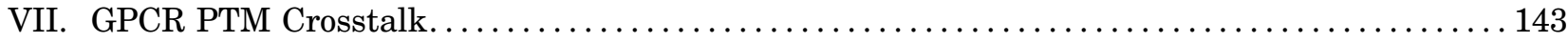

A. GPCR Phosphorylation and Ubiquitination Crosstalk ......................... 143

B. GPCR Phosphorylation and Palmitoylation Crosstalk ....................... 144

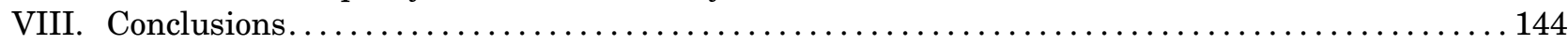

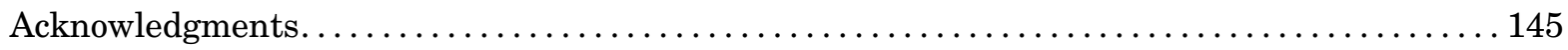

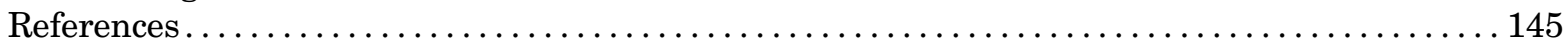

\begin{abstract}
G protein-coupled receptors (GPCRs) are a large family comprising $>800$ signaling receptors that regulate numerous cellular and physiologic responses. GPCRs have been implicated in numerous diseases and represent the largest class of drug targets. Although advances in GPCR structure and pharmacology have improved drug discovery, the regulation of GPCR function by diverse post-translational modifications (PTMs) has received minimal attention. Over 200 PTMs are known to exist in mammalian cells, yet only a few have been reported for GPCRs. Early studies revealed phosphorylation as a major regulator of GPCR signaling, whereas later reports implicated a function for ubiquitination, glycosylation, and palmitoylation in GPCR biology. Although our knowledge of GPCR phosphorylation is extensive, our knowledge of the modifying enzymes, regulation, and function of other GPCR PTMs is limited. In this review we provide a comprehensive overview of GPCR posttranslational modifications with a greater focus on new discoveries. We discuss the subcellular location
\end{abstract}

and regulatory mechanisms that control post-translational modifications of GPCRs. The functional implications of newly discovered GPCR PTMs on receptor folding, biosynthesis, endocytic trafficking, dimerization, compartmentalized signaling, and biased signaling are also provided. Methods to detect and study GPCR PTMs as well as PTM crosstalk are further highlighted. Finally, we conclude with a discussion of the implications of GPCR PTMs in human disease and their importance for drug discovery.

Significance Statement_—Post-translational modification of G protein-coupled receptors (GPCRs) controls all aspects of receptor function; however, the detection and study of diverse types of GPCR modifications are limited. A thorough understanding of the role and mechanisms by which diverse post-translational modifications regulate GPCR signaling and trafficking is essential for understanding dysregulated mechanisms in disease and for improving and refining drug development for GPCRs.

\footnotetext{
ABBREVIATIONS: AIP4, atrophin-1-interacting protein-4; ALIX, apoptosis-linked gene 2-interacting protein X; AMSH, associated molecule with the Src homology 3 domain of STAM; AP-2, adaptor protein complex-2; APT, acyl protein thioesterase; ARRDC, $\alpha$-arrestin domaincontaining protein; $\mathrm{AT}_{1}$, angiotensin type $1 ; \mathrm{AT}_{2}$, angiotensin type 2 ; CCR, chemokine (C-C motif) receptor; CXCR, C-X-C chemokine receptor; DOR, $\delta$-opioid receptor; DUB, deubiquitinase or deubiquitinating enzyme; ECL, extracellular loop; ER, endoplasmic reticulum; ERAD, endoplasmic reticulum-associated protein degradation; ERK, extracellular signal-regulated kinase; ESCRT, endosomal sorting complex required for transport; GalNAc, $N$-acetylgalactosamine; GPCR or GPR, G protein-coupled receptor; GRK, G protein-coupled receptor kinase; HECT, homologous to E6AP C terminus; HRS, hepatocyte growth factor-regulated tyrosine kinase substrate; HT, hydroxytryptamine; ICL, intracellular loop; ILV, intralumenal vesicle; MAP, mitogen-activated protein; $\mathrm{MC}_{1}$, melanocortin 1; mGlu, metabotropic glutamate; MOR, $\mu$-opioid receptor; MVB, multivesicular body; NEDD, neural precursor cell expressed, developmentally downregulated; $\mathrm{NK}_{1}$, neurokinin 1 ; PAR, protease-activated receptor; PAT, palmitoyl acyl transferase; PEG, polyethylene glycol; PKA, protein kinase A; PP, protein phosphatase;

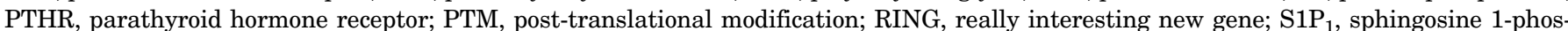
phate; siRNA, small interfering RNA; SMO, smoothened; STAM, signal transducing adapter molecule; Ste2 or Ste2p, Sterile 2; SUMO, small ubiquitin-related modifier; TAB, transforming growth factor $\beta$-activated protein kinase 1-binding protein; UBPY, ubiquitin-specific protease Y; USP, ubiquitin-specific protease; Vps4, vacuolar protein sorting 4; WWP, WW domain-containing E3 ubiquitin protein ligase.
} 


\section{Introduction}

G protein-coupled receptors (GPCRs) are the largest family of cell surface signaling receptors expressed in mammalian cells and control vast physiologic responses. Agonist activation of GPCRs results in coupling to heterotrimeric $\mathrm{G}$ proteins at the plasma membrane and in signaling from endosomes. Signaling by GPCRs is tightly controlled by desensitization, internalization, and lysosomal sorting. Dysregulation of GPCR signaling is prevalent in disease and has been largely attributed to either a deficiency in signaling or an overabundance of signaling responses. These features, combined with the high druggability of GPCRs, have made this receptor class the largest target of drugs, currently representing over $34 \%$ of all Food and Drug Administration-approved therapeutics (Hauser et al., 2017; Sriram and Insel, 2018). Despite recent advances in GPCR structure and pharmacology, one aspect of GPCR regulation that has remained largely ignored is the contribution of posttranslational modifications.

GPCRs are synthesized on ribosomes, large macromolecular structures that are responsible for translating mRNA into nascent polypeptides. All GPCR proteins are modified at least once during their lifetime, and this occurs either cotranslationally during biosynthesis or post-translationally after synthesis and delivery to the cell surface. Post-translational modifications (PTMs), including cotranslational modifications, enable proper GPCR folding and maturation in the biosynthetic pathway as well as regulation of receptor stability and degradation. PTMs occur at amino acid side chains of the GPCR present in the $\mathrm{N}$-terminus, extracellular loops (ECLs), intracellular loops (ICLs), transmembrane domain, and the $\mathrm{C}$ terminus (Fig. 1) via enzymatic activity. PTM enzymes are currently known to represent $5 \%$ of the human proteome and perform over 200 different types of modifications mediated by kinases, ligases, transferases and is a reversible process. $\mathrm{Nu}-$ merous studies have documented GPCR phosphorylation, ubiquitination, glycosylation, and palmitoylation, whereas there are far fewer reports of GPCR tyrosine sulfation, methylation, small ubiquitin-like modifier (SUMO)-ylation, and nitrosylation (Fig. 1). Although the number of GPCRs shown to be modulated by PTMs has rapidly increased over the last two decades, our knowledge of the types of GPCR modifications as well as the regulation and function of PTMs is limited.

A major function of GPCR post-translational modifications is to control the spatial and temporal dynamics of receptor signaling and appropriate physiologic responses. This is best characterized for GPCR phosphorylation. Similar to phosphorylation, GPCR modification with ubiquitination, glycosylation, and palmitoylation controls the dynamics of cellular signaling and is a reversible and finely regulated process. Although our knowledge of the role of phosphorylation in regulating GPCR biology is extensive, we have a limited understanding of the regulation and diverse functions by which other established PTMs control GPCR signaling. Here a comprehensive overview of post-translational modifications of GPCRs is presented with a focus on newer discoveries that control signaling, beginning with phosphorylation, followed by ubiquitination, glycosylation, and palmitoylation and other rare PTMs (Fig. 1). A discussion of the enzymology for each GPCR PTM, subcellular localization of modifying enzymes, the function of PTMs, methods to study PTMs, and GPCR PTM crosstalk is also provided. We conclude with a discussion of GPCR PTM implications in human disease and drug discovery.

\section{GPCR Phosphorylation}

Phosphorylation is a major regulator of GPCR cell signaling dynamics and is the best studied posttranslational modification for this large receptor family expressed in mammalian cells. Phosphorylation occurs through the kinase-catalyzed transfer of $\gamma$-phosphate from ATP primarily to serine and threonine residues of GPCRs and rarely on tyrosine residues (Fig. 2A). GPCR phosphorylation is mediated primarily by GPCR kinases (GRKs), a widely studied family of kinases, as well as second messenger kinases such as protein kinase $\mathrm{A}(\mathrm{PKA})$ and protein kinase $\mathrm{C}$. Phosphorylation of GPCRs is a reversible process and mediated by phosphatases through poorly understood mechanisms (Fig. 2A). GPCR phosphorylation and function have been comprehensively reviewed elsewhere (Pitcher et al., 1998; Reiter and Lefkowitz, 2006; Moore et al., 2007; Gurevich and Gurevich, 2019). Here, we briefly discuss GPCR phosphorylation with a focus on recent discoveries.

\section{A. GPCR Phosphorylation, GRKs, and Phosphatases}

A family of seven GRKs are primarily responsible for GPCR phosphorylation. GRKs are serine/threonine kinases that exhibit tissue-specific expression. GRK1 and 7 are expressed in the visual system, GRK4 is expressed in the testes, and GRK2 and 3 and GRK5 and 6 are ubiquitously expressed, although certain tissues and cell types exhibit preferential expression of specific GRK subtypes (e.g., GRK2 and GRK5 are highly expressed in the heart). GRKs are exquisitely regulated and activated upon binding to agonist-activated GPCRs enabling the phosphorylation of receptor-specific serine and threonine residues (Fig. 3) (Gurevich and Gurevich, 2019), unlike many kinases that recognize consensus sequences within targeted proteins. However, GRKs 


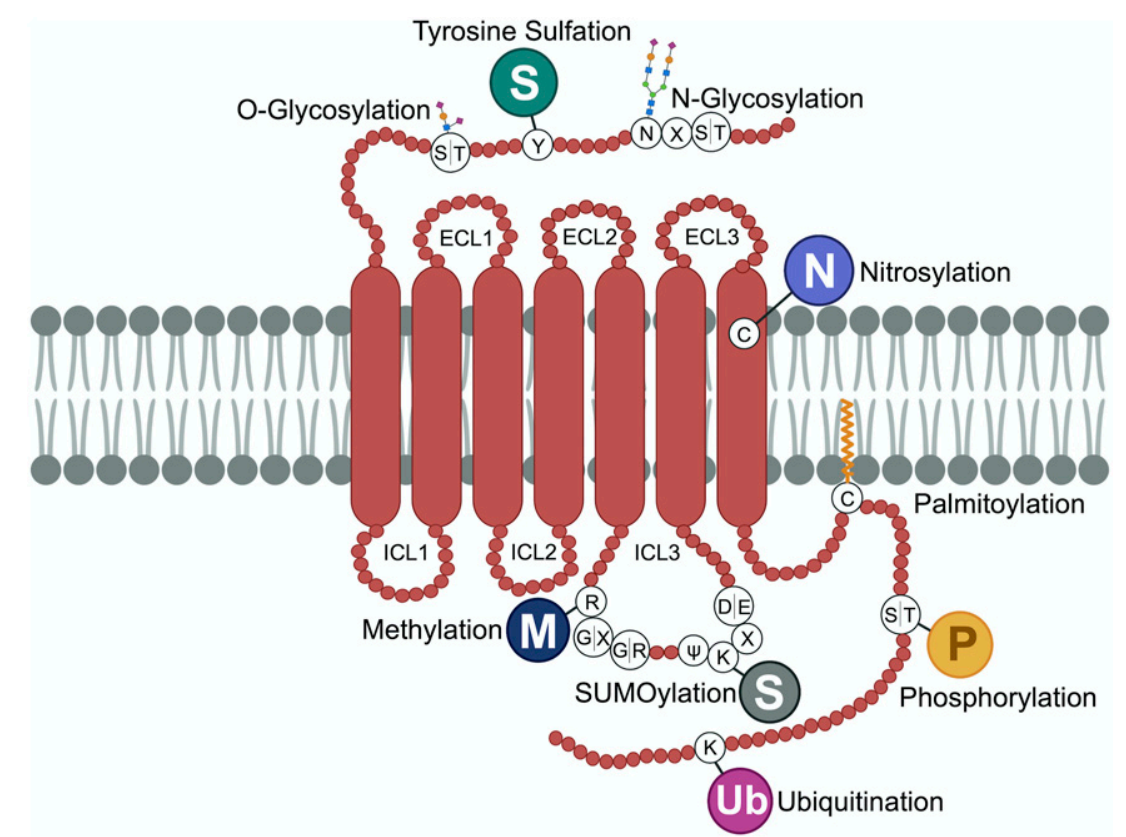

Fig. 1. GPCR post-translational modifications. GPCRs are seven-transmembrane proteins subjected to multiple types of PTMs on ECLs, ICLs, and the C-terminal domain. Here we show the most common sites of GPCR PTMs. PTMs that occur on ECLs include the following: $N$-glycosylation at asparagine $(\mathrm{N})-\mathrm{X}$-serine $(\mathrm{S}) /$ threonine $(\mathrm{T})$ sites, where $\mathrm{X}$ is any amino acid other than proline; $O$-glycosylation at $\mathrm{S}$ or $\mathrm{T}$ residues; and tyrosine $(\mathrm{Y})$ sulfation. Nitrosylation has been shown to occur at transmembrane cysteine (C) residues. PTMs on intracellular loops include the following: SUMOylation on K residues present in the motif $\psi$-K-X-(D/E), where $\psi$ is aliphatic amino acid, $\mathrm{X}$ is any amino acid, aspartic acid is $\mathrm{D}$, and glutamic acid is E; methylation at arginine (R) residues of R-G-G or R-X-R sites, where glycine is G and X is any amino acid; and palmitoylation at cysteine (C). GPCR C-terminal PTMs include phosphorylation on S or T, rarely on Y residues, and ubiquitination (Ub) on specific $\mathrm{K}$ residues.

must be brought in close proximity to the GPCR substrate embedded in the plasma membrane to facilitate phosphorylation, and this is accomplished through different mechanisms. GRK1 and 7 are post-translationally modified by prenylation, and GRK4, 5, and 6 either are palmitoylated or contain an amphipathic helix that binds membrane phospholipids and thereby are constitutively associated with the plasma membrane. GRK2 and 3 are actively recruited to the GPCR after G protein activation and release of $\beta \gamma$-subunits, which bind the pleckstrin homology domain of GRK2 and 3. Besides GRKs, other kinases are known to specifically phosphorylate GPCRs on serine or threonine residues, such as the second messenger kinases PKA, protein kinase $\mathrm{C}$, and casein kinase II, known to target conserved motifs for phosphorylation, that occur either basally or after agonist stimulation, but far less is known about unifying regulatory mechanisms, and phosphorylation appears to be receptor specific.

GPCRs are phosphorylated on multiple residues within the C-terminal tail and on the ICLs (Tobin et al., 2008). In some cases, GPCR phosphorylation is sequential as demonstrated for rhodopsin and other GPCRs. The chemokine receptor $N$-formyl peptide receptor C5a receptor is basally phosphorylated, which appears to prime the receptor for ligand-stimulated phosphorylation (Schreiber et al., 1994; Milcent et al., 1999). Similarly, basal phosphorylation of the bradykinin $B_{2}$ receptor is required for subsequent agonist-induced phosphorylation (Blaukat et al., 2001). In contrast, several
GPCRs display hierarchal agonist-induced phosphorylation, including the $\delta$-opioid receptor (DOR) (Kouhen et al., 2000) and the muscarinic $M_{3}$ receptor (Torrecilla et al., 2007).

Phosphorylation of GPCRs is reversible. As shown here, agonist-induced protease-activated receptor (PAR)1 phosphorylation is rapid, occurs within minutes, and is reversed after agonist removal (Fig. 2B), whereas continuous exposure to agonist results in sustained phosphorylation for at least 30 minutes (Fig. 2B). Unlike agonist-induced GPCR phosphorylation, the regulatory mechanisms that control GPCR dephosphorylation remain poorly understood. This is due in part to the complexity of protein phosphatases (PPs) that exist as multisubunit enzymes and the variety of PPs expressed in mammalian cells, including PP1, PP2A, PP2B (calcineurin), PP3, PP4, and PP5. Protein phosphatase 2A was initially implicated in dephosphorylation of $\beta_{2^{-}}$ adrenoreceptor after agonist stimulation (Pitcher et al., 1995; Krueger et al., 1997), whereas other activated GPCRs appear to be dephosphorylated by $\mathrm{PP} 1 \alpha, \beta$, and $\gamma$ catalytic subunits as well as PP2A and PP2B phosphatases. Dephosphorylation of GPCRs can occur at the plasma membrane and/or on intracellular vesicles (Kliewer et al., 2017) and generally appears to regulate receptor recycling, resensitization, and cellular responsiveness (Fig. 3). Currently, however, there is limited understanding of the mechanisms of PP recruitment, regulation, and the impact on the spatial and temporal dynamics of GPCR signaling. 


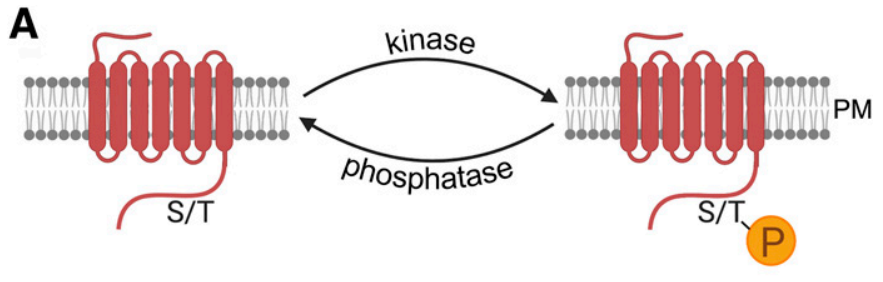

B

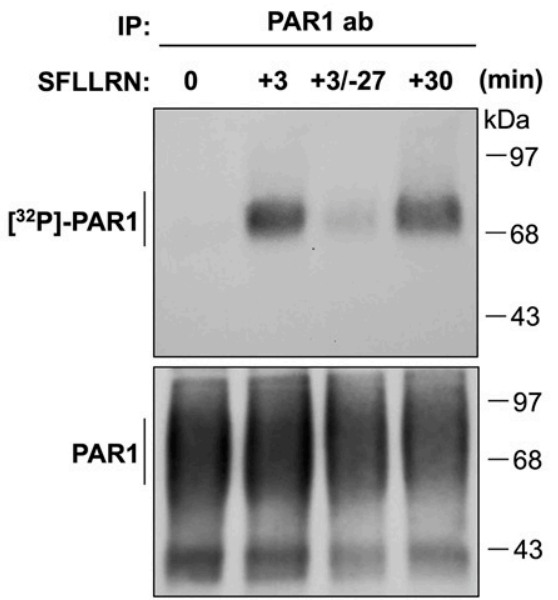

Fig. 2. GPCR phosphorylation. (A) Agonist-activated GPCRs are phosphorylated at the cell surface primarily by GRKs, commonly at the C terminus on serine $(\mathrm{S})$ or threonine $(\mathrm{T})$ residues. Dephosphorylation of GPCRs is carried out by phosphatases. (B) Activation of PAR1 results in rapid phosphorylation as detected by immunoprecipitated (IP) $\left[{ }^{32}\right] \mathrm{P}$ labeled PAR1 and autoradiography after 3 minutes of stimulation with peptide agonist $100 \mu \mathrm{M}$ SFLLRN of PAR1 expressed in Rat1 fibroblasts. In PAR1-expressing cells stimulated with SFLLRN peptide for 3 minutes, followed by wash and chase for 27 minutes without agonist, PAR1 phosphorylation was no longer detectable, whereas continuous stimulation with SFLLRN for 30 minutes sustained phosphorylation. These findings suggest that PAR1 is subjected to phosphorylation and dephosphorylation. PAR1 protein from IPs detected by immunoblot with PAR1 antibody as shown in the bottom panel. ab, antibody; PM, plasma membrane; SFLLRN, Ser-Phe-Leu-Leu-Arg-Asn.

\section{B. GPCR Phosphorylation, Desensitization, and Internalization}

The major function of GPCR phosphorylation is to promote the recruitment of $\beta$-arrestins, which are multifunctional adaptor proteins that were first shown to mediate receptor uncoupling from $G$ protein signaling or desensitization and subsequently demonstrated to promote receptor internalization (Fig. 3). The arrestin family includes two visual arrestins and two ubiquitously expressed $\beta$-arrestins, termed $\beta$-arrestin- 1 and -2 , that are highly conserved and share high sequence homology. After agonist activation, $\beta$-arrestins are recruited to activated phosphorylated GPCRs through a multistep process that results in $\beta$-arrestin conformational rearrangements that allow competition with $G$ protein binding to the same interhelical cavity localized within the cytoplasmic region of the GPCR (Gurevich and Gurevich, 2006). In addition, $\beta$-arrestin engagement with activated phosphorylated GPCRs is also mediated by receptor-associated phosphates, indicating that two distinct features of the receptor control $\beta$-arrestin-GPCR engagement (Fig. 3). This creates high-affinity binding that easily competes with $G$ proteins, which when bound to GTP readily dissociate from the receptor.

The diversity of $\beta$-arrestin function was established by the demonstration that $\beta$-arrestins not only control GPCR desensitization but also interact with the endocytic machinery to promote GPCR internalization (Fig. 3). During $\beta$-arrestin activation, the C-terminal bound to the polar core of $\beta$-arrestin is displaced by the binding of the GPCR phosphorylated C-tail (Peterson and Luttrell, 2017). The release of the $\beta$-arrestin $\mathrm{C}$ terminus then enables engagement with the clathrin endocytic machinery through binding to both clathrin and the clathrin adaptor protein complex-2 (AP-2) via recognition of consensus clathrin and AP-2 binding motifs present in the $\mathrm{C}$ terminus of $\beta$-arrestin (Goodman et al., 1996; Laporte et al., 1999). Ultimately, this results in activated GPCR recruitment to clathrin-coated pits and internalization from the plasma membrane (Fig. 3). Generally, internalization of activated GPCRs serves to terminate $G$ protein signaling; however, new evidence suggests that at least for certain GPCRs, internalization permits a second phase of signaling mediated by either $G$ proteins or $\beta$-arrestins on endocytic vesicles, as discussed below (Fig. 3) (Lobingier and von Zastrow, 2019; Weinberg et al., 2019).

\section{Phosphorylation-Driven GPCR Signaling}

Although the major function of agonist-induced GPCR phosphorylation historically has been ascribed to turning off signaling mediated by rapid desensitization via uncoupling from $G$ proteins as well as internalization and downregulation, which removes the activated receptor from $G$ protein effectors at the plasma membrane (Fig. 3) (DeWire et al., 2007), previous studies indicate that receptor phosphorylation can initiate a new type of signaling. The first example of GPCR phosphorylation initiation of signaling was described for $\beta_{2}$-adrenoceptor C-tail phosphorylation by PKA, which results in uncoupling to Gs protein and increased coupling to Gi protein (Daaka et al., 1997; Zamah et al., 2002). In newer work, phosphorylationdriven GPCR signaling is mediated primarily by the engagement and conformation of the activated GPCRbound $\beta$-arrestin protein (Fig. 3). A substantial literature supports the notion that $\beta$-arrestins can mediate signaling (Peterson and Luttrell, 2017; Gurevich and Gurevich, 2019); however, the precise mechanism that controls $\beta$-arrestin-dependent signaling remains controversial (O'Hayre et al., 2017; Luttrell et al., 2018). Regardless, $\beta$-arrestin-mediated signaling is diverse and differs for the receptor and cellular contexts. In some cases, activated GPCRs engage $\beta$-arrestins to promote Src-dependent signaling and function as scaffolds to promote activation of various mitogen-activated protein (MAP) kinase signaling cascades (Peterson and Luttrell, 2017; Gurevich and Gurevich, 2019). Interestingly, recent studies indicate that certain GPCRs can 


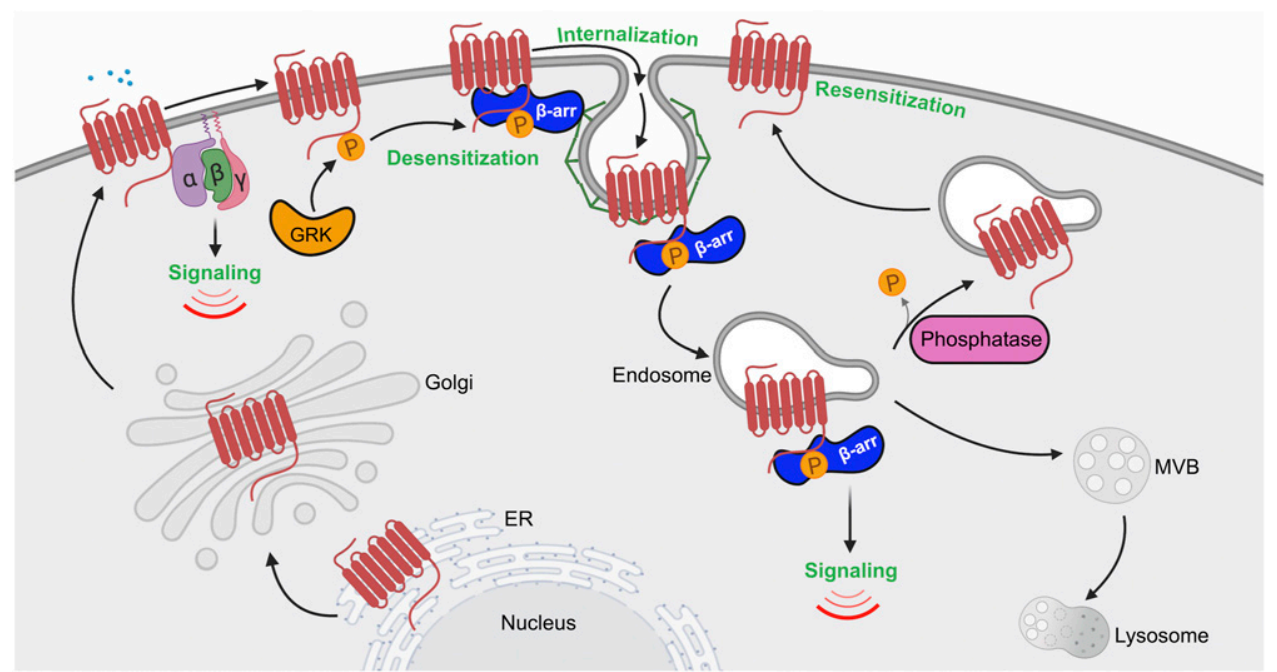

Fig. 3. Model of GPCR regulation by phosphorylation. The schematic presents a classic view of GPCR regulation by phosphorylation in the cell. Agonist activation of a GPCR causes a conformational change that facilitates coupling to heterotrimeric G proteins $(\alpha, \beta, \gamma)$ and initiation of intracellular signaling cascades. Subsequently, GRKs are recruited and phosphorylate activated GPCRs at the C terminus, resulting in increased affinity and binding of $\beta$-arrestins ( $\beta$-arr). $\beta$-arrestins compete with $\mathrm{G}$ protein binding to the same interhelical cavity localized within the cytoplasmic region of the GPCR. Once bound to the GPCR, $\beta$-arrestins prevent G protein coupling (desensitization) and facilitate association with clathrin and the endocytic machinery to promote internalization. Clathrin-coated pits bud inward and pinch off from the plasma membrane to form endocytic vesicles or endosomes. Once internalized, phosphorylation controls GPCRs' capacity to nucleate the assembly of an endosomal $\beta$-arrestin signaling complex or, if dephosphorylated, GPCRs recycle from endosomes and return to the plasma membrane resulting in resensitization.

bind $\beta$-arrestin and $\mathrm{G}$ protein simultaneously via distinct interaction sites; this is particularly relevant for receptors that contain clusters of serine and threonine phosphorylation sites within the C-tail domain (Thomsen et al., 2016; Cahill et al., 2017). A subsequent study nicely demonstrates that an active chimeric $\beta_{2^{-}}$ adrenoceptor fusion with the $\mathrm{C}$-tail of the vasopressin $\mathrm{V}_{2}$ receptor is capable of activating both $\mathrm{G}$ protein and $\beta$-arrestin to facilitate sustained internalized $\mathrm{G}$ protein signaling from endosomes (Nguyen et al., 2019). Moreover, different phosphorylation patterns on the activated GPCR C-tail appear to generate distinct phosphorylation bar codes that can induce conformationally unique active states of arrestins that govern different cellular responses (Shukla et al., 2008; Butcher et al., 2011; Liggett, 2011; Mayer et al., 2019). These studies indicate that the spatial and temporal diversity of GPCR signaling is driven in part by $\beta$-arrestin-mediated signaling, which is primarily controlled by GPCR phosphorylation that regulates the recruitment and activation of $\beta$-arrestin functionality.

\section{Detection and Study of GPCR Phosphorylation}

The study of GPCR phosphorylation has been enabled by the ability to detect and control receptor phosphorylation using a variety of approaches. Computational methods to predict GPCR phosphorylation sites and cognate kinases such as NetPhos3.1, GPS (Group-Based Phosphorylation Scoring), Scansite, PHOSIDA (Phosphorylation Site Database), dbPAF (Database of Phospho-Sites in Animals and Fungi), and Musite are currently available (Blom et al., 1999, 2004; Obenauer et al., 2003; Xue et al., 2005; Shukla et al., 2008; Gnad et al., 2011; Ullah et al., 2016). One conventional and established methods for detection of GPCR phosphorylation is through metabolic labeling of cultured mammalian cells with $\left[{ }^{32} \mathrm{P}\right]$ orthophosphate (Fig. 2B). These assays require the use of radioactive inorganic phosphate and receptor-specific antibodies for immunoprecipitation, which is required for enrichment of phosphorylated receptors, provides a global assessment of GPCR phosphorylation, and has been demonstrated for numerous GPCRs, including PAR1 (Fig. 2B) (Trejo et al., 1996), and well documented in several classic reviews (Sibley et al., 1987; Benovic et al., 1990). A second approach to determine more detailed information about the pattern of phosphorylation of GPCR is two-dimensional peptide mapping as described by Prihandoko et al. (2015). This method also requires metabolic labeling with $\left[{ }^{32} \mathrm{P}\right]$ orthophosphate, immunoprecipitation, and proteolytic digestion and thin layer chromatography. However, the disadvantage of these techniques is that neither provides information about the actual sites of phosphorylation, which requires mass spectrometry.

Although significant advancements in mass spectrometry have enabled the detection of GPCR phosphorylation, it has been hampered by requiring large amounts of receptor, which is challenging for a receptor class that is typically expressed in cells at low levels. Nonetheless, mass spectrometry has been used to detect phosphorylation of several GPCRs, including the $\beta_{2^{-}}$ adrenoceptor (Trester-Zedlitz et al., 2005) and muscarinic $\mathrm{M}_{3}$ receptor (Butcher et al., 2011). Indeed, a mass spectrometry-based quantitative proteomic approach was used to map $\beta_{2}$-adrenoceptor phosphorylation sites 
induced by biased agonists and linked the distinct patterns phosphorylation sites to GRKs and $\beta$-arrestin function, establishing the "bar code" hypothesis (Nobles et al., 2011). The value of identifying specific sites of GPCR phosphorylation is that it permits the generation of GPCR phospho-specific antibodies, which will greatly increase the study of GPCR phosphorylation. In addition to phosphorylation, the study of GPCR dephosphorylation has been conducted using PP inhibitors such as okadaic acid and calyculin, which target both PP2A and PP1, siRNA-mediated depletion of specific phosphatases, and phospho-specific GPCR antibodies. Detailed methods for the determination of GPCR phosphorylation are described in Prihandoko et al. (2015).

\section{GPCR Ubiquitination}

Post-translational modification with ubiquitin is best known to target proteins for degradation via the 26S proteasome and the lysosome (Hershko and Ciechanover, 1998). Ubiquitin is a small 76 amino acid protein, $\sim 8 \mathrm{kDa}$ protein, that is covalently linked to lysine residues of substrate proteins through the sequential action of three distinct enzymes, E1, E2, and E3 (Fig. 4A). Although most proteins are predicted to be modified with ubiquitin at least once during their lifetime, only a small subset of approximately 40 GPCRs have been reported to be ubiquitinated (Jean-Charles et al., 2016). In most of the studies, ubiquitin appears to function mainly as a signal that facilitates GPCR trafficking within the endosomal-lysosomal pathway or targeting to the proteasome (Petaja-Repo et al., 2000; Katzmann et al., 2001; Milojevic et al., 2006). However, new emerging studies indicate that for certain GPCRs, ubiquitin promotes direct interaction with signaling effectors (Grimsey et al., 2015). Thus, the function of ubiquitination may vary depending on the GPCR, cell type, and physiologic function, as discussed below.

\section{A. Ubiquitination of GPCRs}

Ubiquitination is mediated by three types of enzymes: ubiquitin-activating enzymes E1, ubiquitin-conjugating enzymes E2, and ubiquitin ligases E3 (Fig. 4A). Ubiquitin is initially covalently attached by its C-terminal glycine to a cysteine residue of the E1 enzyme and then shuttled to a cysteine residue of the ubiquitinconjugating E2 enzyme. The E2 then binds to the E3 ligase, which directly interacts with the substrate protein and covalently attaches ubiquitin. E3 ubiquitin ligases are critical components of this system since they recognize substrates and thereby provide specificity to the ubiquitination reaction (Fig. 4A). The human genome encodes two E1 enzymes, at least $38 \mathrm{E} 2 \mathrm{~s}$, and $>600$ E3 ubiquitin ligases (Zheng and Shabek, 2017). The E3 ubiquitin ligases encoded in the human proteome are divided into three classes and include 1) really interesting new gene (RING)-type E3 ligases, which represents the largest family with $>600$ members; 2) homologous to E6AP C terminus (HECT)-type E3s, comprising 28 members; and 3) RING between RING-type E3s, with 14 members (Dove and Klevit, 2017; Reiter and Klevit, 2018). GPCRs are distinctly regulated by E3 ubiquitin ligases via diverse mechanisms.

1. E3 Ubiquitin Ligases and GPCRs. E3 ligases of the RING finger family are unique and simultaneously bind to both the charged E2 and the substrate, thereby facilitating the direct transfer of the ubiquitin moiety to the substrate. A notable member of RING family is Casitas B lineage lymphoma, which ubiquitinates
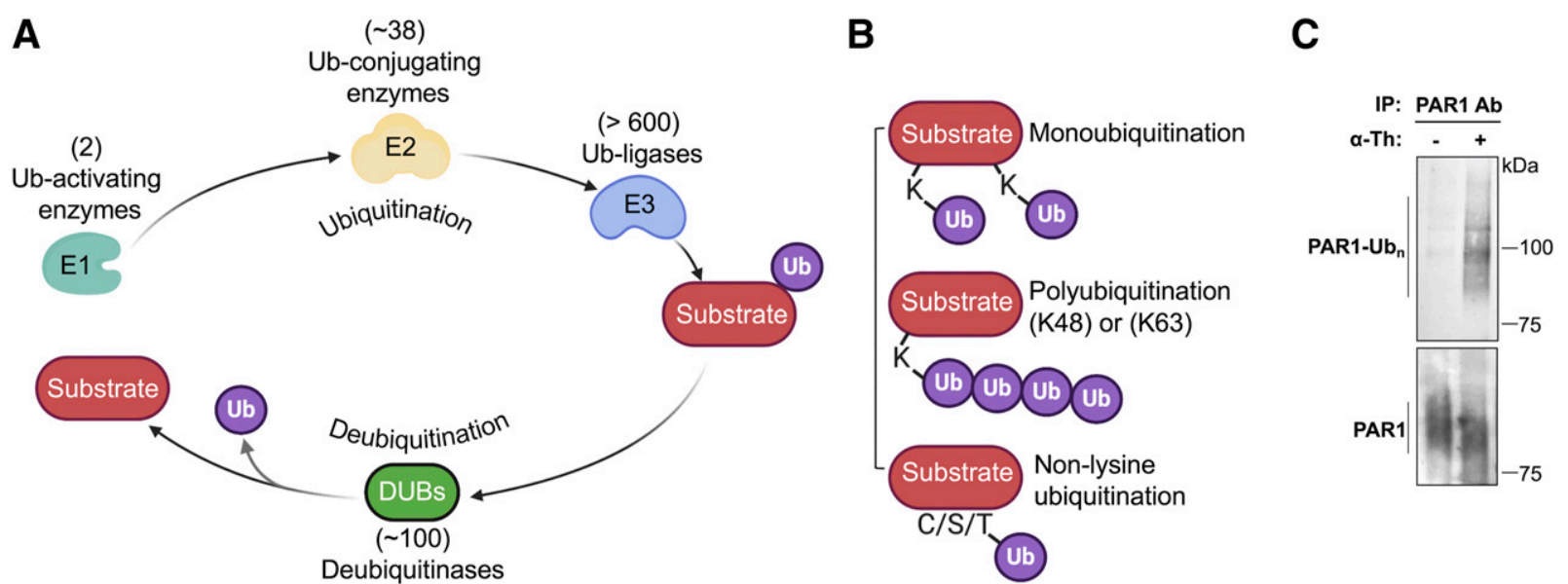

Fig. 4. Ubiquitin modifying enzymes, ubiquitin linkages and detection. (A) Ubiquitination of substrate proteins is carried out sequentially by a ubiquitin (Ub)-activating enzyme E1, $\sim 38$ ubiquitin-conjugating enzyme E2s, and $>600$ ubiquitin ligase E3 enzymes. Ubiquitin is enzymatically cleaved by $\sim 100$ deubiquitinases to release ubiquitin back to cytosolic pool. (B) GPCRs are modified with different ubiquitin conjugations, including monoubiquitin (single or multiple monoubiquitin) and K48- or K63-linked polyubiquitin, which regulate distinct functions. Nonlysine ubiquitination has also been reported to occur on GPCRs. (C) Ubiquitination of endogenous PAR1 ubiquitination in endothelial cells after 7-minute stimulation with $10 \mathrm{nM}$ thrombin ( $\alpha$-Th) detected by immunoblotting of immunoprecipitated (IP) PAR1 using anti-pan ubiquitin P4D1 antibody that detects multiple $\mathrm{Ub}_{\mathrm{n}}$ species. N-terminal proteolytic cleavage of PAR1 by thrombin results in reduced protein size of total protein detected by immunoblotting with PAR1 antibody (ab), bottom panel. 
protease-activated receptor-2 (Jacob et al., 2005). In contrast to RING-types, the HECT-type E3 ligases interact with the E2s, which facilitates the transfer ubiquitin to an active site cysteine residue within the E3 HECT catalytic domain. The ubiquitin is subsequently conjugated to lysine acceptor sites of the substrate protein. Of the HECT E3 ubiquitin ligases, the neural precursor cell expressed, developmentally downregulated (NEDD)-4 subfamily is best known to regulate GPCR trafficking. The NEDD4 family contains nine members, including NEDD4, NEDD4-2, atrophin1-interacting protein-4 (AIP4), WW domain-containing E3 ubiquitin protein ligase (WWP) 1, WWP2, Sma- and Mad-related protein-specific E3 ubiquitin ligase proteins 1 and 2, and NEDD-like ubiquitin protein ligases 1 and 2 (Weber et al., 2019). All NEDD4 family members share a similar domain structure, including an aminoterminal C2 domain, three to four WW domains, and a carboxy-terminal catalytic HECT domain. The first authenticated examples of HECT-type E3 ligasemediated ubiquitination of mammalian GPCRs include AIP4-mediated ubiquitination of the C-X-C chemokine receptor (CXCR) 4 (Marchese et al., 2003) and the $\beta_{2^{-}}$ adrenoceptor (Shenoy et al., 2001, 2008). In both cases, agonist-induced GPCR ubiquitination mediates endolysosomal trafficking and receptor degradation. Finally, the RING between RING type of E3 ubiquitin ligases regulate diverse cellular processes (Dove and Klevit, 2017) with the most notable being Parkin, which expedites the clearance of damaged mitochondria via a process called mitophagy (Lazarou et al., 2012). In addition, Parkin mediates endoplasmic reticulum (ER) associated protein degradation (ERAD) of the class A orphan G protein-coupled receptor 37 (GPR37) that regulates ER stress in Parkinson's disease (Berger et al., 2017). GPR37 also functions as an ER chaperone for the Wnt co-receptor lipoprotein receptor-related protein 6 in neuronal progenitor cells, emphasizing the importance of regulating GPR37 function at the ER (Imai et al., 2001; Berger et al., 2017).

2. GPCR Regulation of E3 Ligase Activity. Mammalian GPCRs are differentially modified with ubiquitin in space and time. This suggest that distinct mechanisms likely exist to control the diverse functions of E3 ligases in regulating GPCR ubiquitination. In most studies, regulation of HECT domain-containing NEDD4 E3 ubiquitin ligase activity appears to occur through recruitment of the E3 ligase to the GPCR substrate either directly through noncanonical WW domain-mediated interactions, as demonstrated for the CXCR4 and E3 ligase AIP4 (Bhandari et al., 2009), or indirectly through interactions with adaptor proteins, mainly $\beta$-arrestin recruitment of NEDD4 to $\beta_{2}$-adrenoceptor (Shenoy et al., 2008) and metabotropic glutamate $(\mathrm{mGlu})_{7}$ receptor (Lee et al., 2019). The less studied, mammalian $\alpha$-arrestin domain-containing proteins (ARRDCs) may also function as adaptors to recruit
E3 ligases to GPCRs (Alvarez, 2008). Several studies indicate that NEDD4 E3 ligases are exquisitely regulated through release of autoinhibition, which can occur through allosteric interactions (Rotin and Kumar, 2009) or via ligand-induced phosphorylation (Persaud et al., 2014) specifically at tyrosine residues (Chen et al., 2017b). A recent study demonstrated that endothelial GPCRs can also regulate NEDD4 E3 ligase activity by release of autoinhibition. In this work, thrombinactivated PAR1 stimulates c-Src-mediated phosphorylation of NEDD4-2 at tyrosine $(\mathrm{Y})^{485}$ located within the autoinhibitory 2,3- linker peptide between WW domains 2 and 3, leading to its activation and ubiquitination of PAR1 (Fig. 4C) (Grimsey et al., 2018). This ultimately results in activated PAR1-stimulated p38 MAP kinase activation and regulation of endothelial inflammatory responses (Grimsey et al., 2018). The purinergic P2Y1 receptors also required c-Src and NEDD4 tyrosine phosphorylation for endothelial inflammatory signaling (Grimsey et al., 2018).

3. Ubiquitin Linkages and GPCRs. GPCR ubiquitination occurs on intracellular loops and on the C-terminal tail (Komander and Rape, 2012). GPCRs can be modified at one or multiple lysine residues with either monoubiquitin, as shown for the yeast $\alpha$-factor receptor Sterile 2 (Ste2 or Ste2p), and CXCR4 or via polyubiquitin chains such as K63-linked ubiquitin for PAR1 (Fig. 4, B and C) (Grimsey et al., 2015), which can differentially affect receptor function. Ubiquitin chains are formed through ubiquitin linkages at several lysine sites within the ubiquitin molecule, including well characterized branched K48-, K63-, and linear N-terminal methionine-linked ubiquitin, offering numerous possibilities of ubiquitin polymer assembly (Fig. 4B) (Peng et al., 2003). In general, monoubiquitin and K63-linked ubiquitin predominate as sorting signals for GPCRs within the endocytic pathway (Terrell et al., 1998; Gulia et al., 2017). However, for certain GPCRs, K63 ubiquitin linkage has been recently implicated in regulating signaling from endosomes (Grimsey et al., 2015). Ubiquitin K48 and K11 linkages serve as a potent proteasomal degradation signals, whereas K29 and K63 linkages function to target substrate proteins for degradation via autophagy (Mukhopadhyay and Riezman, 2007). However, as an internalization signal, a single ubiquitin is exceptionally weak, and ubiquitin is likely operational only as polyubiquitin chains (Barriere et al., 2006). In the case of proteasomal degradation, proteins bearing chains of at least four ubiquitin molecules are the preferred substrates of the 26S proteasome (Chau et al., 1989). Recently, linkage of ubiquitin moieties to nonlysine nucleophilic residues such serine, cysteine, and threonine residues, as well as the free amino group of the N-terminus of proteins, has been demonstrated (Fig. 4B) (McDowell and Philpott, 2016). However, conjugates generated from ubiquitination on nonlysine residues are thermodynamically less 
stable than those generated on canonical lysine residues (McClellan et al., 2019). A recent study showed that a lysine-deficient dopamine $\mathrm{D}_{4}$ receptor was ubiquitinated on cytoplasmic serine and threonine residues that is important for regulating proteasomal degradation (Skieterska et al., 2015; Peeler et al., 2017). Whether nonlysine ubiquitination of GPCRs is common to other GPCRs remains to be determined.

\section{B. Ubiquitin-Driven GPCR Trafficking}

The control of GPCR cellular signaling dynamics is extensively regulated and ultimately governed by receptor expression and activity. Tight regulation of GPCR activity is achieved in part by ubiquitindependent receptor trafficking (Fig. 5). GPCRs are generally subjected to two modes of ubiquitinationconstitutive or basal ubiquitination and ligand-induced ubiquitination-during their lifetime (Dores and Trejo, 2012).

1. GPCR Biosynthesis and Cell Surface Expression. Constitutive or basal GPCR ubiquitination functions primarily to control receptor trafficking through the biosynthetic pathway. During biogenesis, newly synthesized GPCRs are folded in the ER with the assistance of chaperone proteins, undergo maturation in the Golgi, and then traffic to the plasma membrane (Fig. 5). However, misfolded or incompletely folded GPCRs are polyubiquitinated, retro-translocated from the ER to the cytosol via the ERAD quality control system, and then shuttled to the proteasome for proteolytic degradation (Fig. 5) (Petaja-Repo et al., 2001; Cook et al., 2003; Huang et al., 2006). Multiple GPCRs have been shown to be modified with K48 polyubiquitin chains during biogenesis and targeted to the $26 \mathrm{~S}$ proteasome for degradation, often resulting from receptor mutations that can underlie the basis for disease, as reported for the visual GPCR rhodopsin and the vasopressin $\mathrm{V}_{2}$ receptor (Conn et al., 2007; Robben et al., 2009; Athanasiou et al., 2018). This has prompted the development of small molecules or pharmacoperones that bind to GPCRs and correct misfolding of mutant receptors (Nakamura et al., 2010) and has been well described for the gonadotropin-releasing hormone receptor (Bernier et al., 2004; Conn et al., 2007). Thus, at the very beginning of the GPCR life cycle, ubiquitination has an important role in regulating receptor biosynthesis.

In addition to biosynthesis, basal ubiquitination of GPCRs is important for regulating receptor expression at the plasma membrane. This has been illustrated for several GPCRs including PAR1, CXCR7, and chemokine (C-C motif) receptor (CCR) 7 (Moriyoshi et al., 2004; Wolfe et al., 2007; Canals et al., 2012). In the case of PAR1, ubiquitination occurs basally and negatively regulates constitutive internalization, thereby increasing cell surface expression (Wolfe et al., 2007). Constitutive internalization of PAR1 is mediated by the clathrin AP-2, where the $\mu 2$-adaptin subunit of AP-2 binds to the $\mathrm{C}$-tail of PAR1 via interaction with a classic tyrosine-based motif $\left(\mathrm{Y}^{420} \mathrm{KKL}^{423}\right)$ rather than $\beta$-arrestins (Paing et al., 2006; Wolfe et al., 2007). Ubiquitination of PAR1 occurs on C-tail lysine residues that has been confirmed by site-directed mutagenesis (Wolfe et al., 2007) and mass spectrometry high-throughput discovery-based analysis, PhosphoSitePlus (Hornbeck et al., 2015), that reside within the tyrosine-based motif

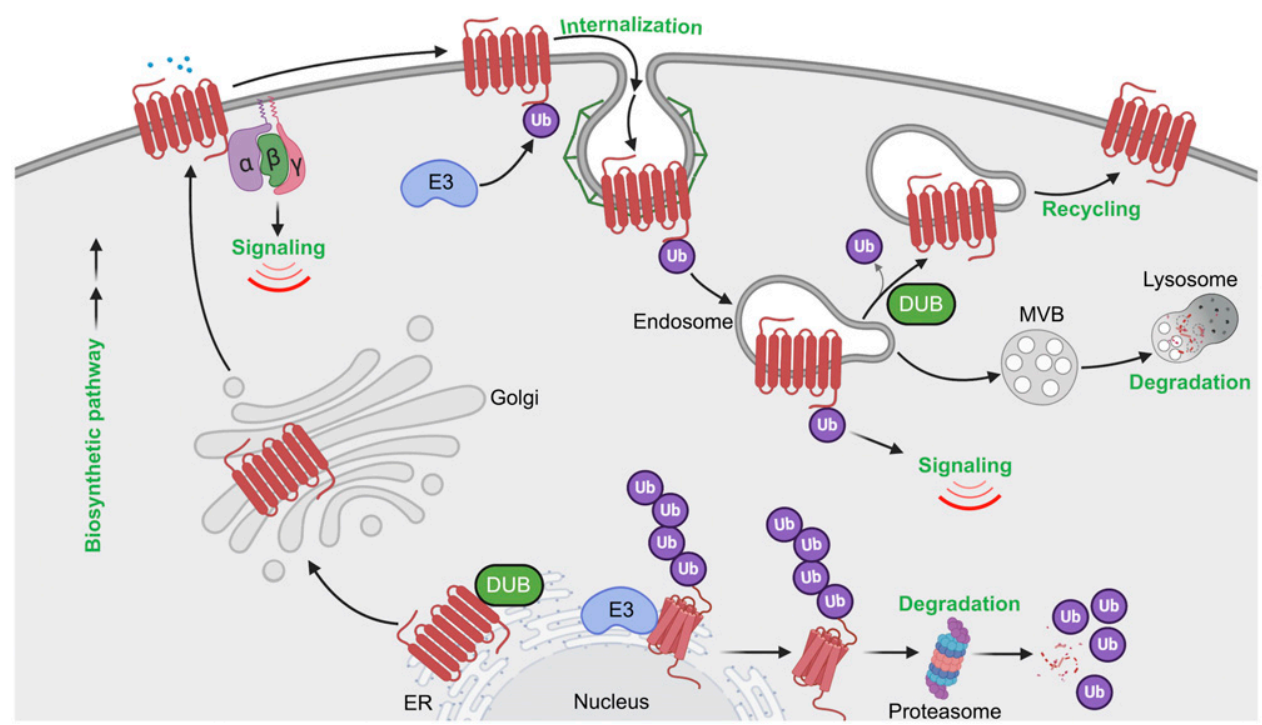

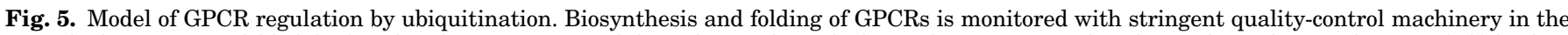

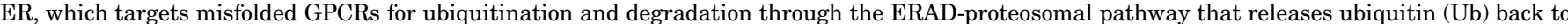

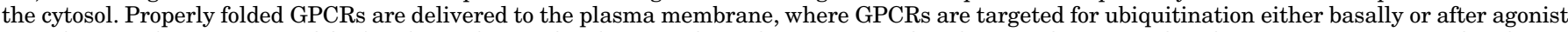

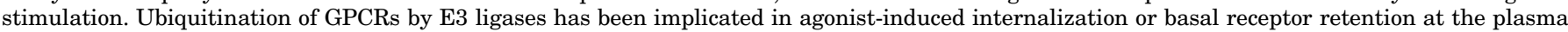

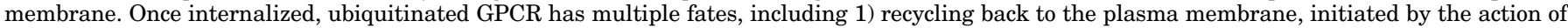
deubiquitinases; 2) targeting for lysosomal degradation; and 3) ubiquitin-driven endosomal signaling. 
and precludes binding of the $\mu 2$-adaptin subunit (Hornbeck et al., 2015). Moreover, a lysineless ubiquitindeficient PAR1 mutant displayed enhanced internalization that was reversed by the fusion of a single ubiquitin moiety to the C-terminal tail, suggesting that ubiquitination is important for retaining PAR1 on the cell surface (Wolfe et al., 2007). Similar to PAR1, basal ubiquitination of the chemokine receptor CXCR7 occurs on a lysine residue located within the $\mathrm{C}$-tail region and is deubiquitinated after agonist activation through a process that requires phosphorylation and $\beta$-arrestin recruitment (Canals et al., 2012). The immune cell expressed CCR7 chemokine receptor is also constitutively modified with K63-linked polyubiquitination and regulates basal trafficking of CCR7 (Schaeuble et al., 2012). A mutant CCR7 defective in ubiquitination alters the spatial distribution of the receptor and impairs immune cell migration (Schaeuble et al., 2012). Thus, basal ubiquitination of GPCRs is important for the appropriate spatial subcellular localization, which has a critical role in governing cellular behavior.

2. Endocytosis of GPCRs. GPCR trafficking through the endocytic pathway is a highly conserved process that includes internalization, recycling, and lysosomal sorting and is regulated by ubiquitination (Fig. 5). A function for ubiquitination in GPCR endocytosis was first described for the yeast Saccharomyces cerevisiae $\alpha$-mating factor GPCR Ste2 (Rohrer et al., 1993). Subsequent studies identified Rsp5, an ortholog of Nedd4like HECT domain E3 ubiquitin ligases, as the key regulator of ligand-induced Ste2p ubiquitination, internalization, and targeting to vacuoles, an organelle equivalent to the mammalian lysosome (Hicke and Riezman, 1996; Dunn and Hicke, 2001). Unlike yeast, most mammalian GPCRs are internalized through clathrin-coated pits via a $\beta$-arrestin-dependent pathway. $\beta$-arrestins act as endocytic adaptors by binding directly to the clathrin heavy chain and to the $\beta$-adaptin subunit of AP-2 (Goodman et al., 1996; Laporte et al., 1999; Gaidarov and Keen, 1999). Interestingly, yeast lack $\beta$-arrestins and rather express a family of ARTs (arrestin-related trafficking proteins) that mediate recruitment of E3 ligases to facilitate internalization of several membrane-spanning proteins, including Ste2 (Alvaro et al., 2014). However, mammalian GPCRs do not require ubiquitination for efficient endocytosis in most cases; in fact, the prevention of ubiquitination has minimal or no effect on endocytosis of a number of GPCRs, including the $\beta_{2}$-adrenoceptor, DOR, and neurokinin $1\left(\mathrm{NK}_{1}\right)$ receptor (Shenoy et al., 2001; Tanowitz and Von Zastrow, 2002; Hanyaloglu et al., 2005). However, not all GPCRs require $\beta$-arrestins for endocytosis, and this is best exemplified for PAR1 (Paing et al., 2002). Instead of $\beta$-arrestins, PAR 1 requires the clathrin adaptors AP-2 and epsin-1 for efficient internalization (Chen et al., 2011). In this case, AP-2 recognizes activated PAR1 phosphorylation sites within the C-tail region rather than the tyrosine-based motif, whereas epsin-1 requires both the ubiquitin-binding motifs of epsin-1 and PAR1 ubiquitination to facilitate efficient endocytosis (Chen et al., 2011).

3. Lysosomal Sorting of GPCRs. The best characterized function of ubiquitination is to target activated receptors to lysosomes for degradation (Fig. 5). The $\beta_{2}$-adrenoceptor was the first mammalian GPCR shown to exhibit ligand-dependent ubiquitination and degradation (Shenoy et al., 2001), and this was closely followed by a report of ligand-induced ubiquitination and degradation of the CXCR4 chemokine receptor (Marchese and Benovic, 2001). Initiation of ligandinduced ubiquitination of GPCRs occurs at the plasma membrane, generally requiring receptor phosphorylation and $\beta$-arrestin recruitment. Isoproterenolstimulated $\beta_{2}$-adrenoceptor is rapidly phosphorylated, which enhances $\beta$-arrestin-mediated recruitment of the NEDD4 E3 ubiquitin ligase (Shenoy et al., 2001, 2008). Mass spectrometry analysis of agonist-induced $\beta_{2}$-adrenoceptor ubiquitination revealed the major sites for polyubiquitination reside in ICL3 at $\mathrm{K}^{263}$ and $\mathrm{K}^{270}$ and in the C-tail at $\mathrm{K}^{348}, \mathrm{~K}^{372}$, and $\mathrm{K}^{375}$ also modified with polyubiquitination (Xiao and Shenoy, 2011), later identified to be K63-type ubiquitin linkages (El Ayadi et al., 2018). A $\beta_{2}$-adrenoceptor variant in which all the phosphorylation sites are mutated showed impaired ubiquitination as well as significantly reduced $\beta$-arrestin interaction (DeWire et al., 2007). In contrast to the $\beta_{2}$-adrenoceptor, CXCR4 displays ligand-induced monoubiquitination (Marchese and Benovic, 2001). The CXCR4 receptor contains two serine residues, $\mathrm{S}^{324}$ and $\mathrm{S}^{325}$, located within the C-tail degradation motif, which are rapidly phosphorylated by agonist activation (Busillo et al., 2010). Agonist-induced ubiquitination of CXCR4 mediated by the E3 ubiquitin ligase AIP4 targets CXCR4 for lysosomal degradation (Marchese et al., 2003). Similarly, thrombin activation of PAR1 results in rapid modification with K63-ubiquitin linkages mediated by the recruitment and activation of NEDD4-2 initiated at the plasma membrane (Fig. 4C) (Grimsey et al., 2015, 2018). Although ligand-induced ubiquitination of GPCRs ultimately controls lysosomal degradation, the time scales for GPCR degradation are vastly different. Activated PAR1 is sorted rapidly to lysosomes and degraded within minutes (Trejo et al., 1998; Trejo and Coughlin, 1999), whereas CXCR4 ubiquitination and degradation occurs much later, within 3-6 hours (Marchese and Benovic, 2001). In contrast, $\beta_{2}$-adrenoceptor is rapidly ubiquitinated, but lysosomal degradation is protracted and occurs after prolonged 6-24 hours of isoproterenol stimulation (Shenoy et al., 2008). Ubiquitination of most classic GPCRs facilitates engagement with the endosomal sorting complex required for transport (ESCRT)-0, -I, -II, and -III machinery. The ubiquitin-binding ESCRT 
components function sequentially to sort GPCRs from endosomes to multivesicular bodies (MVBs) or lysosomes for degradation. The importance of ubiquitin and ESCRTs in receptor lysosomal degradation has been illustrated for several GPCRs. As discussed above, ubiquitination of CXCR4 facilitates lysosomal sorting and requires AIP4-mediated ubiquitination of the ESCRT-0 protein, hepatocyte growth factor-regulated tyrosine kinase substrate (HRS), and vacuolar protein sorting 4 (Vps4), an ATPases associated with diverse cellular activities (AAA)-ATPase (Marchese et al., 2003). Agonist-induced ubiquitination of PAR2 also requires HRS for lysosomal degradation (Hasdemir et al., 2007). Although ubiquitination plays an important role in GPCR lysosomal degradation, there are examples of receptors that can efficiently sort to lysosomes in a ubiquitin-independent manner, as exemplified by DOR. A ubiquitination-deficient DOR mutant is efficiently sorted to the limiting membrane of intralumenal vesicles (ILVs) of MVBs, where extensive proteolytic fragmentation of the receptor ectodomain occurs (Henry et al., 2011). Sorting of DOR to ILVs or MVBs requires HRS and Vps4 but not the ESCRT-I component, tumor susceptibility gene 101 (Hislop et al., 2004), indicating that ubiquitin-independent receptor sorting requires some but not all components of the ubiquitin-binding ESCRT machinery. Ubiquitination of $\mu$-opioid receptor (MOR) mediates ESCRT-dependent degradation by controlling receptor distribution between the limiting endosome membrane and lumen but is not required for receptor delivery to the proteolytic compartments. Instead, this is dictated by the MOR C-terminal tail and is independent of receptor ubiquitination (Hislop et al., 2011). In contrast, the calcitonin-like receptor is not ubiquitinated after activation but nonetheless is sorted and degraded in the lysosomes via an ESCRT-0-dependent pathway, confirming that ubiquitination is not obligatory for GPCRs to enter the ESCRT pathway (Cottrell et al., 2007).

An alternative pathway for GPCR lysosomal sorting that bypasses the requirement for both receptor ubiquitination and ubiquitin-binding ESCRTs has been described for PAR1 and the purinergic P2Y1 receptor. Apoptosis-linked gene-2 (ALG-2)-interacting protein X (ALIX), an ESCRT-III-interacting protein, interacts directly with a highly conserved $\mathrm{YPX}_{3} \mathrm{~L}$ motif present the second intracellular loop of PAR1 and the P2Y1 receptor via its central $\mathrm{V}$ domain to facilitate receptor lysosomal sorting. ALIX also directly binds to the ESCRT-III complex, allowing receptors to bypass the ubiquitin-binding ESCRTs and sort directly into ILVs of MVBs (Dores et al., 2012a, 2016). In recent work, ALIX activity was shown to be regulated by the ARRDC3, which facilitates ALIX ubiquitination and dimerization by the WWP2 HECT domain-containing E3 ubiquitin ligase (Gullapalli et al., 2006; Dores et al., 2012a,b, 2015, 2016). ALIX, ARRDC3, and WWP2 are essential for targeting activated PAR1 and $\mathrm{P}_{1} \mathrm{Y}_{1}$ to MVBs or lysosomes via an ECSRT-III charged MVB protein 4- and Vps4-dependent pathway (Dores et al., 2016). Besides PAR1 and P2Y 1 , six other mammalian GPCRs were found to possess conserved ALIX YPX $\mathrm{L}$ binding motifs within their second ICL2, including the $\alpha_{1 \mathrm{~B}^{-}}$ adrenoreceptor, angiotensin type $2\left(\mathrm{AT}_{2}\right)$ receptor, galanin receptor, histamine $\mathrm{H}_{2}$ receptors, neuropeptide FF receptors, and neuropeptide $\mathrm{S}$ receptor (Dores et al., 2012a). Both ALIX and ARRDC3 exploit diverse pathways to capture receptors for endolysosomal sorting (Tian et al., 2016), suggesting that a vast number of other GPCRs may also be regulated by the ALIXARRDC3 pathway. Together, these studies illustrate that GPCRs have the capacity to use ubiquitin directly or indirectly to facilitate trafficking through the endolysosomal pathway.

\section{Ubiquitin-Driven GPCR Signaling}

Although the role of phosphorylation in regulating GPCR biology is extensive, as discussed above, there is a limited understanding of the diverse functions by which ubiquitination controls GPCR signaling. Here we discuss studies examining the role of ubiquitin in propagating GPCR signaling from the plasma membrane and endosomes and how ubiquitination of GPCRs may influence biased signaling.

1. Ubiquitin and Plasma Membrane GPCR Signaling. Ubiquitin-driven GPCR signaling was recently shown for $\mathrm{mGlu}_{7}$ receptor induction of extracellular signalregulated protein kinase (ERK) 1/2 signaling in hippocampal neurons (Lee et al., 2019). In this scenario, agonist stimulation of $\mathrm{mGlu}_{7}$ receptor enables $\beta$-arrestin recruitment of NEDD4, which forms a complex at the plasma membrane and facilitates ubiquitination of the receptor. Both NEDD4 and $\beta$-arrestin are required for activated $\mathrm{mGlu}_{7}$ receptor-dependent ERK1/2 signaling, whereas induction of c-jun N-terminal kinase signaling occurs independently of NEDD4-mediated ubiquitination (Lee et al., 2019), suggesting that ubiquitin-driven $\mathrm{mGlu}_{7}$ receptor signaling is specific to ERK1/2. Similarly, activation of the chemokine receptor CXCR2 by interleukin-8 promotes ubiquitinmediated proinflammatory signaling and proangiogenic responses in leukocytes and endothelial cells (Leclair et al., 2014). In this study, Leclair et al. mapped the site of CXCR2 ubiquitination to a single C-tail localized lysine $\mathrm{K}^{327}$ residue and showed that an ubiquitinationdeficient CXCR2 mutant with a $\mathrm{K}^{327}$ to arginine $(\mathrm{R})$ conversion failed to recruit $\beta$-arrestin- 2 at the plasma membrane and blocked intracellular signaling including ERK1/2 phosphorylation (Leclair et al., 2014), suggesting that receptor ubiquitination is necessary for triggering signaling cascades. Agonist-induced ubiquitination of the parathyroid hormone receptor (PTHR) also requires phosphorylation and $\beta$-arrestin binding, but here ubiquitination appears to function 
selectively in promoting p38 MAP kinase activation and not cAMP accumulation (Zhang et al., 2018). The chemokine receptor CXCR4 has also been shown to mediate ubiquitin-dependent signaling; however, in this case the effect is indirect via modulation of signal transducing adapter molecule (STAM)-1, an ESCRT0 component (Malik et al., 2012). In this study, agonistinduced CXCR4-mediated ERK1/2 signaling required the E3 ubiquitin ligase AIP4, which facilitates ubiquitination of STAM-1. Interestingly, CXCR4-promoted ERK1/2 activation is governed by a discrete subpopulation of STAM-1 and AIP4 localized to caveolae microdomains at the plasma membrane (Malik et al., 2012). This work expands the role of AIP4 and STAM-1 beyond regulation of CXCR4 lysosomal trafficking (Malik and Marchese, 2010) and provides a new link for ubiquitindriven GPCR signaling between the trafficking machinery and signal propagation from the plasma membrane.

2. Ubiquitination and Endosomal GPCR Signaling. Several recent studies established that agonist-induced ubiquitination of endothelial GPCRs promotes p38 MAP kinase activation on endosomes via a noncanonical pathway (Fig. 5) (Grimsey et al., 2015, 2018, 2019). The activation and ubiquitination of PAR1 by NEDD4-2 initiates the recruitment of transforming growth factor$\beta$-activated protein kinase 1 -binding protein (TAB) 2 via an association with the TAB2 ubiquitin-binding domain, which specifically interacts with K63-linked ubiquitin (Kulathu et al., 2009). TAB2 is known to associate with TAB1 (Bouwmeester et al., 2004). TAB1 has also been shown to directly bind specifically to the p38 $\alpha$ isoform, inducing a conformation change resulting in autophosphorylation and activation through a noncanonical pathway (Ge et al., 2002; DeNicola et al., 2013). Importantly, TAB1-dependent activation of $\mathrm{p} 38 \alpha$ induced by PAR1 bypasses the requirement for upstream MAP2K of the canonical three-tiered kinase cascade. Moreover, although it is presumed that GPCRs activate p38 MAP kinase through the three-tiered kinase cascade, there is very limited supportive evidence, and rarely has the role of MAP kinase kinases been directly tested (Goldsmith and Dhanasekaran, 2007). The ubiquitin-driven PAR1 signaling pathway is specific to p38, as thrombin activation of ERK1/2 proceeds through the canonical three-tiered kinase cascade (Grimsey et al., 2015). Similar to PAR1, ubiquitination of the purinergic $\mathrm{P} 2 \mathrm{Y} 1$ receptor also mediates p38 activation through a TAB1-TAB2-dependent pathway (Grimsey et al., 2015), indicating that this pathway is used by multiple GPCRs. Indeed, multiple endothelial GPCRs agonists including histamine $\left(\mathrm{H}_{1}\right.$ or $\mathrm{H}_{2}$ receptor) and prostaglandin $\mathrm{EP}_{2}\left(\mathrm{EP}_{4}\right.$ prostanoid receptor) also activate p38 MAPK through a noncanonical TAB1-dependent pathway (Grimsey et al., 2019). This work was further advanced by showing that TAB1dependent p38 activation was critical for PAR1promoted endothelial barrier permeability in vitro and that p38 signaling was required for PAR1-induced vascular leakage in vivo (Grimsey et al., 2015). Dysfunction of the endothelial barrier is a hallmark of vascular inflammation and suggests that ubiquitindriven p38 proinflammatory signaling is a common pathway used broadly by GPCRs at least in the context of the vascular endothelium.

3. Ubiquitination and Biased Signaling. Activation of the same GPCR by two or more distinct ligands can elicit different distinct responses, is referred to as biased agonism, and is an important emerging area for drug discovery. Several previous studies indicate that post-translational modification of GPCRs with ubiquitin is uniquely influenced by biased agonists and likely contributes to differential responses. A well studied example is $\mu$-opioid receptor activation with morphine versus DAMGO that resulted in differential recruitment and utilization of $\beta$-arrestins and displayed remarkable differences in receptor ubiquitination. DAMGO stimulated robust ubiquitination of $\mu$-opioid receptor, whereas morphine-induced receptor ubiquitination was negligible (Groer et al., 2011). As stated above, isoproterenol stimulates $\beta_{2}$-adrenoceptor ubiquitination via a $\beta$-arrestin-NEDD4-mediated pathway (Shenoy et al., 2008); however, $\beta_{2}$-adrenoceptor ubiquitination induced by the biased ligand carvedilol is mediated by membrane-associated RING-CH-type finger 2 (MARCH2), a RING-type E3 ligase, in the place of NEDD4 (Han et al., 2012). Clearly, biased ligands have the capacity to differentially regulate the ubiquitination machinery as well as GPCR ubiquitination and are important to consider for understanding the molecular basis of biased signaling and future drug discovery.

\section{Deubiquitination of GPCRs}

Ubiquitination is a reversible post-translational process, and deubiquitination is important for governing ubiquitin-dependent cellular responses such as endocytic trafficking and cell signaling. The accrual of ubiquitin on substrate proteins results from E1, E2, and E3 ubiquitin conjugating enzyme activities as well as by the activity of deubiquitinases or deubiquitinating enzymes (DUBs) (Fig. 4A). DUBs also control the biogenesis and steady state levels of ubiquitin within the cell. Ubiquitin is encoded by four genes that generate linear ubiquitin chains and released as single ubiquitin moieties by the action of DUBs (Grou et al., 2015). DUBs also recycle or reclaim ubiquitin from proteins targeted for degradation. The human genome encodes 99 deubiquitinases that are subdivided into seven families. Of the DUB subfamilies, six, including ubiquitin-specific proteases (USPs), are cysteine proteases, whereas one family comprises zinc-dependent metalloproteinases (Clague et al., 2019). DUBs function as proteolytic enzymes that cleave peptide or isopeptide bonds between linked ubiquitins or between the ubiquitin and substrate protein. DUBs are capable of discriminating 
between distinct ubiquitin chain linkages and chain length and can cleave from the end or within the ubiquitin chain. Thus, DUBs serve multiple functions by 1) removing ubiquitin from protein substrates, which can rescue proteins from degradation or modulate signaling; 2) editing ubiquitin chains, which can convert one type of ubiquitin chain linkage to another; and 3) recycling ubiquitin, which ensures that ubiquitin reenters the ubiquitin pool (Komander et al., 2009; Mevissen and Komander, 2017).

The regulation of DUB activity is important and occurs through controlling the abundance of DUBs expressed in a given cell, post-translational modification with ubiquitin and/or phosphorylation, and interaction with scaffolds or E3 ubiquitin ligases (Leznicki and Kulathu, 2017). An additional major determinant for controlling DUB function is subcellular localization, which permits access to specific substrates proteins. Some DUBs are highly restricted to organelles through transmembrane anchoring, such as localization of USP19 to the ER and USP30 to the mitochondrial outer membrane, whereas the vast majority of DUBs appear to be present in cytosol or nucleus and controlled at least in part by the presence of a nuclear export signal, as described for USP21 (Leznicki and Kulathu, 2017; Clague et al., 2019). Although ubiquitination of GPCRs is important for regulating receptor trafficking and cellular signaling, the role of DUBs is only beginning to emerge and is discussed below.

1. Constitutive GPCR Deubiquitiation. An emerging role for DUBs is in control of GPCR transport to the cell surface and thereby in preventing ubiquitinproteasomal degradation (Fig. 5). The quality control machinery in the ER is stringent and prefers to err on the side of rapid degradation of proteins that, when given time, would fold into a properly functionally active protein. This has been shown for the GPCR adenosine $\mathrm{A}_{2 \mathrm{~A}}$ receptor. Deubiquitination of adenosine $\mathrm{A}_{2 \mathrm{~A}}$ receptor by USP4 relaxes quality control in the ER, enhances cell surface expression, and rescues the receptor from proteasomal degradation (Milojevic et al., 2006). DUBs show remarkably substrate specificity. USP4 binds to the adenosine $\mathrm{A}_{2 \mathrm{~A}}$ receptor $\mathrm{C}$ terminus and deubiquitinates the receptor but does not act on $\mathrm{mGlu}_{5}$ receptor, another GPCR that tends to accumulate intracellularly (Milojevic et al., 2006). Another role for DUBs in regulating GPCR cell surface expression occurs via regulation of receptor recycling as exemplified by Frizzled-4, a seven-transmembrane receptor for Wnt ligands (Mukai et al., 2010). Constitutive ubiquitination of Frizzled-4 promotes internalization and lysosomal degradation, whereas deubiquitination mediated by USP8 leads to recycling and increased surface expression, events that occur independently of stimulation with Wnt ligands (Mukai et al., 2010). Thus, the balance of ubiquitination and deubiquitination mediated by DUBs switch the receptor's fate from lysosomal degradation to recycling and enhanced cellular resensitization.

2. Deubiquitination of Agonist-Activated GPCRs. The regulation of agonist-stimulated GPCR ubiquitination is ultimately important for regulating the biologic function of the receptor but has not been extensively studied. Shenoy et al. identified USP33 in a yeast-two hybrid screen with $\beta$-arrestin (Shenoy et al., 2009), suggesting that $\beta$-arrestins have a dual function to recruit not only the E3 ubiquitin ligases but also DUBs to regulate GPCR function. In a follow-up study, UPS33 as well as its homolog USP20 were shown to reverse agonist-activated $\beta_{2}$-adrenoceptor ubiquitination and thereby switched the receptor fate from lysosomal degradation to recycling, resulting in enhanced cellular resensitization (Berthouze et al., 2009). In addition, phosphorylation of USP20 induced by $\beta_{1}$-adrenoceptor is required for efficient lysosomal degradation of the receptor (Yu et al., 2019). The chemokine receptor CXCR4 has been shown to associate with USP14 in an agonist-dependent manner, which causes a decrease in receptor ubiquitination and lysosomal degradation (Mines et al., 2009). Interestingly, depletion of USP14 expression also results in loss of chemokine (C-X-C motif) ligand 12-CXCR4-induced cell migration but not of ERK1/2 signaling, suggesting that ubiquitin positively modulates certain aspects of CXCR4 signaling (Mines et al., 2009). Another study examined the effect of USP8 on CXCR4 ubiquitation and reported that loss of USP8 expression enhanced CXCR4 expression by preventing degradation without altering CXCR4 ubiquitination status and ERK1/2 signaling (Berlin et al., 2010). USP8 appears to modulate chemokine (C-X-C motif) ligand 12-CXCR4-induced ubiquitination of HRS, a component of ESCRT-0, which is mediated by AIP4 to control CXCR4 lysosomal trafficking (Berlin et al., 2010).

In contrast to most GPCRs, metabotropic GABA $_{B}$ receptor is insensitive to agonist-induced internalization but undergoes constitutive ubiquitination at the cell surface followed by internalization and lysosomal degradation. Overexpression of USP14 decreased $\mathrm{GABA}_{\mathrm{B} 1}$ receptor ubiquitination, which appears to occur at a postendocytic site, and consequently regulates lysosomal degradation independently of USP14 catalytic activity (Lahaie et al., 2016), suggesting that GPCR deubiquitination occurs at multiple subcellular locations. Indeed, the subcellular localization of DUBs is an important spatial-temporal regulatory mechanism for ubiquitinated proteins, especially for signaling receptors, but remains poorly understood for GPCRs (Coyne and Wing, 2016). Although PAR2 is proteolytically activated like PAR1, ubiquitination of activated PAR2 is mediated by a Casitas B lineage lymphoma, a RING-type E3 ligase, rather than NEDD4 HECT E3 ligase, as has been demonstrated for PAR1 and numerous other GPCRs (Grimsey et al., 2015; Jean-Charles 
et al., 2016). In addition, agonist-induced ubiquitination of PAR2 is required for lysosomal degradation, unlike PAR1 (Hasdemir et al., 2009). To understand how ubiquitination regulates PAR2 trafficking and signaling, which occurs from the plasma membrane via $G$ proteins and on endosomes via $\beta$-arrestins, one study focused on the function of two endosomal DUBs, associated molecule with the Src homology 3 domain of STAM (AMSH) and ubiquitin-specific protease Y (UBPY), also known as USP8. This study showed that deubiquitination of activated PAR2 is mediated by both AMSH and UBPY and occurs in the endocytic pathway. Moreover, perturbation of either AMSH or UBPY function results in accumulation of ubiquitinated PAR2 in endosomes and slowed lysosomal degradation but failed to alter activated PAR2- $\beta$-arrestin association or $\beta$-arrestin-dependent signaling (Hasdemir et al., 2009). Given the preponderance of ubiquitinated receptors, there is no doubt that DUBs will have important roles in regulating receptor function by modulating the spatial and temporal dynamics of receptor signaling. However, most studies to date have failed to use comprehensive approaches to identify and study the physiologically relevant DUBs that control cellular responses.

\section{E. Detection and Study of GPCR Ubiquitination}

Unlike phosphorylation, the study and interrogation of GPCR ubiquitination is more difficult. Several ubiquitin prediction tools have been recently developed, including UbPred and ESA-UbiSite (Radivojac et al., 2010; Wang et al., 2017); however, comparative analysis of the software concluded that no universal algorithm exists for predicting ubiquitination consensus sites across all species (Chen et al., 2015). Current, widely used strategies for the detection of GPCR ubiquitination include target protein immunoprecipitation followed by immunoblotting and mass spectrometry (Shenoy et al., 2001; Caballero and Marchese, 2011; Dores et al., 2015; Grimsey et al., 2015, 2018; Lee et al., 2019). However, studying endogenous GPCR ubiquitination is challenging due to the dynamic nature of ubiquitination, lack of consensus sites, low abundance of ubiquitinated proteins, rapid degradation, and the large size of ubiquitin compared with other PTMs, which increases the difficulty of detection by mass spectrometry (Mann and Jensen, 2003; Jadhav and Wooten, 2009; Helbig et al., 2010; Danielsen et al., 2011). Often, epitope-tagged GPCRs coupled with sitedirected mutagenesis of targeted lysine residues are employed to define the sites and function of ubiquitination (Wolfe et al., 2007; Xiao and Shenoy, 2011). Due to the difficulty of detecting GPCR ubiquitination by immunoblotting, many studies employ ectopic expression of epitope-tagged ubiquitins (Caballero and Marchese, 2011; Giordano et al., 2011), and rarely is endogenous ubiquitination detected, as shown for PAR1
(Fig. 4C). A more rigorous approach to identify the precise sites of GPCR ubiquitination has been determined by mass spectrometry and was shown recently for the $\beta_{2}$-adrenoreceptor and PTHR (Xiao and Shenoy, 2011; Zhang et al., 2018). Ubiquitination of multiple GPCRs, including PAR1, have also been detected by curation of high-throughput proteomic mass spectrometry and low-throughput data sources and published on PhosphoSitePlus (Hornbeck et al., 2015). To identify type of ubiquitin linkages, several modified ubiquitin expression constructs with specific lysine mutants are available to detect lysine-specific ubiquitin linkages (Raasi and Pickart, 2005; Avagliano Trezza et al., 2017; Rinaldi et al., 2019). A major advantage of using $\mathrm{K} 48$ and K63 linkage-specific antibodies is the ability to identify ubiquitination status of endogenous proteins under physiologic conditions (Grimsey et al., 2015). GPCR ubiquitination can also be probed using fluorescence and bioluminescence techniques that allow the monitoring of ubiquitination dynamics. Bioluminescence resonance energy transfer-based techniques have also been used to detect ubiquitination of GPCRs in intact cells and in real time (Perroy et al., 2004; Nagi and Shenoy, 2019). Currently, biochemical approaches remain a feasible approach for the detection and study of GPCR ubiquitination. Despite the large number of ubiquitinated GPCRs identified, far less is known about the cognate E3 ligases, and rarely have DUBs for specific GPCR been determined. If such information is known, small interfering RNA (siRNA) depletion of specific E3 ligases or DUBs can be performed to assess function. This should be followed by a rescue approach with an siRNA-resistant E3 ligase wild-type and mutant form as recently demonstrated by Grimsey et al. (2018). Clearly, there is a need to develop better methods to monitor GPCR ubiquitination dynamics and to improve of mass spectrometry-assisted ubiquitinome profiling as well as to develop a repertoire of probes for superresolution cellular imaging (van Wijk et al., 2019).

\section{GPCR Glycosylation}

Most if not all mammalian GPCRs are posttranslationally modified with glycosylation at their extracellular N-terminus or on ECLs. A nascent GPCR undergoes constitutive glycosylation modifications as it traffics from the ER-Golgi to the plasma membrane (Fig. 6A). The role of glycosylation in regulating GPCR biology is expansive and has been attributed to receptor folding, trafficking, ligand binding, signaling, and dimerization (Fig. 7). The ubiquitous roles of glycosylation are due in part to the diversity of glycosylation linkages that differ for a given receptor as well as receptor types and can vary in different cellular contexts. Here we discuss the current knowledge of glycosylation for GPCRs. 
A

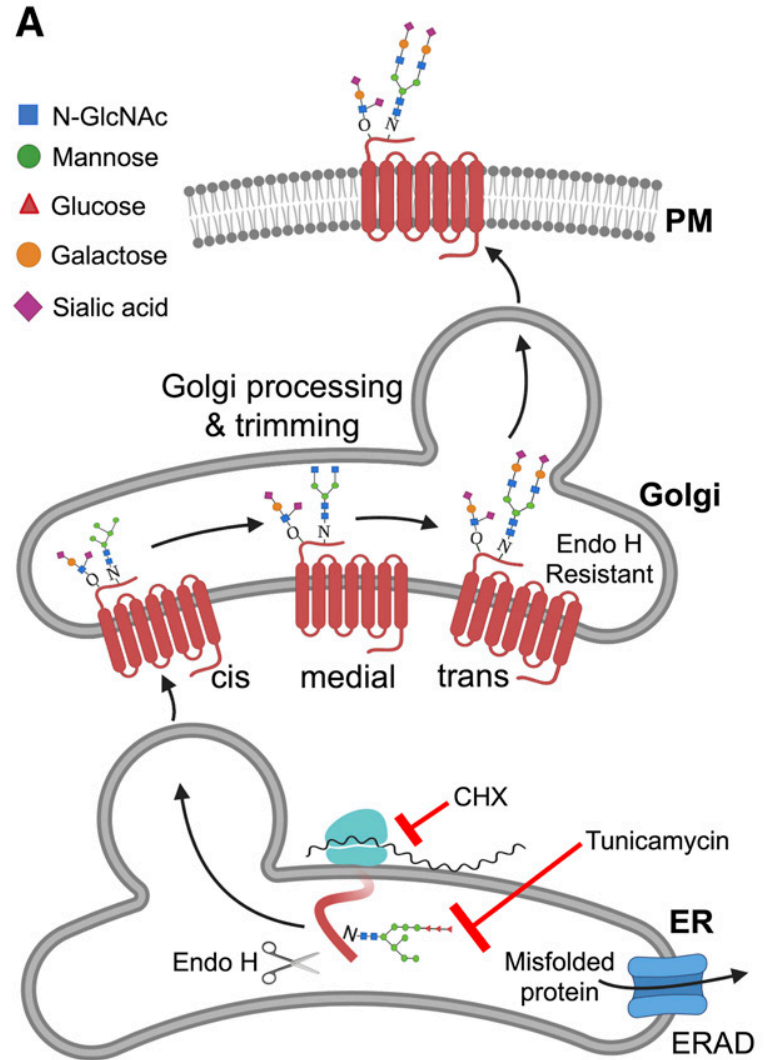

ER glycosylation \& quality control
B N-Glycosylation (N-X-(S/T) motif O-Glycosylation ( $\mathrm{S} / \mathrm{T})$

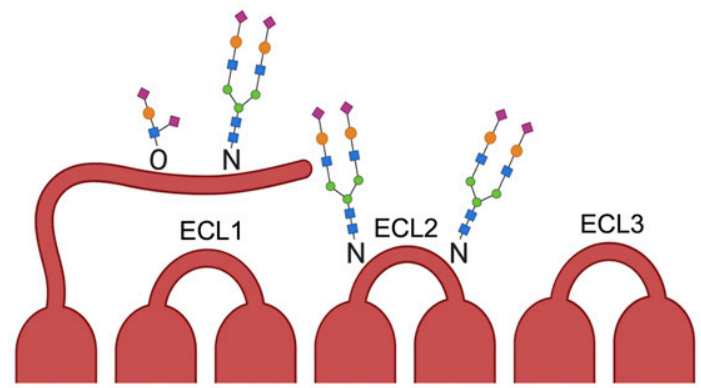

C

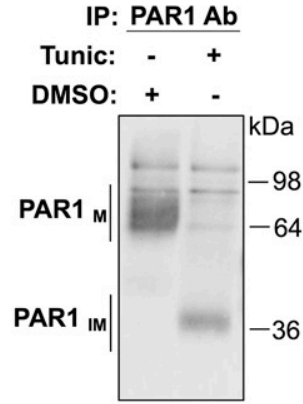

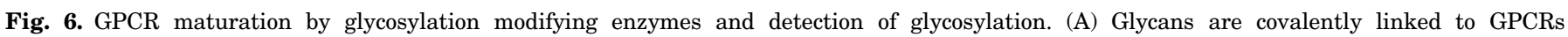

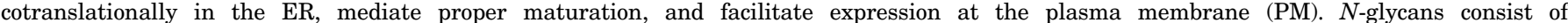

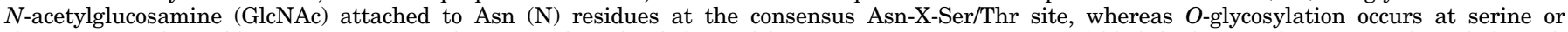

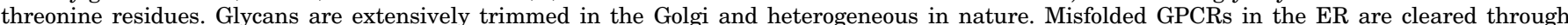

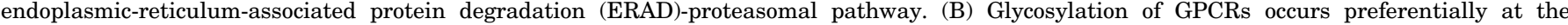

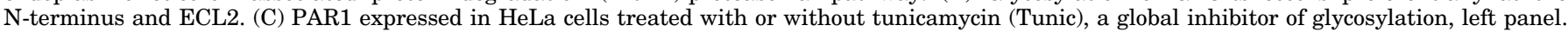

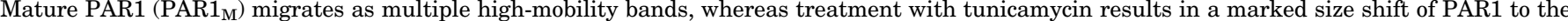

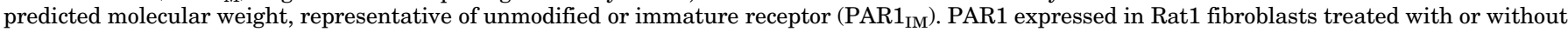

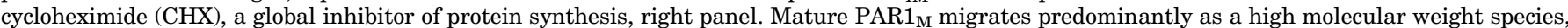

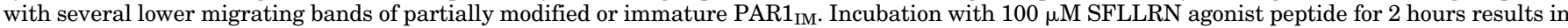

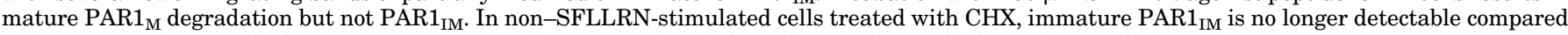

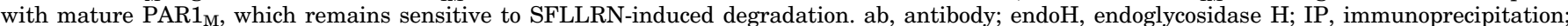
SFLLRN, Ser-Phe-Leu-Leu-Arg-Asn.

\section{A. GPCRs and N-Linked and O-Linked Glycosylation}

Glycosylation is mediated by a complex multistep process involving hundreds of modifying enzymes and results in different types of glycoconjugates covalently linked to lipids or proteins. Glycoconjugates are heterogeneous in nature and differ in their glycan sequences, connections, and length of carbohydrate structures. $N$-linked glycosylation is abundant and well described to occur on most GPCRs, and new developments have led to the recent identification of $O$-linked glycosylation sites in numerous GPCRs (Goth et al., 2020).

1. N-Glycosylation of GPCRs. $N$-glycosylation is initiated in the ER and occurs cotranslationally by the actions of an oligosaccharide transferase (Fig. 6A). The $N$-linked glycan structure then undergoes extensive trimming during protein transport from the Golgi to the plasma membrane resulting in significant heterogeneity of the glycan structure. $N$-glycosylation is one of the most common types of glycosylation, where a complex glycan structure is linked to the amide nitrogen on the side chain of an asparagine $(\mathrm{N})$ residue at the consensus sequence $\mathrm{N}$-X-serine $(\mathrm{S}) /$ threonine $(\mathrm{T})$, where $\mathrm{X}$ is any amino acid other than proline. $N$-linked glycan structures are often capped with negatively charged sialic acids. The vast majority of mammalian GPCRs contain at least one $N$-linked glycosylation consensus sites (N-X-S/T) present in the extracellular N-terminal domain (Wheatley and Hawtin, 1999; Wheatley et al., 2012). GPCRs also often contain $N$-linked glycosylation N-X-S/T sites in ECL2 (Fig. 6B). PAR1 contains five $N$-linked glycosylation sites-three in the N-terminus and two in ECL2-and is subjected to extensive glycosylation (Fig. 6C) (Soto and Trejo, 2010). Treatment of cells with tunicamycin, an inhibitor of glycosylation, causes a marked mobility shift of PAR1 to $\sim 39 \mathrm{kDa}$, its predicted size based on amino acid sequence (Fig. 6C). Interestingly, continuous agonist stimulation caused degradation of mature PAR1 (Fig. 6C), whereas inhibition of protein synthesis with 


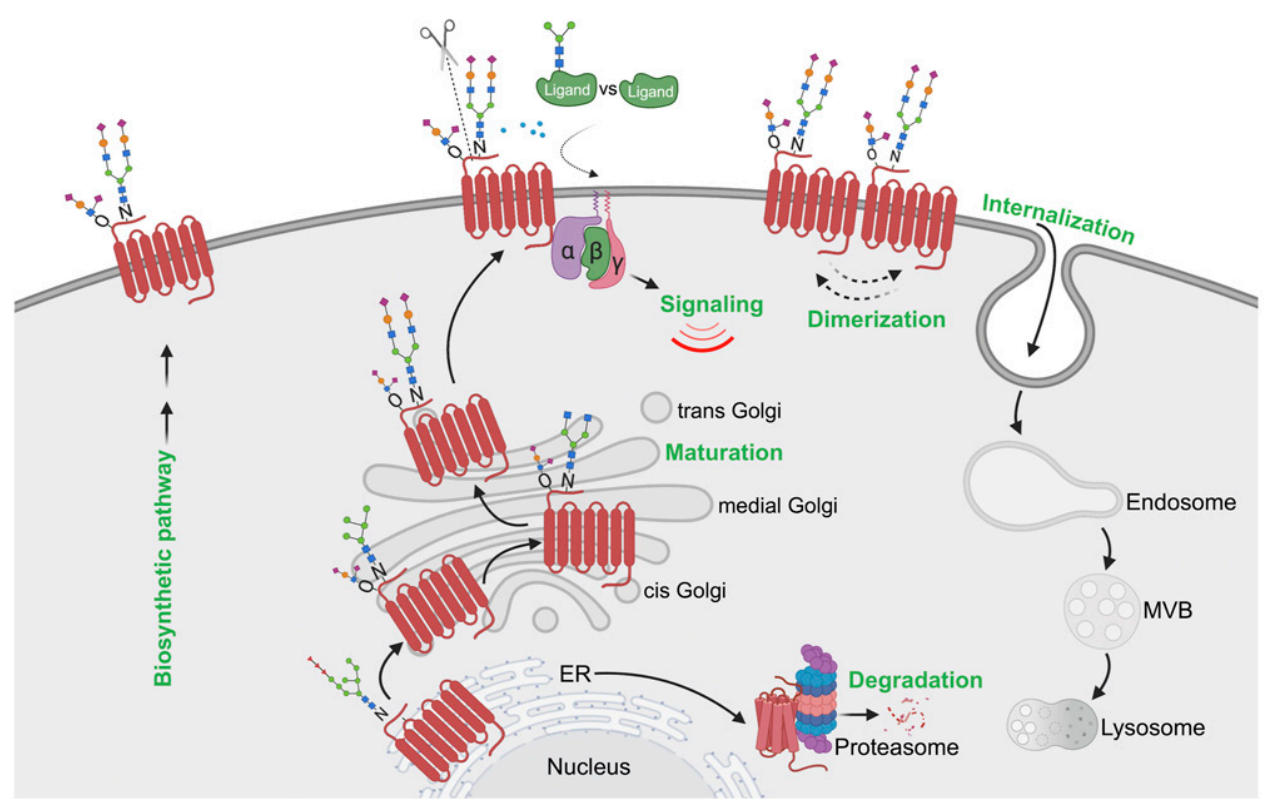

Fig. 7. Model of GPCR regulation by glycosylation. GPCRs are extensively modified with $N$-glycosylation and $O$-glycosylation during biosynthesis and transport through the ER-Golgi en route to the plasma membrane. Glycosylation-deficient or misfolded GPCRs undergo ER-associated proteasomal degradation pathway. Glycosylation controls GPCR folding and maturation in the biosynthetic pathway, transport to the cell surface, signaling, ligand affinity, N-terminal cleavage, receptor dimerization, and internalization. Importantly, glycosylation controls GPCR biased signaling through direct modulation of the GPCR or in some cases the GPCR ligand. Glycosylation also regulates metalloprotease-mediated N-terminal cleavage of GPCR to influence biased signaling and modulates ligand-binding affinity by providing a larger and potentially more flexible binding surface of the GPCR. Dimerization of certain GPCRs is also positively modulated by glycosylation.

cycloheximide resulted in loss of nascent forms of PAR1 but not the mature form (Fig. 6C). In-depth analysis of GPCRs using computational methods revealed that the consensus N-X-S/T sequence is present on ECL2 (66\%), ECL1 (14\%), and ECL3 (20\%) (Lanctot et al., 2005). Overall, $N$-glycosylation of GPCR is abundant and occurs at the extracellular $\mathrm{N}$-terminal domain as well as on ECL2 in most receptors and is capable of performing various GPCR functions.

2. O-Linked Glycosylation of GPCRs. O-glycosylation is initiated by the transfer a $N$-acetylgalactosamine (GalNAc) to the hydroxyl group of serine or threonine residues, rarely on tyrosine, and occurs in the Golgi after protein folding (Stanley et al., 2009) (Figs. 6A and 7). This reaction is catalyzed by 20 different GalNAc transferases, which can produce eight different core structures (Mulloy et al., 2015). Elongation occurs by the addition of monosaccharides to yield higher-order linear and branched glycan structures, which are capped with negatively charged sialic acids. Unlike $N$-linked glycosylation, $O$-glycosylation occurs at serine or threonine residues, usually in stretches rich in hydroxy amino acids, but there is no consensus sequence. Currently, over 60 GPCRs have detected $O$-linked glycosylation sites within the N-terminal domain, whereas more than 350 GPCRs have predicted $O$-glycosylation sites based on the use of the NetOGlyc 4.0 model for prediction of $O$-glycosylation (Steentoft et al., 2013). The quantity and quality of glycosylation depends both on the GPCR itself and on the cell type expressing the protein. However, validation of these predicted sites on the GPCRs and the regulatory functions of $O$-glycosylation is only beginning to emerge.

\section{B. N-Linked Glycosylation and GPCR Trafficking}

1. GPCR Biosynthesis and Cell Surface Expression. The functional effects of $N$-glycosylation on GPCRs generally control biosynthesis and cell surface expression (Fig. 7). However, for certain receptors, there seem to be no detectable deficits in receptor function if $\mathrm{N}$-glycosylation is blocked, as has been described for the muscarinic $\mathrm{M}_{2}$ receptor, $\mathrm{H}_{2}$ histamine receptor, dopamine $\mathrm{D}_{1}$ receptor, class $\mathrm{A}$ orphan GPR61, $\alpha_{1^{-}}$ adrenoreceptor, vasopressin $\mathrm{V}_{2}$ receptor, PTHR, and others (van Koppen and Nathanson, 1990; Fukushima et al., 1995; Kozielewicz et al., 2017), whereas for many other GPCRs, disrupting $N$-glycosylation or expression of aglycosylated mutant perturbs receptor surface expression, as shown for the $\beta_{2}$-adrenoceptor, angiotensin type $1\left(\mathrm{AT}_{1}\right)$ receptor, dopamine $\mathrm{D}_{5}$ receptor, smoothened (SMO), PAR2, GPR176, and others (Karpa et al., 1999; Lanctôt et al., 1999; Compton et al., 2002; Michineau et al., 2004; Marada et al., 2015; Wang et al., 2020). Notably, mutation of all angiotensin $\mathrm{AT}_{1}$ receptor $N$-glycosylation sites resulted in loss of plasma membrane expression, where the nonglycosylated receptors accumulated in the ER (Deslauriers et al., 1999). However, preservation of $\mathrm{AT}_{1}$ receptor $\mathrm{Asn}^{176}$ in the second extracellular loop enabled surface expression similar to wild-type receptors. A glycosylationdefective gonadotropin-releasing hormone receptor also displayed decreased expression (Davidson et al., 1995). 
Other studies showed that the final processing for $N$-glycans for DOR occurs in the trans-Golgi network, whereas $O$-linked glycosylation is mediated in the trans-Golgi cisternae (Petaja-Repo et al., 2000). Two $\mathrm{N}$-glycosylation sites in the $\mathrm{N}$-terminus of DOR were subsequently shown to enhance transport through the ER but resulted in loss of receptor surface expression due to increased internalization and lysosomal degradation (Markkanen and Petäjä-Repo, 2008). Similarly, the $\beta_{2}$-adrenoceptor $\mathrm{N}$-terminus harbors two $N$-glycosylation sites that have been implicated in receptor trafficking to cell surface but not in ligand binding or G protein coupling (Rands et al., 1990; He et al., 2002). A more recent report indicates that a mutant purinergic $\mathrm{P}_{2} \mathrm{Y}_{2}$ receptor deficient in glycosylation undergoes ER-associated proteasomal degradation pathway, possibly due to retention in ER lipid rafts and failure of traffic to the Golgi (Nakagawa et al., 2017). A similar observation was made for $\alpha_{1 \mathrm{D}}$-adrenoreceptor, where a glycosylation-deficient mutant displays impaired plasma membrane expression likely because of degradation via ERAD (Janezic et al., 2020). Collectively, substantial evidence suggests that $N$-glycosylation of GPCRs during maturation in the biosynthetic pathway is essential to achieve optimal cell surface expression.

2. GPCR Plasma Membrane Compartmentalization and Internalization. Once GPCRs reach the cell surface, they can partition into plasma membrane subdomains, including clathrin-coated pits and caveolar microdomains (Guo et al., 2015), which appears to be governed in part by $N$-glycosylation. The sphingosine 1phosphate $\left(\mathrm{S}_{1} \mathrm{P}_{1}\right)$ receptor is modified at an $\mathrm{N}$-terminal site with $N$-glycosylation, and a mutant receptor lacking glycosylation fails to efficiently partition in caveolinenriched microdomains (Kohno et al., 2002), suggesting that $N$-glycans may function in plasma membrane compartmentalization. Another study examining the role of $N$-glycosylation in trafficking of the dopamine $\mathrm{D}_{2}$ and $D_{3}$ receptor showed that glycosylation regulates not only receptor transit through the biosynthetic pathway but also receptor uptake within microdomains at the plasma membrane (Min et al., 2015). Specifically, glycosylation on the $\mathrm{N}$-terminus was shown to mediate internalization of dopamine $\mathrm{D}_{2}$ receptor through caveolae, whereas glycosylation of dopamine D3 receptor mediates internalization via clathrin-coated pits, which is regulated through direct interactions with caveolin-1 and clathrin (Min et al., 2015). These new findings support a role for $N$-glycans in mediating GPCR internalization via clathrin-mediated and caveolaedependent pathways, the major internalization routes of GPCRs (Guo et al., 2015).

In addition to the dopamine $\mathrm{D}_{2}$ and $\mathrm{D}_{3}$ receptor, $N$-glycan functions have been linked to the chemokine receptor CCR7 internalization (Hauser et al., 2016). Using $N$-glycosylation prediction software NetNGlyc
4.0, two potential $N$-glycosylation sites were identified: one in the N-terminus and one within ECL3 of human CCR7. Surprisingly, only the CCR7 receptor variant with mutation of the N-terminal site had a significantly reduced endocytic rate, whereas the ECL3 mutant variant behaved similar to the wild type (Hauser et al., 2016). $\mathrm{S}_{1} \mathrm{P}_{1}$ receptor containing a mutation in an $\mathrm{N}$-terminal $\mathrm{N}$-glycosylation site also exhibited impaired endocytosis (Kohno et al., 2002). Thus, $N$-glycosylation of $\mathrm{S}_{1} \mathrm{P}_{1}$ receptor is required not only for association with caveolae but also for agonistinduced internalization (Kohno et al., 2002). In contrast, a glycosylation-deficient $\mathrm{NK}_{1}$ receptor displayed enhanced internalization after agonist-stimulated compared with wild-type glycosylated $\mathrm{NK}_{1}$ receptor, suggesting that glycosylation may function to retain $\mathrm{NK}_{1}$ receptor at the cell surface (Tansky et al., 2007). In many cases, $N$-glycosylation has multiple purposes in controlling biosynthesis, export to the cell surface, and internalization through clathrin-coated pits. This has been exemplified for PAR1, which is extensively modified by $N$-linked glycosylation on both the $\mathrm{N}$-terminus and ECL2 (Fig. 6C). Although N-terminal glycosylation was shown to function in export to the cell surface, glycosylation of PAR1 at ECL2 caused a modest impact on agonist-induced internalization, whereas constitutive internalization remained intact (Soto and Trejo, 2010).

\section{N-Linked Glycosylation and GPCR Signaling}

Given that $N$-glycosylation occurs on the extracellular regions of GPCRs, it is not surprising that glycosylation can influence GPCR signaling at multiple levels, including ligand binding, $G$ protein coupling, and biased signaling.

1. N-Glycosylation, Ligand Binding, and GPCR Signaling. In early studies of mammalian GPCRs, perturbation of $N$-glycosylation resulted in either nonfunctional receptors or receptors with severe functional deficits in ligand binding, as was demonstrated for the thyrotropin receptor, parathyroid hormone, shekel somatostatin receptor type 3, and rhodopsin (Russo et al., 1991; Kaushal et al., 1994; Nehring et al., 2000). In the case of PAR1, loss of $N$-glycosylation at ECL2 caused a marked increase in signaling compared with wild-type receptor (Soto and Trejo, 2010), suggesting that the lack of glycosylation in this region allows the ligand to bind the receptor in a manner that induces an active receptor conformation that is more efficient in coupling to $G$ protein signaling. Glycosylation may hinder stabilization of the active conformation of the loop or may orientate the loop to prevent ligand access to binding pocket. Similarly, glycosylation of the human chemokine receptor CCR7 at the N-terminus and ECL3 reduces responsiveness, where the lack of glycosylation enhances chemokine signaling (Hauser et al., 2016). In contrast, $\mathrm{N}$-glycosylation of CXCR4 at the $\mathrm{N}$-terminus is 
necessary for high-affinity binding of the chemokine ligand (Wang et al., 2004). Constitutive signaling by GPR30, an emerging player in breast cancer and cardiometabolic regulation, is regulated by $N$-glycosylation. A recent study demonstrated that one of the three $\mathrm{N}$-glycosylation sites in the $\mathrm{N}$-terminus is important for receptor-stimulated ERK1/2 activity (Gonzalez de Valdivia et al., 2019), suggesting that a single site is critical for receptor structure and activity. In addition to diffusible ligands, recent work suggests that GPCRs can act as mechanosensors activated by mechanical stimulus that appears to be governed by $N$-glycans (Langenhan et al., 2016). In this case, activation of the $\beta_{2}$-adrenoceptor expressed in endothelial cells occurs during infection with the bacteria meningococcus, where the filamentous structures appear to trigger receptor signaling by exerting direct mechanical traction forces via the exposed $N$-glycans $\left(\mathrm{N}^{6}\right.$ and $\left.\mathrm{N}^{15}\right)$ present in the $\mathrm{N}$-terminus of $\beta_{2}$-adrenoceptor (Virion et al., 2019). This is the first example of a glycan-dependent mode of allosteric mechanical activation of a GPCR.

2. N-Linked Glycosylation and GPCR Biased Signaling. GPCRs are dynamic molecules that assume different conformational states. Consequently, different ligands can stabilize unique active conformations of the same GPCR and facilitate activation of distinct signaling effectors such as $\mathrm{G}$ proteins or $\beta$-arrestins (Walker et al., 2003; Kenakin and Christopoulos, 2013). This process is termed biased agonism or functional selectivity. New work suggests that $N$-glycosylation can control GPCR biased signaling. The first report to show a role for $N$-glycosylation in controlling biased signaling was demonstrated for PAR1. In this study, PAR1 $N$-glycosylation at ECL2 was shown to direct differential coupling of PAR1 to $\mathrm{Gq}$ versus G12/13 signaling (Soto et al., 2015). A fully glycosylated activated PAR1 wild type displayed greater efficacy at coupling to G12/13-dependent Ras homolog family member A signaling than the glycosylation-deficient mutant. In contrast, activation of PAR1 mutant lacking glycosylation at ECL2 exhibited a greater capacity to elicit Gq signaling compared with G12/13 signaling. Both PAR1 wild type and glycosylation-deficient mutant were equally effective at coupling to $\mathrm{Gi}$ signaling and $\beta$-arrestin recruitment. These findings suggest that $N$-glycosylation at ECL2 contributes to the stabilization of an active PAR1 state that preferentially couples to G12/13 versus Gq and defines a previously unappreciated function for $N$-glycosylation of GPCRs in regulating $G$ protein signaling bias (Soto et al., 2015). Similarly, $N$-glycosylation of SMO, a GPCR that contains seven predicted glycosylation sites, functions as the signal transducer of the Hedgehog pathway and can bias SMO signaling. SMO signals via a noncanonical pathway mediated by $\mathrm{G} \alpha \mathrm{i}$ as well as through a canonical route mediated by Gli transcriptional factors. In this study, an SMO mutant rendered glycosylation deficient via mutation of four $N$-glycosylation sites failed to induce a noncanonical signal through Goi, whereas it retained normal receptor trafficking, ligand binding, and canonical Gli signaling (Marada et al., 2015). These studies demonstrate that modification of PAR1 and SMO with $N$-glycosylation can regulate biased signaling.

\section{N-Linked Glycosylation and GPCR Dimerization}

Substantial evidence supports the notion that GPCRs self-associate or associate with other GPCRs, resulting in dimeric complex formation that modulates receptor function. A plethora of biochemical and pharmacological evidence supports the idea that class A GPCRs exist as homodimers or heterodimers when expressed exogenously or endogenously in native tissues (Milligan, 2009). In addition, several high-resolution crystal structures of class A GPCR homodimeric complexes have been solved, including CXCR4 (Wu et al., 2010), DOR (Granier et al., 2012), and $\kappa$-opioid receptor (Wu et al., 2012) receptors. Although heterodimerization of class $C$ GPCRs such as GABA $_{\mathrm{B}}$ receptor and taste receptors is obligate and essential for expression and function, more recent studies indicate that class A GPCRs also form functionally significant heterodimers (Milligan, 2009). However, in many cases, the role of class A GPCR dimerization remains elusive. Post-translational modifications are likely to influence GPCR heterodimerization, which can alter specific receptor active conformations, resulting in unique signaling responses, and is important to understand for drug development. Here, we briefly discuss studies showing $N$-glycosylation control of GPCR dimerization (Fig. 7).

The first reported study showed that $N$-glycosylation of the $\beta_{1}$-adrenoreceptor at the $\mathrm{N}$-terminus reduces dimerization compared with wild-type receptors ( $\mathrm{He}$ et al., 2002), suggesting that glycosylation positively modulates homodimerization. Similarly, mutating two $N$-glycosylation sites in the $\mathrm{N}$-terminus of the $\beta_{2^{-}}$ adrenoceptor decreased receptor dimerization as well as receptor function (Li et al., 2017). $N$-glycosylation has also been reported to negatively regulate receptor heterodimerization between the $\beta_{1}$-adrenoreceptor and $\alpha_{2 \mathrm{~A}^{-}}$ adrenoreceptor (Xu et al., 2003). Moreover, a study showed that introduction of an $N$-glycan at the GABA $\mathrm{B}_{2}$ obligate dimer interface prevents the association of the two subunits and abolishes all activities of $\mathrm{GABA}_{\mathrm{B} 2}$, including agonist activation of $G$ protein signaling (Rondard et al., 2008). These studies suggest that the capacity of GPCRs to form dimers is regulated by their state of $N$-glycosylation.

\section{E. O-Linked Glycosylation and GPCR Function}

In addition to $N$-glycosylation, new studies predict that over 350 GPCRs undergo $O$-linked glycosylation. $O$-glycosylation occurs in a stepwise fashion where the process is initiated by the attachment of $\alpha$-linked 
GalNAc residues primarily to the hydroxyl group of serine, threonine, and tyrosine residues. $O$-glycans are usually capped with terminal negatively charged sialic acids and vary in structure and size. $O$-glycosylation is initiated in the Golgi after protein folding, where newly synthesized proteins or recycled membrane proteins serve as substrates (Figs. 6A and 7). Despite the vast number of GPCRs predicted to be modified by $O$-linked glycosylation, in most cases, experimental validation is lacking, and the role of $O$-linked glycosylation of GPCRs in trafficking, ligand binding, and signaling is largely unexplored. In this section, we discuss recent advances and challenges in understanding functions of $O$-glycosylation in GPCR biology.

1. O-Glycosylation and GPCR Cell Surface Expression. The study of $O$-glycosylation is challenging; nonetheless, mass spectrometry has been used to detect $O$-glycans on rhodopsin (Nakagawa et al., 2001) and human opsins (Nakagawa et al., 2001), but in neither case was the function determined. In more recent work, using an improved prediction algorithm for $O$-glycosylation (NetOGlyc 4.0), five potential $O$-glycosylated sites were predicted to reside in the $\mathrm{N}$-terminal domain of human DOR, with three sites- $S^{6}, S^{25}$, and $S^{29}$ - experimentally validated and shown to regulate DOR transport to the cell surface (Lackman et al., 2018). This study further identified the enzyme GalNAc-transferase 2, one of 20 GalNAc transferase isoforms expressed in mammalian cells, as the specific regulator of DOR $O$-glycosylation using a human embryonic kidney (HEK293) cell knockout system (Lackman et al., 2018). However, it should be noted that GPCRs are often modified with both $N$ - and $O$-glycosylation simultaneously, which may perform different and overlapping functions (Sadeghi and Birnbaumer, 1999; Park et al., 2017; Goth et al., 2018; Salom et al., 2019).

2. O-Glycosylation and GPCR Ligand Binding. Similar to $N$-glycosylation, modification of the N-terminus of GPCRs with $O$-glycosylation influences ligand binding. $O$-linked glycosylation of the $\mathrm{DP}_{2}$ and $\mathrm{EP}_{2}$ prostanoid receptors is important for maintaining high-affinity ligand-binding activity (Morii and Watanabe, 1992), as was similarly demonstrated for $N$-linked glycosylation of the same receptors. The chemokine receptor system controls fundamental biologic processes such as inflammation and cell migration; however, there are far more ligands then receptors, and various ligands bind to multiple receptors; thus, understanding critical features of ligands and receptors that dictate ligand-binding specificity is important. One such determinant that contributes to the specificity of chemokine binding is the post-translational modification of the CCR5 chemokine receptor by the addition of $O$-linked glycans and tyrosine sulfates (Bannert et al., 2001). These modifications provide not only a larger and potentially more flexible binding surface but also supply an array of negative charges that allow electrostatic interactions with the generally positive receptor-binding interface of the chemokines (Bannert et al., 2001). Although there is no consensus sequence for $O$-glycosylation, a high prevalence of serine, threonine, and tyrosine residues in the $\mathrm{N}$-terminal domain of chemokine receptors suggests that $O$-glycosylation may function broadly to modulate chemokine receptor function.

3. O-Glycosylation, GPCR N-Terminal Cleavage, and Signaling. In recent work, $O$-glycosylation has been implicated in N-terminal cleavage of certain GPCRs (Fig. 7) (Goth et al., 2017, 2018; Park et al., 2017). Interestingly, almost all GPCRs reported to undergo N-terminal cleavage possess identified or predicted $O$-glycosylation modifications in close proximity to the reported cleavage sites (Goth et al., 2018). Two studies examined the role and function of $O$-glycosylation on $\beta_{1}$-adrenoreceptor $\mathrm{N}$-terminal cleavage and signaling (Goth et al., 2017; Park et al., 2017). Using in vitro $O$-glycosylation assays, synthetic peptides representing the $\beta_{1}$-adrenoreceptor $\mathrm{N}$-terminus and recombinantly expressed GalNAc-transferase 2 identified $O$-glycosylation at several serine residues. Moreover, loss of $\beta_{1}$-adrenoreceptor $O$-glycosylation in cells, using GalNAc-transferase 2-deficient cells, resulted in a decrease in isoproterenol-induced Gsmediated cAMP formation (Goth et al., 2017), suggesting that $O$-glycosylation is important for signaling. In contrast, other work showed that different serine residues of the $\beta_{1}$-adrenoreceptor $\mathrm{N}$-terminus are $O$-glycosylated in GalNAc-transferase 2-expressing CHO cells (Park et al., 2017). This study also demonstrated that $\beta_{1}$-adrenoreceptor N-terminal cleavage controlled by $O$-glycosylation functions alters the balance of $\beta_{1}$-adrenoreceptor signaling between the Gs/cAMP and ERK signaling, with a preference for cAMP signaling (Park et al., 2017). $\mathrm{N}$-terminal proteolysis of PAR2 by neutrophil elastase is also inhibited by the presence of $O$-glycosylation (King et al., 2017), indicating control of proteolytic activation of certain GPCRs. Finally, modulation of CCR7 on immune cells with multiple sialic acids attached to both the $N$ - and $O$-linked glycans is important for maintaining immune cell responsiveness and immune cell trafficking (Kiermaier et al., 2016) (Figs. 6 and 7). Thus, similar to $N$-glycosylation, $O$-glycosylation has important functions in regulating GPCR biology.

\section{F. Detection and Study of GPCR Glycosylation}

Recent advancements in the field of bioinformatics, mass spectrometry, molecular biology, and genetic engineering have led to an enormous expansion in the identification of glycosylated GPCRs. NetNGlyc 4.0 and NetOGlyc 4.0 softwares are most widely used to predict $N$-linked and $O$-linked glycosylation of GPCRs, respectively (Steentoft et al., 2013; Hauser et al., 2016; 
Lackman et al., 2018). Standard molecular biology and biochemical techniques to study $N$-glycosylation of GPCRs include mutagenesis of known or predicted glycosylation sites as well as enzymes that cleave glycans from protein substrates such as peptide:Nglycosidase F (PNGaseF), endoglycosidase H (EndoH), neuraminidase, and $O$-glycosidase treatment to discriminate between terminally and core-glycosylated $N$-glycans. Another commonly used reagent is tunicamycin, an antibiotic derived from Streptomyces lysosuperificus, that functions as a global inhibitor of $N$-linked glycosylation (Fig. 6C) (Rands et al., 1990; Sadeghi and Birnbaumer, 1999; Roy et al., 2010). Typically, GPCR post-translational modification with glycan moieties changes the electrophoretic mobility of the protein, which can be readily observed by immunoblotting with GPCR-specific antibodies. As demonstrated for PAR1, treatment with tunicamycin results in the loss of multiple high-mobility bands and the appearance of a major aglycosylated receptor that migrates near the predicted molecular weight (Fig. 6C). Typically, GPCR post-translational modification with glycan moieties changes the electrophoretic mobility of the protein, which can be analyzed by gel electrophoresis and immunoblotting with GPCRspecific antibodies.

The study of GPCR $O$-glycosylation is more challenging because $O$-glycans are complex and heterogenous and there are no known consensus sequence sites. Second, unlike peptide:N-glycosidase F (PNGaseF) for $N$-glycans, there is not a single universal glycosidase that is able to specifically remove $O$-linked glycan structures (Yang et al., 2018; Salom et al., 2019). The structures of glycans released after digestion may be determined by a combination of liquid or gas chromatography, mass spectrometry, and nuclear magnetic resonance spectroscopy (Mulloy et al., 2015). Moreover, glycan heterogeneity and flexibility can prevent formation of ordered GPCR crystals (Milić and Veprintsev, 2015). To avoid effects of heterogeneous glycosylation in overexpression system, some researchers have used cell lines lacking $N$-acetylglucosaminyltransferase I activity. These cells express proteins with homogeneous $N$-linked glycosylation, which proved beneficial for the expression of rhodopsin for applications such as crystallization (Reeves et al., 2002; Standfuss et al., 2011).

In the last decade, X-ray crystallography has provided a significant contribution to our understanding of GPCR structure and pharmacology. However, in most if not all cases, GPCR structures lacked modification with glycans because of the complexity and heterogeneity of glycan structures that interfere with GPCR crystallization (Milić and Veprintsev, 2015). Thus, future work on the development of more advanced techniques is important to study native structures with their full repertoire of post-translational modifications, including $N$-glycosylation.

\section{GPCR Palmitoylation}

Palmitoylation of GPCRs occurs via the covalent attachment of a 16-carbon fatty acid palmitate to one or more cysteine residues, generally in the C-terminal tail (Fig. 8, A and C), specifically termed $S$-palmitoylation. More than $70 \%$ of mammalian GPCRs contain at least one cysteine residue located 10-14 amino acids carboxyl to the seventh transmembrane helical domain. The rhodopsin and $\beta_{2}$-adrenoceptor were the first GPCRs shown to be palmitoylated, and early work indicated that palmitoylation of rhodopsin results in the formation of a fourth cytoplasmic loop (O'Brien and Zatz, 1984; O'Dowd et al., 1989; Palczewski et al., 2000). The preponderance of predicted palmitoylation of GPCRs suggests that palmitoylation serves broad functions in receptor regulation. Here, we discuss the mechanism of GPCR palmitoylation and the role of palmitoylation in regulating spatial and temporal aspects of receptor signaling (Qanbar and Bouvier, 2003).

\section{A. Regulation of GPCR Palmitoylation}

GPCR palmitoylation is a reversible process. Although early studies of rhodopsin suggested that spontaneous transfer of palmitate can occur in vitro, newer studies clearly indicate that palmitoylation occurs via an enzymatic catalytic process (O'Brien and Zatz, 1984; Korycka et al., 2012). Moreover, GPCRs are basally modified with palmitoylation, and in some cases GPCR palmitoylation is induced by agonist stimulation.

1. Enzymology of GPCR Palmitoylation. A family of palmitoyl acyl transferases (PATs) catalyze the attachment of a palmitoyl group to cytosolic cysteine (C) residues and include at least 23 enzymes (Fig. 8, A and C). PATs contain a conserved D-H-H-C (Asp-HisHis-Cys) cysteine-rich domain, designated as DHHC 1-23, that mediates the transfer of palmitoyl to substrate proteins (Fukata et al., 2006; Korycka et al., 2012; De and Sadhukhan, 2018). DHHC proteins are localized in the ER and Golgi, and some are targeted to the plasma membrane (Ohno et al., 2006; Petäjä-Repo et al., 2006; Korycka et al., 2012). Several GPCRs have been shown to be palmitoylated by various DHHCs in different subcellular compartments. GPCR palmitoylation in the ER-Golgi has been shown for DOR, $\beta_{2^{-}}$ adrenoceptor, PAR2, CCR5, thyrotropin receptor, and vasopressin $\mathrm{V}_{1 \mathrm{~A}}$ receptor, whereas other GPCRs appear to be palmitoylated at the plasma membrane, including $\mathrm{DOR}$ and $\mathrm{S}_{1} \mathrm{P}_{1}$ receptor (Petäjä-Repo et al., 2006; Adams et al., 2011; Adachi et al., 2016; Badawy et al., 2017). The substrate specificity of DHHCs is due in part to subcellular localization (Roth et al., 2006; Linder and Deschenes, 2007; Ohno et al., 2012). Palmitoylation is a reversible process, and depalmitoylation of substrate proteins is catalyzed by the action of acylprotein thioesterase (APT) 1, APT2, and APT1-like and palmitoyl-protein thioesterase-1 and -2 (Fig. 8, A and C) 
(Linder and Deschenes, 2003). Currently, only APT1 and APT2 have been reported to mediate depalmitoylation of $\beta_{2}$-adrenoceptor and melanocortin $\mathrm{MC}_{1}$ receptor, respectively (Adachi et al., 2016; Chen et al., 2019).

2. Basal and Agonist-Induced GPCR Palmitoylation. The majority of newly synthesized GPCRs are subjected to palmitoylation basally during biosynthesis. This appears to be the case for PAR1, where the detection of palmitoylation occurs basally and is not further modified after agonist stimulation (Fig. 8B). However, a few GPCRs appear to be palmitoylated after agonist stimulation. This has been demonstrated for the $\beta_{2}$ adrenoceptor, which is basally palmitoylated at $\mathrm{C}^{341}$, whereas agonist-induced palmitoylation and depalmitoylation occurs predominantly on $\mathrm{C}^{265}$ (O'Dowd et al., 1989; Adachi et al., 2016). Several other GPCRs undergo agonist-induced palmitoylation and depalmitoylation, including but not limited to the vasopressin $\mathrm{V}_{1 \mathrm{~A}}$ receptor, dopamine $\mathrm{D}_{1}$ receptor, $\alpha_{1 \mathrm{~B}}$-adrenoreceptor, 5-hydroxytryptamine $(\mathrm{HT})_{4}$ receptor, $\mathrm{S}_{1} \mathrm{P}_{1}$ receptor, $\alpha_{2 \mathrm{~A}}$-adrenoreceptor, and muscarinic $\mathrm{M}_{2}$ receptor (Ponimaskin et al., 2001; Badawy et al., 2017; Naumenko and Ponimaskin, 2018).

\section{B. Palmitoylation and GPCR Trafficking}

An important function of GPCR palmitoylation is the efficient transport of receptors through the biosynthetic pathway and delivery to the cell surface, compartmentalization in plasma membrane microdomains, dimerization, and trafficking through the endocytic pathway.

1. GPCR Surface Expression. A role for palmitoylation in regulating GPCR surface expression has been demonstrated for several GPCRs (Fig. 9). Mutation of three C-tail cysteine residues of the chemokine CCR5 receptor resulted in retention largely in the ER and
A

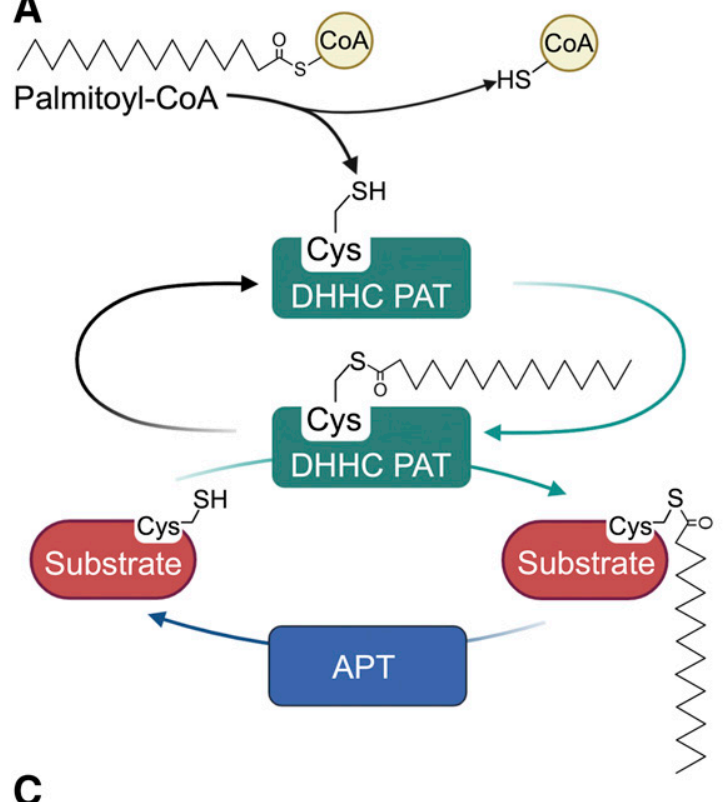

B

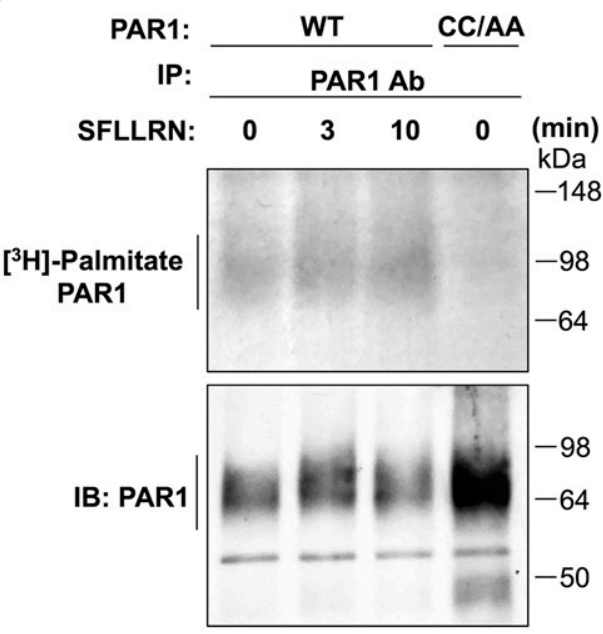

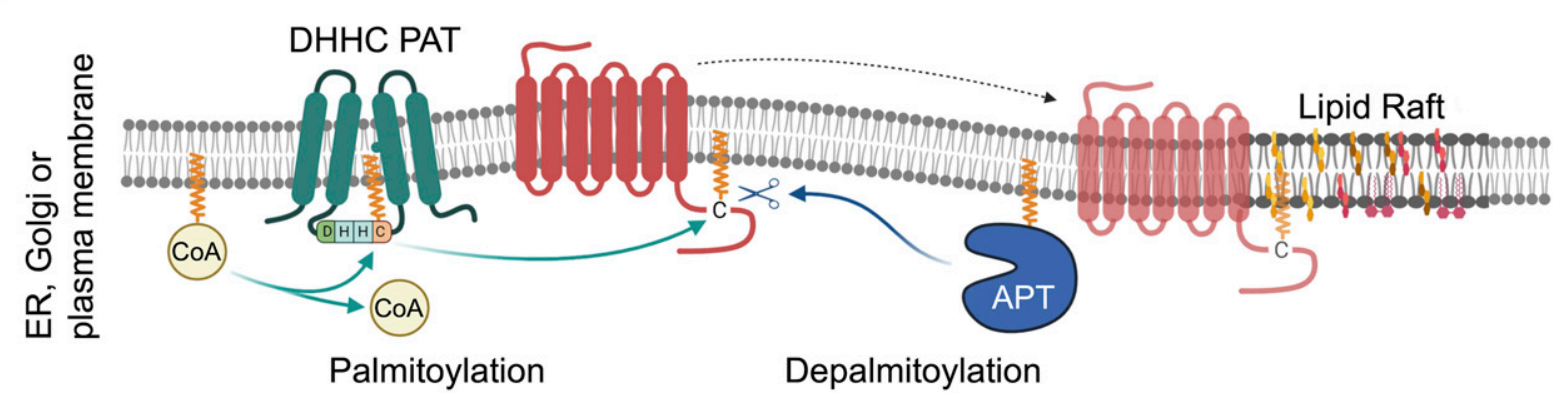

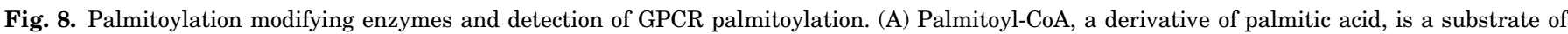

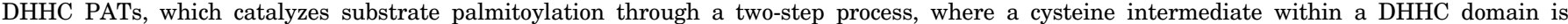

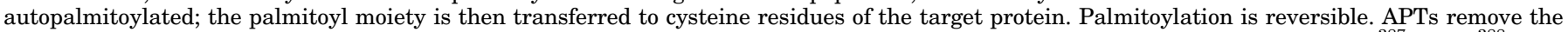

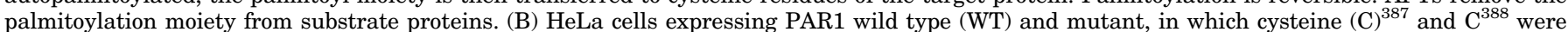

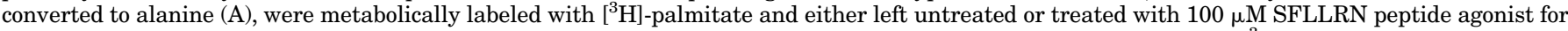

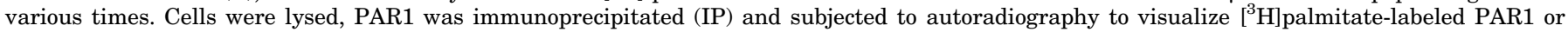

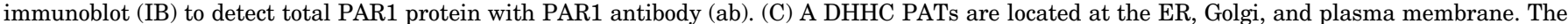

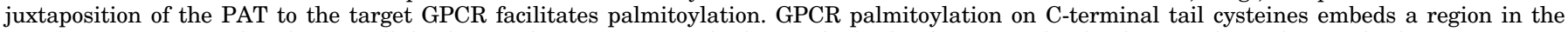

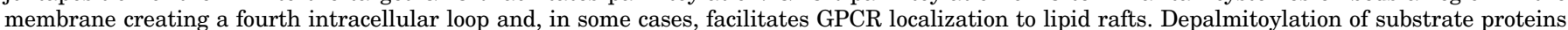

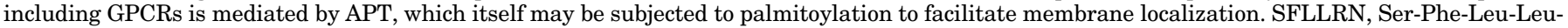
Arg-Asn. 
Golgi complex (Blanpain et al., 2001; Percherancier et al., 2001). The authors further showed that the nonpalmitoylated CCR5 mutant displays impaired diffusion properties within the ER. Similarly, defects in palmitoylation caused a marked loss of endogenous PAR2 expression at the cell surface (Adams et al., 2011) as well as diminished surface expression of the thyrotropin receptor, vasopressin $\mathrm{V}_{2}$ receptor, adenosine $\mathrm{A}_{1}$ receptor, histamine $\mathrm{H}_{2}$ receptor, and the dopamine $\mathrm{D}_{1}$ and $\mathrm{D}_{2}$ receptors (Schülein et al., 1996; Sadeghi et al., 1997; Tanaka et al., 1998; Fukushima et al., 2001; Ebersole et al., 2015). The mechanism by which defects in palmitoylation diminish GPCR surface expression is attributed mainly to receptor misfolding and proteasomal degradation. This has been shown for deficiencies in palmitoylation of CCR5 and adenosine $\mathrm{A}_{1}$ receptor, which enhance degradation (Gao et al., 1999; Percherancier et al., 2001). Follicle-stimulating hormone receptor contains three cytosolic cysteine residues; however, mutation of a single $C^{269}$ was sufficient to impair cell surface expression, likely due to misfolding and degradation (Uribe et al., 2008). These findings are consistent with an important role for palmitoylation in facilitating the proper folding and maturation of GPCRs.

2. GPCR Dimerization and Lipid Rafts. GPCRs partition into lipid raft plasma membrane microdomains enriched in cholesterol and is regulated by palmitoylation (Figs. 8C and 9) (Barnett-Norris et al., 2005; Villar et al., 2016). The serotonin $5-\mathrm{HT}_{1 \mathrm{~A}}$ receptor defective in palmitoylation showed decreased association with lipid rafts (Papoucheva et al., 2004; Renner et al., 2007). Similarly, dopamine $\mathrm{D}_{1}$ receptor (Tiu et al., 2020) and cannabinoid receptor type 1 (Oddi et al., 2012, 2018) mutants deficient in palmitoylation exhibited impaired lipid raft association. Interestingly, the crystal structure of the human $\beta_{2}$-adrenoceptor revealed a receptor dimer complex, where lipid-mediated contacts via palmitic acid and cholesterol are the major interactions (Cherezov et al., 2007). In addition, palmitoylation of several other GPCRs has been shown to promote lipid raft association and dimerization, including the MOR (Zheng et al., 2012), rhodopsin (Seno and Hayashi, 2017), and the serotonin $5-\mathrm{HT}_{1 \mathrm{~A}}$ receptor (Kobe et al., 2008). These results indicate that for certain GPCRs, palmitoylation facilitates receptor compartmentalization in lipid rafts and dimerization.

3. GPCR Internalization, Recycling, and Lysosomal Degradation. In addition to GPCR plasma membrane localization, palmitoylation has been shown to regulate GPCR internalization, recycling, and lysosomal degradation (Fig. 9). Several studies have documented a role for palmitoylation in GPCR internalization. Defects in cannabinoid receptor type 1 palmitoylation inhibited agonist-induced internalization and coassociation with caveolin 1 (Oddi et al., 2017). Similarly, defects in palmitoylation of the prostanoid thromboxane $\mathrm{A}_{2}$ receptor, PAR2, and thyrotropin receptor perturbed agonist-induced $\beta$-arrestin recruitment and receptor internalization (Tanaka et al., 1998; Reid and Kinsella, 2007; Adams et al., 2011). In contrast, a vasopressin $V_{1 A}$ receptor mutant deficient in palmitoylation displayed an increased rate of agonist-induced internalization without affecting intracellular signaling

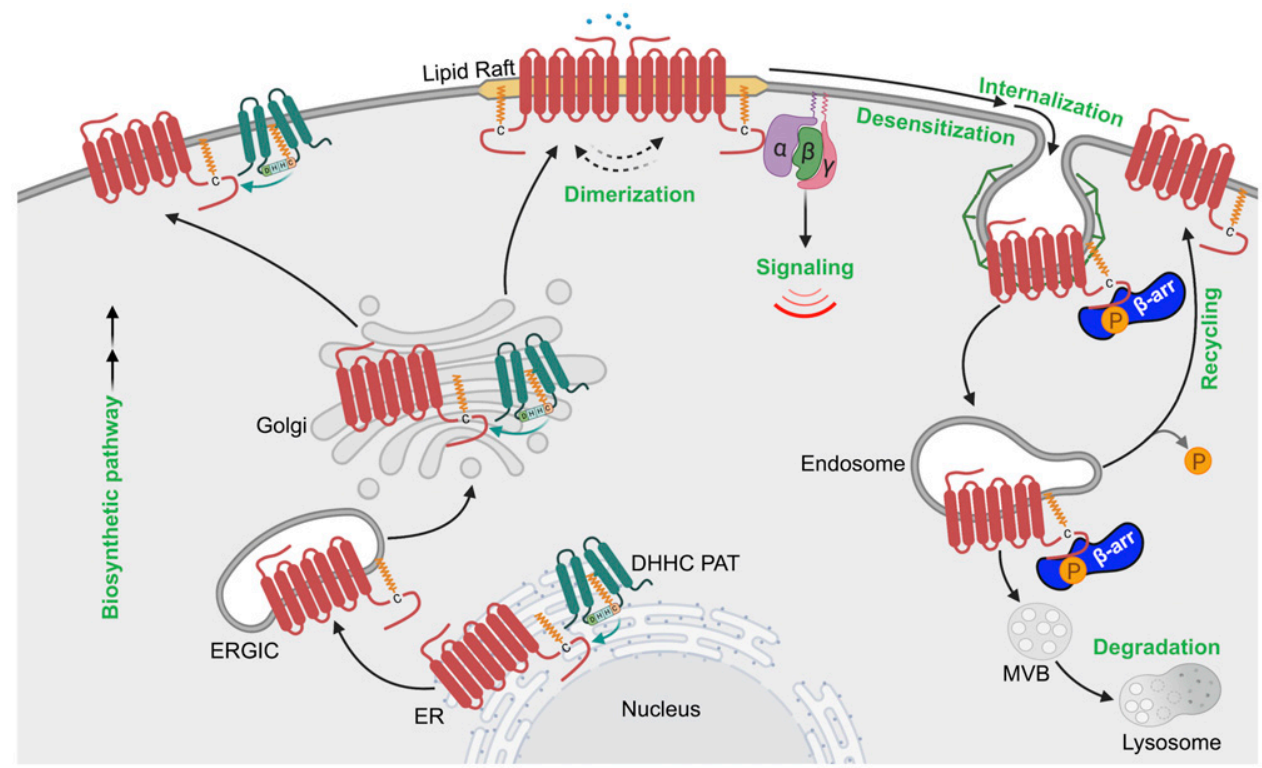

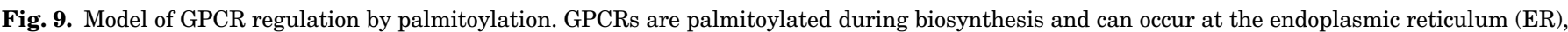

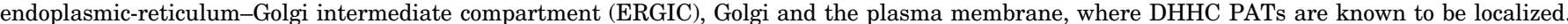

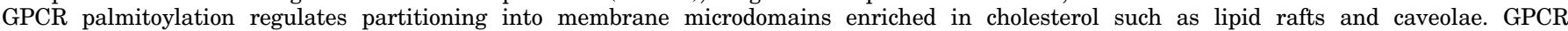

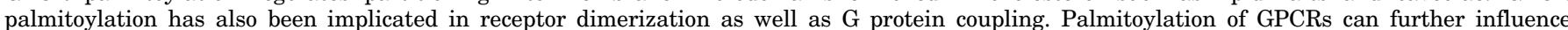

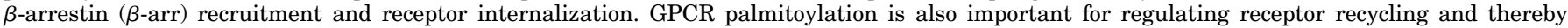
prevents lysosomal degradation. 
(Hawtin et al., 2001). Similarly, a palmitoylationdeficient dopamine $D_{1}$ receptor mutant exhibited an enhanced rate of internalization compared with wild type and showed preferentially internalization via a clathrin-dependent pathway over caveolae (Kong et al., 2011).

Once internalized, GPCRs are either recycled back to the cell surface or targeted to lysosomes for degradation. Although palmitoylation of PAR2 is required for efficient internalization and lysosomal degradation (Adams et al., 2011), palmitoylation has an opposing function for PAR1, as a palmitoylationdeficient PAR1 mutant exhibited an enhanced rate of internalization and lysosomal degradation (Canto and Trejo, 2013). The defects in trafficking caused by alteration of PAR1 palmitoylation are due to inappropriate utilization of C-tail tyrosine-based sorting motifs for endocytic adaptor proteins (Canto and Trejo, 2013). In the absence of palmitoylation, PAR 1 sorting motifs appear to be more accessible to the clathrin adaptor binding proteins AP-2 and adaptor protein complex 3, which accelerate the rate of internalization from the plasma membrane as well as enhanced sorting from endosomes to lysosomes and degradation (Canto and Trejo, 2013). Similarly, a CCR5 palmitoylation mutant exhibits rapid lysosomal degradation and a reduced half-life (Percherancier et al., 2001).

\section{Palmitoylation and GPCR Signaling}

In addition to GPCR trafficking, palmitoylation is important for regulating activated GPCR coupling to G protein signaling. In several cases, deficiencies in GPCR palmitoylation fail to affect ligand binding but impact $G$ protein coupling or alter the specificity of coupling to certain $\mathrm{G}$ protein subtypes. Studies of a $\beta_{2}$-adrenoceptor $\mathrm{C}^{341}$ mutant showed defects in coupling to Gs and impaired cAMP production (O'Dowd et al., 1989). In other studies, defects in GPCR palmitoylation were shown to compromise $\mathrm{G}$ protein coupling of the agonistactivated serotonin $5-\mathrm{HT}_{1 \mathrm{~A}}$ receptor, human somatostatin receptor type 5, human endothelin $\mathrm{ET}_{\mathrm{A}}$ receptor, $\alpha_{2 \mathrm{~A}}$-adrenoreceptor, dopamine $\mathrm{D}_{1}$ receptor, human adenosine $\mathrm{A}_{1}$ receptor, and the human thyrotropin receptor (Hukovic et al., 1998; Doi et al., 1999). This is not surprising since GPCR localization in lipid rafts is known to facilitate the assembly of signaling ensembles (Barnett-Norris et al., 2005; Villar et al., 2016). Indeed, methyl- $\beta$-cyclodextrin, a cholesterol-chelating agent that disrupts lipid rafts, reduced the localization of serotonin 5- $\mathrm{HT}_{1 \mathrm{~A}}$ receptor to lipid rafts and $\mathrm{G}$ protein coupling (Papoucheva et al., 2004; Renner et al., 2007). Thus, palmitoylation-driven lipid raft localization of certain GPCRs is important for regulating signaling. However, some studies suggest that conformational changes induced by modulating lipid interaction of preexisting dimers may alter $\mathrm{G}$ protein coupling preferences. Although the $\beta_{2}$-adrenoceptor couples to both
Gs and Gi proteins, depletion of cholesterol resulted in preferential coupling to Gs proteins (Xiang et al., 2002). Moreover, $\beta_{2}$-adrenoceptor coupled to Gs protein was shown to occur with receptor monomers (Whorton et al., 2007), indicating that dimers are not a prerequisite for Gs coupling. In mice, treatment with palmostatin B, a cell-permeable inhibitor of APT1, increased $\mathrm{MC}_{1}$ receptor palmitoylation and enhanced the $\mathrm{MC}_{1}$ receptor-stimulated cAMP production, which provided protection against progression of melanoma (Chen et al., 2017a). Thus, the impacts of palmitoylation are partly due to defects in compartmentalization, receptor conformation, and receptor capacity to couple to $\mathrm{G}$ protein activation.

\section{Detection and Study of GPCR Palmitoylation}

Although there are no consensus sites for palmitoylation, several palmitoylation prediction tools are currently available, such as CSS-Palm, GPS-Lipid, PalmPred, and SwissPalm (Ren et al., 2008; Kumari et al., 2014; Blanc et al., 2015; Xie et al., 2016). Although palmitoylation of GPCRs has been reported, the detection of GPCR palmitoylation is challenging and includes the use of metabolic labeling with $\left[{ }^{3} \mathrm{H}\right]$ palmitate and more recently with click chemistry. The traditional method to study GPCR palmitoylation uses $\left[{ }^{3} \mathrm{H}\right]$ palmitate metabolic labeling followed by autoradiography and is reliable but has limited sensitivity (Fig. 8B) (O'Dowd et al., 1989; Ponimaskin et al., 2002; Petäjä-Repo et al., 2006). In recent years, bioorthogonal labeling or click chemistry has been employed to study palmitoylation of GPCRs (Ebersole et al., 2014). In this method, a cell-permeable chemical probe that mimics palmitic acid is covalently attached to proteins by PATs. The GPCR modified with the chemical probe is then detected using bioorthogonal azide-labeled fluorescent chromophore or biotin azide via click chemistry (Hannoush and Sun, 2010; De and Sadhukhan, 2018). If using biotin, this method allows streptavidin-mediated pulldown of the modified GPCR, which can be subjected to mass spectrometry analysis, whereas a fluorescent chromophore allows in-gel fluorescence visualization of palmitoylation (Hannoush and Sun, 2010; Broncel et al., 2015; De and Sadhukhan, 2018). Acyl-biotin exchange coupled with mass spectrometry is an approach used to identify and characterize protein palmitoylation on a proteomewide scale (Drisdel and Green, 2004; Collins et al., 2017; Gorinski et al., 2019). Acyl-polyethylene glycol (PEG) exchange (APE) shift assay is a modification of the acyl-biotin exchange method, where acyl-PEG exchange utilizes cysteine chemistry to exchange $S$-palmitoylation sites with different PEG mass tags of defined size, which can be observed by immunoblotting and can determine the number of $S$-palmitoylation sites (Percher et al., 2016).

To study the function of GPCR palmitoylation, multiple approaches have been taken, including site-directed 
mutagenesis of key cysteine residues as shown for PAR1, where mutation of two $\mathrm{C}$-tail $\mathrm{C}^{387}$ and $\mathrm{C}^{388}$ residues to alanine resulted in a loss of $\left[{ }^{3} \mathrm{H}\right]$ palmitate incorporation (Fig. 8B) (Canto and Trejo, 2013), as well as knockdownrescue of palmitoyl transferase enzymes (Zuckerman et al., 2011). Another common approach includes the use of 2-bromopalmitate, a general inhibitor of palmitoylation, that is converted to 2-bromopalmitoyl-CoA and is known to inhibit palmitoyltransferase activity of all the DHHC enzymes (Adams et al., 2011; Davda et al., 2013). Due to the lack of available more feasible methods, the extent, function, and dynamic nature of GPCR palmitoylation remain poorly understood.

\section{Other GPCR Post- Translational Modifications}

In addition to PTMs discussed above, a few reports indicate that GPCRs are targets of other types of PTMs such as SUMOylation, $S$-nitrosylation, tyrosine sulfation, and methylation (Fig. 1). SUMOylation, which is mediated by the covalent conjugation of a $11 \mathrm{kDa}$ SUMO protein to lysine residues present in the consensus motif $[\psi-\mathrm{K}-\mathrm{X}-(\mathrm{D} / \mathrm{E})$, where $\psi$ is aliphatic amino acid and $\mathrm{X}$ is any amino acid; Geiss-Friedlander and Melchior, 2007]. SUMOylation occurs via an enzymatic cascade mediated by a dedicated set of SUMO E1, E2, and E3 enzymes targeting intracellular domains GPCRs (Flotho and Melchior, 2013); this is analogous to and reminiscent of ubiquitin-catalyzed reactions. SUMOylation was believed to be a predominantly nuclear process, but recent advancements found connection with integral membrane proteins, such as GPCRs (cannabinoid receptor type $1, \mathrm{SMO}, \mathrm{mGlu}_{7}$ receptor, serotonin $5-\mathrm{HT}_{1 \mathrm{~A}}$ receptor) (Luo et al., 2013; Choi et al., 2016; Zhang et al., 2017; Xu et al., 2019). A recent notable example of GPCR SUMOylation was described for the muscarinic $M_{1}$ receptor, which is SUMOlyated on $\mathrm{K}^{327}$ within the intracellular loop (IL3) and increases ligand-binding affinity to the muscarinic $\mathrm{M}_{1}$ receptor, resulting in enhanced signaling efficiency and receptor endocytosis (Xu et al., 2019). In other work, agonist treatment was shown to increase expression of SUMOylated serotonin $5-\mathrm{HT}_{1 \mathrm{~A}}$ receptors in specific regions of the rat brain and was postulated to regulate receptor endocytosis ( $\mathrm{Li}$ and Muma, 2013). GPCRs are also subjected to $S$-nitrosylation, most likely in the transmembrane domain, which is mediated by the covalent attachment of a nitric oxide moiety to specific cysteine thiol groups of the receptor. This has been shown for the $\alpha_{1}$-adrenoreceptor using an in vitro biotin switch assay; however, the actual sites of $S$-nitrosylation among the possible 14 cysteine residues were not determined (Jaffrey et al., 2001; Nozik-Grayck et al., 2006). The function of $\alpha_{1}$-adrenoreceptor $S$-nitrosylation has been attributed to decreases in the vasoconstrictor response in response to agonist stimulation (Nozik-Grayck et al., 2006). $S$-nitrosylation of the angiotensin $\mathrm{AT}_{2}$ receptor decreases the binding affinity of angiotensin and occurs on $\mathrm{C}^{289}$ located in the seventh transmembrane domain of the receptor (Leclerc et al., 2006).

In contrast to SUMOlyation and $S$-nitrosylation, tyrosine sulfation has been described for a select group of chemokine GPCRs and occurs in the Golgi through attachment of a negatively charged sulfate group to an exposed tyrosine residue, yielding tyrosyl $O$-sulfate. Tyrosine sulfation has been experimentally confirmed for several human chemokine GPCRs, including CCR2, CCR3, CCR5, and CCR8, as well as CXCR3, CXCR4, and CX3CR1 receptors (Colvin et al., 2006; Liu et al., 2008; Zhu et al., 2011; Ludeman and Stone, 2014) and shown to enhance the affinity, potency, and specificity of chemokine ligands (Ludeman and Stone, 2014; Stone et al., 2017). An additional new PTM for GPCRs is provided by studies suggesting that arginine methylation of GPCRs is prevalent and contributes to the regulation of GPCR function. A bioinformatics analysis has identified 300 human GPCRs with greater than 583 predicted methylation motifs (RGG or RXR, where arginine is $\mathrm{R}$, glycine is $\mathrm{G}$, and $\mathrm{X}$ is any amino acid), localized within ICL3 (Likhite et al., 2015). A study of the human dopamine $\mathrm{D}_{2}$ receptor revealed methylation modification at ICL3 mediated by an arginine methyltransferase 5 , which resulted in attenuation of dopamine $\mathrm{D}_{2}$-mediated inhibition of cAMP signaling in cultured human cells in vitro and in vivo in C. elegans (Likhite et al., 2015; Bowitch et al., 2018). The ICL3 of the dopamine $\mathrm{D}_{2}$ receptor facilitates coupling to $G$ proteins and signaling effectors, consistent with the idea that methylation may perturb receptor-G protein coupling. Despite these findings, the role of other types of PTMs, including SUMOylation, $S$-nitrosylation, tyrosine sulfation, and methylation, remains relatively unexplored for most members of the vast GPCR superfamily and is important to consider to thoroughly understand mechanisms of GPCR regulation and for drug discovery.

\section{GPCR PTM Crosstalk}

Clearly, post-translational modifications of GPCRs are essential for function. GPCRs are also subjected to multiple diverse types of post-translational modifications at a given time, which is critical for expanding their function. Although over 200 types of PTMs have been identified (Olsen and Mann, 2013), the best characterized PTMs for GPCRs include phosphorylation, ubiquitination, glycosylation, and palmitoylation. Moreover, different PTMs can either positively or negatively influence each other. Here, we briefly discuss examples of GPCR post-translational modification crosstalk.

\section{A. GPCR Phosphorylation and Ubiquitination Crosstalk}

The crosstalk between ligand-induced GPCR phosphorylation and ubiquitination has been well described. 
The yeast Ste2 GPCR is hyperphosphorylated and ubiquitinated after $\alpha$-factor stimulation (Hicke et al., 1998). Phosphorylation occurs on the Ste 2 C-terminal tail and positively regulates ubiquitination at neighboring lysine residues via recruitment of the E3 ligase Rsp5, which is required for both constitutive and ligandinduced receptor internalization. The precise mechanism by which Ste2 phosphorylation regulates ubiquitination is unclear, but the ability of WW domains of Rsp5p might serve to recognize phosphoserine (Lu et al., 1999). Certain mammalian GPCRs also require phosphorylation for ubiquitination. The $\beta_{2}$-adrenoceptor requires phosphorylation, which occurs mainly within the $\mathrm{C}$-terminal tail region, for agonist-induced ubiquitination. In this case, $\beta_{2}$-adrenoceptor phosphorylation is important for $\beta$-arrestin association, which facilitates recruitment of the E3 ligase NEDD4-1 (Shenoy et al., 2001; DeWire et al., 2007; Han et al., 2013). Similarly, activated CXCR4 phosphorylation occurs at two critical serine residues within the C-tail region and is required for the recruitment of the E3 ligase AIP4. AIP4 binds to activated and phosphorylated CXCR4 and ubiquitinates adjacent lysine residues (Marchese and Benovic, 2001; Bhandari et al., 2009). Other studies have shown that the PTHR and PAR1 require phosphorylation for ubiquitination (Chen et al., 2011; Zhang et al., 2018); however, the mechanistic details are lacking. Thus, the vast majority of ligandactivated GPCR ubiquitination is likely to require phosphorylation for either direct recruitment of the E3 ligase or an adaptor protein that mediates E3 ligase recruitment. However, the role of phosphorylation is expansive and likely to regulate GPCR ubiquitination at multiple levels, including the activity of the adaptor proteins as well as the ubiquitination machinery itself (Song and Luo, 2019). In the case of GPCRs, this has been demonstrated recently for PAR1-induced NEDD42 tyrosine phosphorylation and activation as described above (Grimsey et al., 2018).

\section{B. GPCR Phosphorylation and Palmitoylation Crosstalk}

Another prominent studied GPCR post-translational modification crosstalk occurs between phosphorylation and palmitoylation. Palmitoylation has a critical role in generating a GPCR fourth ICL through membrane insertion and is thus likely to impact receptor structure and major domains that serve as sites for phosphorylation. Indeed, deficiencies in palmitoylation have been shown to impair phosphorylation of multiple GPCRs. A palmitoylation-deficient vasopressin $\mathrm{V}_{1 \mathrm{~A}}$ receptor exhibited lower phosphorylation both basally and after agonist activation (Hawtin et al., 2001). Similar observations were made for the chemokine receptor CCR5 (Kraft et al., 2001). In contrast, a palmitoylationdeficient mutant of the $\beta_{2}$-adrenoceptor is hyperphosphorylated and constitutively desensitized (Moffett et al., 1993). In other work, $\beta_{2}$-adrenoceptor palmitoylation of $\mathrm{C}^{341}$ was shown to control PKA-dependent C-tail phosphorylation and receptor responsiveness (Moffett et al., 1996). Such observations were also reported for serotonin $5-\mathrm{HT}_{4}$ receptor where a palmitoylation-deficient mutant exhibited enhanced receptor phosphorylation under basal conditions and after agonist stimulation (Ponimaskin et al., 2002). Moreover, in vitro studies confirmed that for certain GPCRs the lack of palmitoylation renders the receptor more susceptible to phosphorylation. In vitro studies of depalmitoylated $\beta_{2}$-adrenoceptor and rhodopsin were found to be robustly phosphorylated by PKA (Moffett et al., 1996) and rhodopsin kinase (Karnik et al., 1993), respectively. Overall, these studies indicate that crosstalk exists between GPCR palmitoylation and phosphorylation.

\section{Conclusions}

Although modulation of the GPCR phosphorylation state is likely to occur in multiple disease settings, phosphorylation of $\beta_{2}$-adrenoceptor in heart disease is well described. In this case, chronic stimulation of $\beta_{1^{-}}$ adrenoceptor and $\beta_{2}$-adrenoceptor, which are critical modulators of contractile function, in heart failure results in GRK2-mediated phosphorylation, desensitization, and ultimately degradation of the vast majority of receptors (Sato et al., 2015).

In addition to phosphorylation, several well described GPCRs modified with ubiquitination have been implicated in disease, including the $\beta_{2}$-adrenoceptor, CXCR4, and PAR1. Carvedilol is a well described nonselective $\beta$ blocker used for the treatment of heart failure and shown to induce ubiquitination of $\beta_{2}$-adrenoceptor via a unique mechanism mediated by the RING-type membrane-associated RING-CH-type finger (MARCH) E3 ubiquitin ligase (Han et al., 2012), but the precise contribution of ubiquitination to regulation of $\beta_{2}$-adrenoceptor in cardiac myocytes and heart failure remains poorly understood. PAR1 is an important drug target for treatment of thrombotic cardiovascular events and has also been implicated in metastatic cancer (Hamilton and Trejo, 2017; Arakaki et al., 2018a,b). Ubiquitination of PAR1 is clearly important for regulating the temporal and spatial dynamics of signaling in various cells types (Wolfe et al., 2007; Grimsey et al., 2015, 2018, 2019). In fact, metastatic breast carcinoma displays aberrant PAR1 trafficking, resulting in increased surface expression, persistent signaling, and tumor cell invasion (Booden et al., 2004; Arora et al., 2008; Arakaki et al., $2018 \mathrm{~b})$. However, the contribution of ubiquitination to dysregulated PAR1 function in metastatic cancer has not been explored and represents an opportunity for drug development. CXCR4 is also overexpressed in various types of cancer, including breast carcinoma, and contributes to breast cancer progression. Interestingly, the oncogene human epidermal growth factor 
receptor 2 enhances CXCR4 expression in breast cancer by increasing translation and inhibiting ubiquitination and degradation of CXCR4 ( $\mathrm{Li}$ et al., 2004; Luker and Luker, 2006), whereas epidermal growth factor receptor increases transcription of CXCR4 and diminishes AIP4 and $\beta$-arrestin activity and reduces CXCR4 degradation (Rahimi et al., 2010). Thus, CXCR4 expression in breast cancer is controlled by ubiquitination at multiple levels.

Similar to phosphorylation and ubiquitination, the vast majority of GPCRs contain potential sites for palmitoylation within their C-terminal tail domain, suggesting it may represent a general feature of this receptor family. As discussed above, palmitoylation is important for GPCR structural conformation, trafficking, plasma membrane localization, and signaling. The link between palmitoylation and disease is best described in the brain, which express multiple types of GPCRs, including adrenergic, serotonin, dopamine, opioid, muscarinic, vasopressin, adenosine, melatonin, and cannabinoid GPCRs that function in various cellular processes such as signal transduction and synaptic plasticity (Naumenko and Ponimaskin, 2018). Importantly, studies have documented alterations in palmitoylation in the brain associated with various pathologic disorders such as Alzheimer's, Huntington's disease, schizophrenia, and mental retardation (Sanders and Hayden, 2015; Cho and Park, 2016). However, the precise link to specific defects in GPCR palmitoylation remains to be determined. Glycosylation has been linked primarily to GPCR maturation protein folding and controls transport of GPCRs via the biosynthetic pathway to the cell surface. Interestingly, the vast majority of GPCR mutations linked to disease have been associated with defects in maturation and folding. This is best documented for rhodopsin, where naturally occurring mutations in $N$-glycosylation consensus sequences of rhodopsin have been linked to retinitis pigmentosa (Sullivan et al., 1993; van den Born et al., 1994), indicating that modulation of GPCR glycosylation status is directly linked to disease progression. In recent work, Trypanosoma cruzi infection was shown to decrease $\beta_{1}$-adrenergic receptor sialylation and $\mathrm{N}$-terminal cleavage that resulted in enhanced signaling and adverse effects on cardiac remodeling (Freirede-Lima et al., 2015; Park et al., 2017). Given the expansive roles of GPCRs in physiology and disease, coupled with the critical function of post-translational modifications in regulating GPCR function, more work is needed to address how modulation of specific GPCRs by PTMs alters the spatial and temporal dynamics of signaling leading to disease progression.

Clearly, post-translational modifications offer novel and diverse mechanisms for regulation of GPCR biology and opportunities for new or refined drug development. Although there has been major progress in understanding the role and function of ubiquitination, glycosylation, and palmitoylation in GPCR function, we have very limited knowledge about other PTMs. A major barrier to generally studying GPCR PTMs is the lack of ability to predict PTMs and technology for detecting PTM dynamics in response to agonist stimulation. One promising approach is the development of mass spectrometry-based quantitative proteomics that can rapidly and accurately detect the dynamics of PTMs and has shown significant advancements, particularly for clinical applications (Pagel et al., 2015). Although the characterization of PTMs is challenging, particularly for GPCRs, a thorough understanding of the molecular mechanisms by which key regulators and mediators of PTMs regulate GPCR signaling is essential for understanding dysregulated mechanisms in disease and for identifying new targets for drug development. GPCRs are important drug targets, with 108 GPCRs representing the target of over 475 of Food and Drug Administration-approved drugs (Hauser et al., 2018). Given the large number of GPCRs $>800$ and vast functions, GPCRs continue to present an enormous opportunity for drug development. Similar to natural genetic variations within GPCRs that alter or cause adverse drug responses, post-translational modification of GPCRs vary between individuals as well as in different tissues and cell types due to genetic variation and/or epigenetic factors and are likely to influence drug responses. Despite the fact that PTMs of GPCRs has an essential role in receptor folding, conformation, stability, activity, and ultimately function, the role and function of PTMs in GPCR drug response have been largely ignored and require greater attention.

\section{Acknowledgments}

We thank the Trejo laboratory and especially Isabel Canto, Antonio Soto, and Neil Grimsey for their contribution to work related to PAR1 palmitoylation, glycosylation, and ubiquitination. Illustrations in the figures were created with BioRender.com.

Authorship Contributions

Wrote or contributed to the writing of the manuscript: Patwardhan, Cheng, Trejo.

\section{References}

Adachi N, Hess DT, McLaughlin P, and Stamler JS (2016) S-palmitoylation of a novel site in the $\beta 2$-adrenergic receptor associated with a novel intracellular itinerary. J Biol Chem 291:20232-20246.

Adams MN, Christensen ME, He Y, Waterhouse NJ, and Hooper JD (2011) The role of palmitoylation in signalling, cellular trafficking and plasma membrane localization of protease-activated receptor-2. PLoS One 6:e28018.

Alvarez CE (2008) On the origins of arrestin and rhodopsin. BMC Evol Biol 8:222.

Alvaro CG, O'Donnell AF, Prosser DC, Augustine AA, Goldman A, Brodsky JL, Cyert MS, Wendland B, and Thorner J (2014) Specific $\alpha$-arrestins negatively regulate Saccharomyces cerevisiae pheromone response by down-modulating the G-proteincoupled receptor Ste2. Mol Cell Biol 34:2660-2681.

Arakaki AKS, Pan WA, Lin H, and Trejo J (2018a) The $\alpha$-arrestin ARRDC3 suppresses breast carcinoma invasion by regulating $\mathrm{G}$ protein-coupled receptor lysosomal sorting and signaling. J Biol Chem 293:3350-3362.

Arakaki AKS, Pan WA, and Trejo J (2018b) GPCRs in cancer: protease-activated receptors, endocytic adaptors and signaling. Int J Mol Sci 19:1886.

Arora P, Cuevas BD, Russo A, Johnson GL, and Trejo J (2008) Persistent transactivation of EGFR and ErbB2/HER2 by protease-activated receptor-1 promotes breast carcinoma cell invasion. Oncogene 27:4434-4445.

Athanasiou D, Aguila M, Bellingham J, Li W, McCulley C, Reeves PJ, and Cheetham ME (2018) The molecular and cellular basis of rhodopsin retinitis pigmentosa reveals potential strategies for therapy. Prog Retin Eye Res 62:1-23. 
Avagliano Trezza R, van den Burg J, van den Oever N, and Distel B (2017) A versatile plasmid system for reconstitution and analysis of mammalian ubiquitination cascades in yeast. Microb Cell 5:150-157.

Badawy SMM, Okada T, Kajimoto T, Ijuin T, and Nakamura SI (2017) DHHC5mediated palmitoylation of S1P receptor subtype 1 determines G-protein coupling. Sci Rep 7:16552.

Bannert N, Craig S, Farzan M, Sogah D, Santo NV, Choe H, and Sodroski J (2001) Sialylated O-glycans and sulfated tyrosines in the NH2-terminal domain of CC chemokine receptor 5 contribute to high affinity binding of chemokines. $J$ Exp Med 194:1661-1673.

Barnett-Norris J, Lynch D, and Reggio PH (2005) Lipids, lipid rafts and caveolae: their importance for GPCR signaling and their centrality to the endocannabinoid system. Life Sci 77:1625-1639.

Barriere H, Nemes C, Lechardeur D, Khan-Mohammad M, Fruh K, and Lukacs GL (2006) Molecular basis of oligoubiquitin-dependent internalization of membrane proteins in Mammalian cells. Traffic 7:282-297.

Benovic JL, Onorato JJ, Caron MG, and Lefkowitz RJ (1990) Regulation of G proteincoupled receptors by agonist-dependent phosphorylation. Soc Gen Physiol Ser 45 87-103.

Berger BS, Acebron SP, Herbst J, Koch S, and Niehrs C (2017) Parkinson's diseaseassociated receptor GPR37 is an ER chaperone for LRP6. EMBO Rep 18:712-725.

Berlin I, Higginbotham KM, Dise RS, Sierra MI, and Nash PD (2010) The deubiquitinating enzyme USP8 promotes trafficking and degradation of the chemokine receptor 4 at the sorting endosome. J Biol Chem 285:37895-37908.

Bernier V, Lagacé M, Bichet DG, and Bouvier M (2004) Pharmacological chaperones: potential treatment for conformational diseases. Trends Endocrinol Metab 15 $222-228$

Berthouze M, Venkataramanan V, Li Y, and Shenoy SK (2009) The deubiquitinases USP33 and USP20 coordinate beta2 adrenergic receptor recycling and resensitization $E M B O J \mathbf{2 8} \cdot 1684-1696$.

Bhandari D, Robia SL, and Marchese A (2009) The E3 ubiquitin ligase atrophin interacting protein 4 binds directly to the chemokine receptor CXCR4 via a novel WW domain-mediated interaction. Mol Biol Cell 20:1324-1339.

Blanc M, David F, Abrami L, Migliozzi D, Armand F, Bürgi J, and van der Goot FG (2015) SwissPalm: protein Palmitoylation database. F1000 Res 4:261.

Blanpain C, Wittamer V, Vanderwinden JM, Boom A, Renneboog B, Lee B, Le Poul E, El Asmar L, Govaerts C, Vassart G, et al. (2001) Palmitoylation of CCR5 is critical for receptor trafficking and efficient activation of intracellular signaling pathways. J Biol Chem 276:23795-23804.

Blaukat A, Pizard A, Breit A, Wernstedt C, Alhenc-Gelas F, Muller-Esterl W, and Dikic I (2001) Determination of bradykinin B2 receptor in vivo phosphorylation sites and their role in receptor function. $J$ Biol Chem 276:40431-40440.

Blom N, Gammeltoft S, and Brunak S (1999) Sequence and structure-based prediction of eukaryotic protein phosphorylation sites. J Mol Biol 294: 1351-1362.

Blom N, Sicheritz-Pontén T, Gupta R, Gammeltoft S, and Brunak S (2004) Prediction of post-translational glycosylation and phosphorylation of proteins from the amino acid sequence. Proteomics 4:1633-1649.

Booden MA, Eckert LB, Der CJ, and Trejo J (2004) Persistent signaling by dysregulated thrombin receptor trafficking promotes breast carcinoma cell invasion. $M o$ Cell Biol 24:1990-1999.

Bouwmeester T, Bauch A, Ruffner H, Angrand PO, Bergamini G, Croughton K, Cruciat C, Eberhard D, Gagneur J, Ghidelli S, et al. (2004) A physical and functional map of the human TNF-alpha/NF-kappa B signal transduction pathway. Nat Cell Biol 6:97-105.

Bowitch A, Michaels KL, Yu MC, and Ferkey DM (2018) The protein arginine methyltransferase PRMT-5 regulates SER-2 tyramine receptor-mediated behaviors in Caenorhabditis elegans. G3 (Bethesda) 8:2389-2398.

Broncel M, Serwa RA, Ciepla P, Krause E, Dallman MJ, Magee AI, and Tate EW (2015) Multifunctional reagents for quantitative proteome-wide analysis of protein modification in human cells and dynamic profiling of protein lipidation during vertebrate development. Angew Chem Int Ed Engl 54:5948-5951.

Busillo JM, Armando S, Sengupta R, Meucci O, Bouvier M, and Benovic JL (2010) Site-specific phosphorylation of CXCR4 is dynamically regulated by multiple kinases and results in differential modulation of CXCR4 signaling. J Biol Chem 285:7805-7817.

Butcher AJ, Prihandoko R, Kong KC, McWilliams P, Edwards JM, Bottrill A, Mistry $\mathrm{S}$, and Tobin AB (2011) Differential G-protein-coupled receptor phosphorylation provides evidence for a signaling bar code. J Biol Chem 286:11506-11518.

Caballero A and Marchese A (2011) Ubiquitination of GPCRs. Methods Mol Biol 746: 251-259.

Cahill TJ III, Thomsen AR, Tarrasch JT, Plouffe B, Nguyen AH, Yang F, Huang LY, Kahsai AW, Bassoni DL, Gavino BJ, et al. (2017) Distinct conformations of GPCR$\beta$-arrestin complexes mediate desensitization, signaling, and endocytosis. Proc Natl Acad Sci USA 114:2562-2567.

Canals M, Scholten DJ, de Munnik S, Han MK, Smit MJ, and Leurs R (2012) Ubiquitination of CXCR7 controls receptor trafficking. PLoS One 7:e34192.

Canto I and Trejo J (2013) Palmitoylation of protease-activated receptor-1 regulates adaptor protein complex-2 and -3 interaction with tyrosine-based motifs and endocytic sorting. J Biol Chem 288:15900-15912.

Chau V, Tobias JW, Bachmair A, Marriott D, Ecker DJ, Gonda DK, and Varshavsky A (1989) A multiubiquitin chain is confined to specific lysine in a targeted shortlived protein. Science 243:1576-1583.

Chen B, Dores MR, Grimsey N, Canto I, Barker BL, and Trejo J (2011) Adaptor protein complex-2 (AP-2) and epsin-1 mediate protease-activated receptor-1 internalization via phosphorylation- and ubiquitination-dependent sorting signals. $J$ Biol Chem 286:40760-40770.

Chen S, Han C, Miao X, Li X, Yin C, Zou J, Liu M, Li S, Stawski L, Zhu B, et al. (2019) Targeting MC1R depalmitoylation to prevent melanomagenesis in redheads. Nat Commun 10:877.
Chen S, Zhu B, Yin C, Liu W, Han C, Chen B, Liu T, Li X, Chen X, Li C, et al. (2017a) Palmitoylation-dependent activation of MC1R prevents melanomagenesis. Nature 549:399-403.

Chen Z, Jiang H, Xu W, Li X, Dempsey DR, Zhang X, Devreotes P, Wolberger C, Amzel LM, Gabelli SB, et al. (2017b) A tunable brake for HECT ubiquitin ligases. Mol Cell 66:345-357.e6.

Chen Z, Zhou Y, Zhang Z, and Song J (2015) Towards more accurate prediction of ubiquitination sites: a comprehensive review of current methods, tools and features. Brief Bioinform 16:640-657.

Cherezov V, Rosenbaum DM, Hanson MA, Rasmussen SG, Thian FS, Kobilka TS, Choi HJ, Kuhn P, Weis WI, Kobilka BK, et al. (2007) High-resolution crysta structure of an engineered human beta2-adrenergic $\mathrm{G}$ protein-coupled receptor. Science 318:1258-1265.

Cho E and Park M (2016) Palmitoylation in Alzheimer's disease and other neurodegenerative diseases. Pharmacol Res 111:133-151.

Choi JH, Park J-Y, Park SP, Lee H, Han S, Park KH, and Suh YH (2016) Regulation of mGluR7 trafficking by SUMOylation in neurons. Neuropharmacology 102 : $229-235$

Clague MJ, Urbé S, and Komander D (2019) Breaking the chains: deubiquitylating enzyme specificity begets function. Nat Rev Mol Cell Biol 20:338-352.

Collins MO, Woodley KT, and Choudhary JS (2017) Global, site-specific analysis of neuronal protein S-acylation. Sci Rep 7:4683.

Colvin RA, Campanella GS, Manice LA, and Luster AD (2006) CXCR3 requires tyrosine sulfation for ligand binding and a second extracellular loop arginine residue for ligand-induced chemotaxis. Mol Cell Biol 26:5838-5849.

Compton SJ, Sandhu S, Wijesuriya SJ, and Hollenberg MD (2002) Glycosylation of human proteinase-activated receptor-2 (hPAR2): role in cell surface expression and signalling. Biochem $J$ 368:495-505.

Conn PM, Ulloa-Aguirre A, Ito J, and Janovick JA (2007) G protein-coupled receptor trafficking in health and disease: lessons learned to prepare for therapeutic mutant rescue in vivo. Pharmacol Rev 59:225-250.

Cook LB, Zhu CC, and Hinkle PM (2003) Thyrotropin-releasing hormone receptor processing: role of ubiquitination and proteasomal degradation. Mol Endocrinol 17: $1777-1791$

Cottrell GS, Padilla B, Pikios S, Roosterman D, Steinhoff M, Grady EF, and Bunnett NW (2007) Post-endocytic sorting of calcitonin receptor-like receptor and receptor activity-modifying protein 1. J Biol Chem 282:12260-12271.

Coyne ES and Wing SS (2016) The business of deubiquitination - location, location, location. F1000 Res 5:163.

Daaka Y, Luttrell LM, and Lefkowitz RJ (1997) Switching of the coupling of the beta2adrenergic receptor to different $\mathrm{G}$ proteins by protein kinase A. Nature 390:88-91.

Danielsen JMR, Sylvestersen KB, Bekker-Jensen S, Szklarczyk D, Poulsen JW, Horn H, Jensen LJ, Mailand N, and Nielsen ML (2011) Mass spectrometric analysis of lysine ubiquitylation reveals promiscuity at site level. Mol Cell Proteomics 10: M110.003590.

Davda D, El Azzouny MA, Tom CT, Hernandez JL, Majmudar JD, Kennedy RT, and Martin BR (2013) Profiling targets of the irreversible palmitoylation inhibitor 2-bromopalmitate. ACS Chem Biol 8:1912-1917.

Davidson JS, Flanagan CA, Zhou W, Becker II, Elario R, Emeran W, Sealfon SC, and Millar RP (1995) Identification of N-glycosylation sites in the gonadotropinreleasing hormone receptor: role in receptor expression but not ligand binding. $\mathrm{Mol}$ Cell Endocrinol 107:241-245.

De I and Sadhukhan S (2018) Emerging roles of DHHC-mediated protein S-palmitoylation in physiological and pathophysiological context. Eur J Cell Biol 97:319-338.

DeNicola GF, Martin ED, Chaikuad A, Bassi R, Clark J, Martino L, Verma S, Sicard P, Tata R, Atkinson RA, et al. (2013) Mechanism and consequence of the autoac tivation of $\mathrm{p} 38 \alpha$ mitogen-activated protein kinase promoted by TAB1. Nat Struct Mol Biol 20:1182-1190.

Deslauriers B, Ponce C, Lombard C, Larguier R, Bonnafous JC, and Marie J (1999) $\mathrm{N}$-glycosylation requirements for the AT1a angiotensin II receptor delivery to the plasma membrane. Biochem $J$ 339:397-405.

DeWire SM, Ahn S, Lefkowitz RJ, and Shenoy SK (2007) Beta-arrestins and cell signaling. Annu Rev Physiol 69:483-510.

Doi T, Sugimoto H, Arimoto I, Hiroaki Y, and Fujiyoshi Y (1999) Interactions of endothelin receptor subtypes $\mathrm{A}$ and $\mathrm{B}$ with $\mathrm{Gi}$, Go, and $\mathrm{Gq}$ in reconstituted phospholipid vesicles. Biochemistry 38:3090-3099.

Dores MR, Chen B, Lin H, Soh UJ, Paing MM, Montagne WA, Meerloo T, and Trejo J (2012a) ALIX binds a YPX(3)L motif of the GPCR PAR1 and mediates ubiquitinindependent ESCRT-III/MVB sorting. J Cell Biol 197:407-419.

Dores MR, Grimsey NJ, Mendez F, and Trejo J (2016) ALIX regulates the ubiquitinindependent lysosomal sorting of the P2Y1 purinergic receptor via a YPX3L motif. PLoS One 11:e157587.

Dores MR, Lin H, J Grimsey N, Mendez F, and Trejo J (2015) The $\alpha$-arrestin ARRDC3 mediates ALIX ubiquitination and G protein-coupled receptor lysosomal sorting. Mol Biol Cell 26:4660-4673.

Dores MR, Paing MM, Lin H, Montagne WA, Marchese A, and Trejo J (2012b) AP-3 regulates PAR1 ubiquitin-independent MVB/lysosomal sorting via an ALIXmediated pathway. Mol Biol Cell 23:3612-3623.

Dores MR and Trejo J (2012) Ubiquitination of G protein-coupled receptors: functional implications and drug discovery. Mol Pharmacol 82:563-570.

Dove KK and Klevit RE (2017) RING-Between-RING E3 ligases: emerging themes amid the variations. J Mol Biol 429:3363-3375.

Drisdel RC and Green WN (2004) Labeling and quantifying sites of protein palmitoylation. Biotechniques 36:276-285.

Dunn R and Hicke L (2001) Multiple roles for Rsp5p-dependent ubiquitination at the internalization step of endocytosis. J Biol Chem 276:25974-25981.

Ebersole B, Petko J, and Levenson R (2014) Bioorthogonal click chemistry to assay mu-opioid receptor palmitoylation using 15-hexadecynoic acid and immunoprecipitation. Anal Biochem 451:25-27. 
Ebersole B, Petko J, Woll M, Murakami S, Sokolina K, Wong V, Stagljar I, Lüscher B, and Levenson R (2015) Effect of C-terminal S-palmitoylation on D2 dopamine receptor rafficking and Stability. PLoS One 10:e0140661.

El Ayadi A, Prasai A, Wang Y, Herndon DN, and Finnerty CC (2018) $\beta$-Adrenergic receptor trafficking, degradation, and cell surface expression are altered in dermal fibroblasts from hypertrophic scars. J Invest Dermatol 138:1645-1655.

Flotho A and Melchior F (2013) Sumoylation: a regulatory protein modification in health and disease. Annu Rev Biochem 82:357-385.

Freire-de-Lima L, Fonseca LM, Oeltmann T, Mendonça-Previato L, and Previato JO (2015) The trans-sialidase, the major Trypanosoma cruzi virulence factor: three decades of studies. Glycobiology 25:1142-1149.

Fukata Y, Iwanaga T, and Fukata M (2006) Systematic screening for palmitoyl transferase activity of the DHHC protein family in mammalian cells. Methods 40: 177-182.

Fukushima Y, Oka Y, Saitoh T, Katagiri H, Asano T, Matsuhashi N, Takata K, van Breda E, Yazaki Y, and Sugano K (1995) Structural and functional analysis of the canine histamine $\mathrm{H} 2$ receptor by site-directed mutagenesis: $\mathrm{N}$-glycosylation is not vital for its action. Biochem $J$ 310:553-558.

Fukushima Y, Saitoh T, Anai M, Ogihara T, Inukai K, Funaki M, Sakoda H, Onishi Y, Ono H, Fujishiro M, et al. (2001) Palmitoylation of the canine histamine H2 receptor occurs at $\mathrm{Cys}(305)$ and is important for cell surface targeting. Biochim Biophys Acta 1539:181-191.

Gaidarov I and Keen JH (1999) Phosphoinositide-AP-2 interactions required for targeting to plasma membrane clathrin-coated pits. J Cell Biol 146:755-764.

Gao Z, Ni Y, Szabo G, and Linden J (1999) Palmitoylation of the recombinant human A1 adenosine receptor: enhanced proteolysis of palmitoylation-deficient mutant receptors. Biochem J 342:387-395.

Ge B, Gram H, Di Padova F, Huang B, New L, Ulevitch RJ, Luo Y, and Han J (2002) MAPKK-independent activation of p38alpha mediated by TAB1-dependent autophosphorylation of p38alpha. Science 295:1291-1294.

Geiss-Friedlander R and Melchior F (2007) Concepts in sumoylation: a decade on. Nat Rev Mol Cell Biol 8:947-956.

Giordano F, Simoes S, and Raposo G (2011) The ocular albinism type 1 (OA1) GPCR is ubiquitinated and its traffic requires endosomal sorting complex responsible for transport (ESCRT) function. Proc Natl Acad Sci USA 108:11906-11911.

Gnad F, Gunawardena J, and Mann M (2011) PHOSIDA 2011: the posttranslational modification database. Nucleic Acids Res 39:D253-D260.

Goldsmith ZG and Dhanasekaran DN (2007) G protein regulation of MAPK networks. Oncogene 26:3122-3142.

Gonzalez de Valdivia E, Sanden C, Kahn R, Olde B, and Leeb-Lundberg LMF (2019) Human G protein-coupled receptor 30 is N-glycosylated and N-terminal domain asparagine 44 is required for receptor structure and activity. Biosci Rep 39: BSR20182436

Goodman OB Jr, Krupnick JG, Santini F, Gurevich VV, Penn RB, Gagnon AW, Keen JH, and Benovic JL (1996) Beta-arrestin acts as a clathrin adaptor in endocytosis of the beta2-adrenergic receptor. Nature 383:447-450.

Gorinski N, Bijata M, Prasad S, Wirth A, Abdel Galil D, Zeug A, Bazovkina D, Kondaurova E, Kulikova E, Ilchibaeva T, et al. (2019) Attenuated palmitoylation of serotonin receptor 5-HT1A affects receptor function and contributes to depressionlike behaviors. Nat Commun 10:3924.

Goth CK, Petäjä-Repo UE, and Rosenkilde MM (2020) G protein-coupled receptors in the sweet spot: glycosylation and other Post-translational Modifications. ACS Pharmacol Transl Sci 3:237-245.

Goth CK, Tuhkanen HE, Khan H, Lackman JJ, Wang S, Narimatsu Y, Hansen LH, Overall CM, Clausen H, Schjoldager KT, et al. (2017) Site-specific $O$-glycosylation by polypeptide $N$-acetylgalactosaminyltransferase 2 (GalNAc-transferase T2) Coregulates $\beta_{1}$-adrenergic receptor N-terminal cleavage. J Biol Chem 292:4714-4726.

Goth CK, Vakhrushev SY, Joshi HJ, Clausen H, and Schjoldager KT (2018) Finetuning limited proteolysis: a major role for regulated site-specific O-glycosylation. Trends Biochem Sci 43:269-284.

Granier S, Manglik A, Kruse AC, Kobilka TS, Thian FS, Weis WI, and Kobilka BK (2012) Structure of the $\delta$-opioid receptor bound to naltrindole. Nature 485 : 400-404.

Grimsey NJ, Aguilar B, Smith TH, Le P, Soohoo AL, Puthenveedu MA, Nizet V, and Trejo J (2015) Ubiquitin plays an atypical role in GPCR-induced p38 MAP kinase activation on endosomes. $J$ Cell Biol 210:1117-1131.

Grimsey NJ, Lin Y, Narala R, Rada CC, Mejia-Pena H, and Trejo J (2019) G proteincoupled receptors activate p38 MAPK via a non-canonical TAB1-TAB2- and TAB1TAB3-dependent pathway in endothelial cells. J Biol Chem 294:5867-5878.

Grimsey NJ, Narala R, Rada CC, Mehta S, Stephens BS, Kufareva I, Lapek J, Gonzalez DJ, Handel TM, Zhang J, et al. (2018) A tyrosine switch on NEDD4-2 E3 ligase transmits GPCR inflammatory signaling. Cell Rep 24:3312-3323.e5.

Groer CE, Schmid CL, Jaeger AM, and Bohn LM (2011) Agonist-directed interactions with specific beta-arrestins determine mu-opioid receptor trafficking, ubiquitination, and dephosphorylation. $J$ Biol Chem 286:31731-31741.

Grou CP, Pinto MP, Mendes AV, Domingues P, and Azevedo JE (2015) The de novo synthesis of ubiquitin: identification of deubiquitinases acting on ubiquitin precursors. Sci Rep 5:12836.

Gulia R, Sharma R, and Bhattacharyya S (2017) A critical role for ubiquitination in the endocytosis of glutamate receptors. J Biol Chem 292:1426-1437.

Gullapalli A, Wolfe BL, Griffin CT, Magnuson T, and Trejo J (2006) An essential role for SNX1 in lysosomal sorting of protease-activated receptor-1: evidence for retromer-, Hrs-, and Tsg101-independent functions of sorting nexins. Mol Biol Cell 17: $1228-1238$.

Guo S, Zhang X, Zheng M, Zhang X, Min C, Wang Z, Cheon SH, Oak MH, Nah SY, and Kim KM (2015) Selectivity of commonly used inhibitors of clathrin-mediated and caveolae-dependent endocytosis of G protein-coupled receptors. Biochim Biophys Acta 1848:2101-2110.

Gurevich VV and Gurevich EV (2006) The structural basis of arrestin-mediated regulation of G-protein-coupled receptors. Pharmacol Ther 110:465-502.
Gurevich VV and Gurevich EV (2019) GPCR signaling regulation: the role of GRKs and arrestins. Front Pharmacol 10:125.

Hamilton JR and Trejo J (2017) Challenges and opportunities in protease-activated receptor drug development. Annu Rev Pharmacol Toxicol 57:349-373.

Han SO, Kommaddi RP, and Shenoy SK (2013) Distinct roles for $\beta$-arrestin2 and arrestin-domain-containing proteins in $\beta 2$ adrenergic receptor trafficking. EMBO Rep 14:164-171.

Han SO, Xiao K, Kim J, Wu JH, Wisler JW, Nakamura N, Freedman NJ, and Shenoy SK (2012) MARCH2 promotes endocytosis and lysosomal sorting of carvedilolbound $\beta(2)$-adrenergic receptors. J Cell Biol 199:817-830.

Hannoush RN and Sun J (2010) The chemical toolbox for monitoring protein fatty acylation and prenylation. Nat Chem Biol 6:498-506.

Hanyaloglu AC, McCullagh E, and von Zastrow M (2005) Essential role of Hrs in a recycling mechanism mediating functional resensitization of cell signaling. EMBO J 24:2265-2283.

Hasdemir B, Bunnett NW, and Cottrell GS (2007) Hepatocyte growth factorregulated tyrosine kinase substrate (HRS) mediates post-endocytic trafficking of protease-activated receptor 2 and calcitonin receptor-like receptor. J Biol Chem 282:29646-29657.

Hasdemir B, Murphy JE, Cottrell GS, and Bunnett NW (2009) Endosomal deubiquitinating enzymes control ubiquitination and down-regulation of proteaseactivated receptor 2. J Biol Chem 284:28453-28466.

Hauser AS, Attwood MM, Rask-Andersen M, Schiöth HB, and Gloriam DE (2017) Trends in GPCR drug discovery: new agents, targets and indications. Nat Rev Drug Discov 16:829-842.

Hauser AS, Chavali S, Masuho I, Jahn LJ, Martemyanov KA, Gloriam DE, and Babu MM (2018) Pharmacogenomics of GPCR drug targets. Cell 172:41-54.e19.

Hauser MA, Kindinger I, Laufer JM, Späte AK, Bucher D, Vanes SL, Krueger WA Wittmann V, and Legler DF (2016) Distinct CCR7 glycosylation pattern shapes receptor signaling and endocytosis to modulate chemotactic responses. J Leukoc Biol 99:993-1007.

Hawtin SR, Tobin AB, Patel S, and Wheatley M (2001) Palmitoylation of the vasopressin $\mathrm{V} 1 \mathrm{a}$ receptor reveals different conformational requirements for signaling, agonist-induced receptor phosphorylation, and sequestration. J Biol Chem 276: 38139-38146.

He J, Xu J, Castleberry AM, Lau AG, and Hall RA (2002) Glycosylation of beta(1)adrenergic receptors regulates receptor surface expression and dimerization. Biochem Biophys Res Commun 297:565-572.

Helbig AO, Heck AJ, and Slijper M (2010) Exploring the membrane proteomechallenges and analytical strategies. J Proteomics 73:868-878.

Henry AG, White IJ, Marsh M, von Zastrow M, and Hislop JN (2011) The role of ubiquitination in lysosomal trafficking of $\delta$-opioid receptors. Traffic 12:170-184.

Hershko A and Ciechanover A (1998) The ubiquitin system. Annu Rev Biochem 67: $425-479$.

Hicke L and Riezman H (1996) Ubiquitination of a yeast plasma membrane receptor signals its ligand-stimulated endocytosis. Cell 84:277-287.

Hicke L, Zanolari B, and Riezman H (1998) Cytoplasmic tail phosphorylation of the alpha-factor receptor is required for its ubiquitination and internalization. $J$ Cell Biol 141:349-358.

Hislop JN, Henry AG, and von Zastrow M (2011) Ubiquitination in the first cytoplasmic loop of $\mu$-opioid receptors reveals a hierarchical mechanism of lysosoma down-regulation. $J$ Biol Chem 286:40193-40204.

Hislop JN, Marley A, and Von Zastrow M (2004) Role of mammalian vacuolar protein-sorting proteins in endocytic trafficking of a non-ubiquitinated G proteincoupled receptor to lysosomes. J Biol Chem 279:22522-22531.

Hornbeck PV, Zhang B, Murray B, Kornhauser JM, Latham V, and Skrzypek E (2015) PhosphoSitePlus, 2014: mutations, PTMs and recalibrations. Nucleic Acids Res 43:D512-D520.

Huang Y, Niwa J, Sobue G, and Breitwieser GE (2006) Calcium-sensing receptor ubiquitination and degradation mediated by the E3 ubiquitin ligase dorfin. $J$ Biol Chem 281:11610-11617.

Hukovic N, Panetta R, Kumar U, Rocheville M, and Patel YC (1998) The cytoplasmic tail of the human somatostatin receptor type 5 is crucial for interaction with adenylyl cyclase and in mediating desensitization and internalization. $J$ Biol Chem 273:21416-21422.

Imai Y, Soda M, Inoue H, Hattori N, Mizuno Y, and Takahashi R (2001) An unfolded putative transmembrane polypeptide, which can lead to endoplasmic reticulum stress, is a substrate of Parkin. Cell 105:891-902.

Jacob C, Cottrell GS, Gehringer D, Schmidlin F, Grady EF, and Bunnett NW (2005) c-Cbl mediates ubiquitination, degradation, and down-regulation of human protease-activated receptor 2. J Biol Chem 280:16076-16087.

Jadhav T and Wooten MW (2009) Defining an embedded code for protein ubiquitination. J Proteomics Bioinform 2:316.

Jaffrey SR, Erdjument-Bromage H, Ferris CD, Tempst P, and Snyder SH (2001) Protein S-nitrosylation: a physiological signal for neuronal nitric oxide. Nat Cell Biol 3:193-197.

Janezic EM, Lauer SM, Williams RG, Chungyoun M, Lee KS, Navaluna E, Lau HT, Ong SE, and Hague C (2020) N-glycosylation of alpha1D-adrenergic receptor $\mathrm{N}$-terminal domain is required for correct trafficking, function, and biogenesis. $\mathrm{Sci}$ Rep 10:7209.

Jean-Charles PY, Snyder JC, and Shenoy SK (2016) Chapter one - ubiquitination and deubiquitination of G protein-coupled receptors. Prog Mol Biol Transl Sci 141 $1-55$

Karnik SS, Ridge KD, Bhattacharya S, and Khorana HG (1993) Palmitoylation of bovine opsin and its cysteine mutants in COS cells. Proc Natl Acad Sci USA 90: 40-44.

Karpa KD, Lidow MS, Pickering MT, Levenson R, and Bergson C (1999) N-linked glycosylation is required for plasma membrane localization of D5, but not D1, dopamine receptors in transfected mammalian cells. Mol Pharmacol 56: 1071-1078. 
Katzmann DJ, Babst M, and Emr SD (2001) Ubiquitin-dependent sorting into the multivesicular body pathway requires the function of a conserved endosomal protein sorting complex, ESCRT-I. Cell 106:145-155.

Kaushal S, Ridge KD, and Khorana HG (1994) Structure and function in rhodopsin: the role of asparagine-linked glycosylation. Proc Natl Acad Sci USA 91:4024-4028.

Kenakin T and Christopoulos A (2013) Signalling bias in new drug discovery: detection, quantification and therapeutic impact. Nat Rev Drug Discov 12:205-216.

Kiermaier E, Moussion C, Veldkamp CT, Gerardy-Schahn R, de Vries I, Williams LG, Chaffee GR, Phillips AJ, Freiberger F, Imre R, et al. (2016) Polysialylation controls dendritic cell trafficking by regulating chemokine recognition. Science 351:186-190.

King SL, Joshi HJ, Schjoldager KT, Halim A, Madsen TD, Dziegiel MH, Woetmann A, Vakhrushev SY, and Wandall HH (2017) Characterizing the $O$-glycosylation landscape of human plasma, platelets, and endothelial cells. Blood Adv 1:429-442.

Kliewer A, Reinscheid RK, and Schulz S (2017) Emerging paradigms of G proteincoupled receptor dephosphorylation. Trends Pharmacol Sci 38:621-636.

Kobe F, Renner U, Woehler A, Wlodarczyk J, Papusheva E, Bao G, Zeug A, Richter DW, Neher E, and Ponimaskin E (2008) Stimulation- and palmitoylationdependent changes in oligomeric conformation of serotonin 5-HT1A receptors. Biochim Biophys Acta 1783:1503-1516.

Kohno T, Wada A, and Igarashi Y (2002) N-glycans of sphingosine 1-phosphate receptor Edg-1 regulate ligand-induced receptor internalization. FASEB $J \mathbf{1 6}$ : 983-992

Komander D, Clague MJ, and Urbé S (2009) Breaking the chains: structure and function of the deubiquitinases. Nat Rev Mol Cell Biol 10:550-563.

Komander D and Rape M (2012) The ubiquitin code. Annu Rev Biochem 81:203-229.

Kong MM, Verma V, O'Dowd BF, and George SR (2011) The role of palmitoylation in directing dopamine $\mathrm{D} 1$ receptor internalization through selective endocytic routes. Biochem Biophys Res Commun 405:445-449.

Korycka J, Łach A, Heger E, Bogusławska DM, Wolny M, Toporkiewicz M, Augoff K, Korzeniewski J, and Sikorski AF (2012) Human DHHC proteins: a spotlight on the hidden player of palmitoylation. Eur J Cell Biol 91:107-117.

Kouhen OM, Wang G, Solberg J, Erickson LJ, Law PY, and Loh HH (2000) Hierarchical phosphorylation of delta-opioid receptor regulates agonist-induced receptor desensitization and internalization. J Biol Chem 275:36659-36664

Kozielewicz P, Alomar H, Yusof S, Grafton G, Cooper AJ, Curnow SJ, Ironside JW, Pall H, and Barnes NM (2017) $N$-glycosylation and expression in human tissues of the orphan GPR61 receptor. FEBS Open Bio 7:1982-1993.

Kraft K, Olbrich H, Majoul I, Mack M, Proudfoot A, and Oppermann M (2001) Characterization of sequence determinants within the carboxyl-terminal domain of chemokine receptor CCR5 that regulate signaling and receptor internalization. $J$ Biol Chem 276:34408-34418.

Krueger KM, Daaka Y, Pitcher JA, and Lefkowitz RJ (1997) The role of sequestration in $\mathrm{G}$ protein-coupled receptor resensitization. Regulation of beta2-adrenergic receptor dephosphorylation by vesicular acidification. J Biol Chem 272:5-8.

Kulathu Y, Akutsu M, Bremm A, Hofmann K, and Komander D (2009) Two-sided ubiquitin binding explains specificity of the TAB2 NZF domain. Nat Struct Mol Biol 16:1328-1330.

Kumari B, Kumar R, and Kumar M (2014) PalmPred: an SVM based palmitoylation prediction method using sequence profile information. PLoS One 9:e89246.

Lackman JJ, Goth CK, Halim A, Vakhrushev SY, Clausen H, and Petäjä-Repo UE (2018) Site-specific O-glycosylation of N-terminal serine residues by polypeptide GalNAc-transferase 2 modulates human $\delta$-opioid receptor turnover at the plasma membrane. Cell Signal 42:184-193.

Lahaie N, Kralikova M, Prézeau L, Blahos J, and Bouvier M (2016) Post-endocytotic deubiquitination and degradation of the metabotropic $\gamma$-aminobutyric acid receptor by the ubiquitin-specific protease 14. J Biol Chem 291:7156-7170.

Lanctot PM, Leclerc PC, Clément M, Auger-Messier M, Escher E, Leduc R, and Guillemette G (2005) Importance of N-glycosylation positioning for cell-surface expression, targeting, affinity and quality control of the human AT1 receptor Biochem J 390:367-376.

Lanctôt PM, Leclerc PC, Escher E, Leduc R, and Guillemette G (1999) Role of $\mathrm{N}$-glycosylation in the expression and functional properties of human AT1 receptor. Biochemistry 38:8621-8627.

Langenhan T, Piao X, and Monk KR (2016) Adhesion G protein-coupled receptors in nervous system development and disease. Nat Rev Neurosci 17:550-561.

Laporte SA, Oakley RH, Zhang J, Holt JA, Ferguson SSG, Caron MG, and Barak LS (1999) The $\beta 2$-adrenergic receptor/betaarrestin complex recruits the clathrin adaptor AP-2 during endocytosis. Proc Natl Acad Sci USA 96:3712-3717.

Lazarou M, Jin SM, Kane LA, and Youle RJ (2012) Role of PINK1 binding to the TOM complex and alternate intracellular membranes in recruitment and activation of the E3 ligase Parkin. Dev Cell 22:320-333.

Leclair HM, Dubois SM, Azzi S, Dwyer J, Bidère N, and Gavard J (2014) Control of CXCR2 activity through its ubiquitination on K327 residue. BMC Cell Biol 15:38.

Leclerc PC, Lanctot PM, Auger-Messier M, Escher E, Leduc R, and Guillemette G (2006) S-nitrosylation of cysteine 289 of the AT1 receptor decreases its binding affinity for angiotensin II. Br J Pharmacol 148:306-313.

Lee S, Park S, Lee H, Han S, Song JM, Han D, and Suh YH (2019) Nedd4 E3 ligase and beta-arrestins regulate ubiquitination, trafficking, and stability of the mGlu7 receptor. eLife 8:e44502.

Leznicki P and Kulathu Y (2017) Mechanisms of regulation and diversification of deubiquitylating enzyme function. J Cell Sci 130:1997-2006.

Li Q and Muma NA (2013) Estradiol potentiates 8-OH-DPAT-induced sumoylation of 5- $\mathrm{HT}_{1} \mathrm{~A}$ receptor: characterization and subcellular distribution of sumoylated 5$\mathrm{HT}_{1}$ A receptors. Psychoneuroendocrinology 38:2542-2553.

Li X, Zhou M, Huang W, and Yang H (2017) N-glycosylation of the $\beta_{2}$ adrenergic receptor regulates receptor function by modulating dimerization. FEBS J $\mathbf{2 8 4}$ 2004-2018.

Li YM, Pan Y, Wei Y, Cheng X, Zhou BP, Tan M, Zhou X, Xia W, Hortobagyi GN, Yu $\mathrm{D}$, et al. (2004) Upregulation of CXCR4 is essential for HER2-mediated tumor metastasis. Cancer Cell 6:459-469.
Liggett SB (2011) Phosphorylation barcoding as a mechanism of directing GPCR signaling. Sci Signal 4:pe36.

Likhite N, Jackson CA, Liang MS, Krzyzanowski MC, Lei P, Wood JF, Birkaya B, Michaels KL, Andreadis ST, Clark SD, et al. (2015) The protein arginine methyltransferase PRMT5 promotes D2-like dopamine receptor signaling. Sci Signal 8:ra115

Linder ME and Deschenes RJ (2003) New insights into the mechanisms of protein palmitoylation. Biochemistry 42:4311-4320.

Linder ME and Deschenes RJ (2007) Palmitoylation: policing protein stability and traffic. Nat Rev Mol Cell Biol 8:74-84.

Liu J, Louie S, Hsu W, Yu KM, Nicholas HB Jr, and Rosenquist GL (2008) Tyrosine sulfation is prevalent in human chemokine receptors important in lung disease. Am J Respir Cell Mol Biol 38:738-743.

Lobingier BT and von Zastrow M (2019) When trafficking and signaling mix: how subcellular location shapes $\mathrm{G}$ protein-coupled receptor activation of heterotrimeric G proteins. Traffic 20:130-136.

Lu PJ, Zhou XZ, Shen M, and Lu KP (1999) Function of WW domains as phosphoserine- or phosphothreonine-binding modules. Science 283:1325-1328.

Ludeman JP and Stone MJ (2014) The structural role of receptor tyrosine sulfation in chemokine recognition. Br J Pharmacol 171:1167-1179.

Luker KE and Luker GD (2006) Functions of CXCL12 and CXCR4 in breast cancer. Cancer Lett 238:30-41.

Luo J, Ashikaga E, Rubin PP, Heimann MJ, Hildick KL, Bishop P, Girach F, JosaPrado F, Tang LT, Carmichael RE, et al. (2013) Receptor trafficking and the regulation of synaptic plasticity by SUMO. Neuromolecular Med 15:692-706.

Luttrell LM, Wang J, Plouffe B, Smith JS, Yamani L, Kaur S, Jean-Charles PY, Gauthier C, Lee MH, Pani B, et al. (2018) Manifold roles of $\beta$-arrestins in GPCR signaling elucidated with siRNA and CRISPR/Cas9. Sci Signal 11:eaat7650.

Malik R and Marchese A (2010) Arrestin-2 interacts with the endosomal sorting complex required for transport machinery to modulate endosomal sorting of CXCR4. Mol Biol Cell 21:2529-2541.

Malik R, Soh UJ, Trejo J, and Marchese A (2012) Novel roles for the E3 ubiquitin ligase atrophin-interacting protein 4 and signal transduction adaptor molecule 1 in G protein-coupled receptor signaling. J Biol Chem 287:9013-9027.

Mann M and Jensen ON (2003) Proteomic analysis of post-translational modifications. Nat Biotechnol 21:255-261.

Marada S, Navarro G, Truong A, Stewart DP, Arensdorf AM, Nachtergaele S, Angelats E, Opferman JT, Rohatgi R, McCormick PJ, et al. (2015) Functional divergence in the role of N-linked glycosylation in smoothened signaling. PLoS Genet 11:e1005473.

Marchese A and Benovic JL (2001) Agonist-promoted ubiquitination of the G proteincoupled receptor CXCR4 mediates lysosomal sorting. J Biol Chem 276: 45509-45512.

Marchese A, Raiborg C, Santini F, Keen JH, Stenmark H, and Benovic JL (2003) The E3 ubiquitin ligase AIP4 mediates ubiquitination and sorting of the G proteincoupled receptor CXCR4. Dev Cell 5:709-722.

Markkanen PM and Petäjä-Repo UE (2008) N-glycan-mediated quality control in the endoplasmic reticulum is required for the expression of correctly folded delta-opioid receptors at the cell surface. J Biol Chem 283:29086-29098.

Mayer D, Damberger FF, Samarasimhareddy M, Feldmueller M, Vuckovic Z, Flock T, Bauer B, Mutt E, Zosel F, Allain FHT, et al. (2019) Distinct G protein-coupled receptor phosphorylation motifs modulate arrestin affinity and activation and global conformation. Nat Commun 10:1261.

McClellan AJ, Laugesen SH, and Ellgaard L (2019) Cellular functions and molecular mechanisms of non-lysine ubiquitination. Open Biol 9:190147.

McDowell GS and Philpott A (2016) New insights into the role of ubiquitylation of proteins. Int Rev Cell Mol Biol 325:35-88.

Mevissen TET and Komander D (2017) Mechanisms of deubiquitinase specificity and regulation. Annu Rev Biochem 86:159-192.

Michineau S, Muller L, Pizard A, Alhenc-Gélas F, and Rajerison RM (2004) N-linked glycosylation of the human bradykinin B2 receptor is required for optimal cellsurface expression and coupling. Biol Chem 385:49-57.

Milcent MD, Christophe T, Rabiet MJ, Tardif M, and Boulay F (1999) Overexpression of wild-type and catalytically inactive forms of GRK2 and GRK6 fails to alter the agonist-induced phosphorylation of the C5a receptor (CD88): evidence that GRK6 is autophosphorylated in COS-7 cells. Biochem Biophys Res Commun 259:224-229.

Milić D and Veprintsev DB (2015) Large-scale production and protein engineering of $\mathrm{G}$ protein-coupled receptors for structural studies. Front Pharmacol 6:66.

Milligan G (2009) G protein-coupled receptor hetero-dimerization: contribution to pharmacology and function. Br J Pharmacol 158:5-14.

Milojevic T, Reiterer V, Stefan E, Korkhov VM, Dorostkar MM, Ducza E, Ogris E, Boehm S, Freissmuth M, and Nanoff C (2006) The ubiquitin-specific protease Usp4 regulates the cell surface level of the A2A receptor. Mol Pharmacol 69:1083-1094. Min C, Zheng M, Zhang X, Guo S, Kwon KJ, Shin CY, Kim HS, Cheon SH, and Kim $\mathrm{KM}$ (2015) N-linked Glycosylation on the N-terminus of the dopamine D2 and D3 receptors determines receptor association with specific microdomains in the plasma membrane. Biochim Biophys Acta 1853:41-51.

Mines MA, Goodwin JS, Limbird LE, Cui FF, and Fan GH (2009) Deubiquitination of CXCR4 by USP14 is critical for both CXCL12-induced CXCR4 degradation and chemotaxis but not ERK ativation. J Biol Chem 284:5742-5752.

Moffett S, Adam L, Bonin H, Loisel TP, Bouvier M, and Mouillac B (1996) Palmitoylated cysteine 341 modulates phosphorylation of the beta2-adrenergic receptor by the cAMP-dependent protein kinase. J Biol Chem 271:21490-21497.

Moffett S, Mouillac B, Bonin H, and Bouvier M (1993) Altered phosphorylation and desensitization patterns of a human beta 2-adrenergic receptor lacking the palmitoylated Cys341. EMBO J 12:349-356.

Moore CA, Milano SK, and Benovic JL (2007) Regulation of receptor trafficking by GRKs and arrestins. Annu Rev Physiol 69:451-482.

Morii $\mathrm{H}$ and Watanabe Y (1992) A possible role of carbohydrate moieties in prostaglandin D2 and prostaglandin E2 receptor proteins from the porcine temporal cortex. Arch Biochem Biophys 292:121-127. 
Moriyoshi K, Iijima K, Fujii H, Ito H, Cho Y, and Nakanishi S (2004) Seven in absentia homolog 1A mediates ubiquitination and degradation of group 1 metabotropic glutamate receptors. Proc Natl Acad Sci USA 101:8614-8619.

Mukai A, Yamamoto-Hino M, Awano W, Watanabe W, Komada M, and Goto S (2010) Balanced ubiquitylation and deubiquitylation of Frizzled regulate cellular responsiveness to Wg/Wnt. EMBO J 29:2114-2125.

Mukhopadhyay D and Riezman H (2007) Proteasome-independent functions of ubiquitin in endocytosis and signaling. Science 315:201-205.

Mulloy B, Dell A, Stanley P, and Prestegard JH (2015) Structural analysis of glycans, in Essentials of GlycobiologyVarki A, Cummings RD, Esko JD, Stanley P, Hart GW, Aebi M, Darvill AG, Kinoshita T, Packer NH, Prestegard JH, Schnaar RL, and Seeberger PH eds) pp 639-652, Cold Spring Harbor, New York.

Nagi K and Shenoy SK (2019) Detection of $\beta$-arrestin-mediated G protein-coupled receptor ubiquitination using BRET. Methods Mol Biol 1957:93-104.

Nakagawa M, Miyamoto T, Kusakabe R, Takasaki S, Takao T, Shichida Y, and Tsuda M (2001) O-glycosylation of G-protein-coupled receptor, octopus rhodopsin. Direct analysis by FAB mass spectrometry. FEBS Lett 496:19-24.

Nakagawa T, Takahashi C, Matsuzaki H, Takeyama S, Sato S, Sato A, Kuroda Y, and Higashi $\mathrm{H}$ (2017) N-glycan-dependent cell-surface expression of the $\mathrm{P} 2 \mathrm{Y}_{2}$ receptor and N-glycan-independent distribution to lipid rafts. Biochem Biophys Res Commun 485:427-431.

Nakamura M, Yasuda D, Hirota N, and Shimizu T (2010) Specific ligands as pharmacological chaperones: the transport of misfolded G-protein coupled receptors to the cell surface. IUBMB Life 62:453-459.

Naumenko VS and Ponimaskin E (2018) Palmitoylation as a functional regulator of neurotransmitter receptors. Neural Plast 2018:5701348.

Nehring RB, Richter D, and Meyerhof W (2000) Glycosylation affects agonist binding and signal transduction of the rat somatostatin receptor subtype 3. J Physiol Paris 94:185-192.

Nguyen AH, Thomsen ARB, Cahill TJ III, Huang R, Huang LY, Marcink T, Clarke OB, Heissel S, Masoudi A, Ben-Hail D, et al. (2019) Structure of an endosomal signaling GPCR-G protein- $\beta$-arrestin megacomplex. Nat Struct Mol Biol 26 $1123-1131$

Nobles KN, Xiao K, Ahn S, Shukla AK, Lam CM, Rajagopal S, Strachan RT, Huang TY, Bressler EA, Hara MR, et al. (2011) Distinct phosphorylation sites on the $\beta(2)$ adrenergic receptor establish a barcode that encodes differential functions of $\beta$-arrestin. Sci Signal 4:ra51.

Nozik-Grayck E, Whalen EJ, Stamler JS, McMahon TJ, Chitano P, and Piantadosi CA (2006) S-nitrosoglutathione inhibits alpha1-adrenergic receptor-mediated vasoconstriction and ligand binding in pulmonary artery. Am J Physiol Lung Cell Mol Physiol 290:L136-L143.

Obenauer JC, Cantley LC, and Yaffe MB (2003) Scansite 2.0: proteome-wide prediction of cell signaling interactions using short sequence motifs. Nucleic Acids Res 31:3635-3641.

O'Brien PJ and Zatz M (1984) Acylation of bovine rhodopsin by [3H]palmitic acid. J Biol Chem 259:5054-5057.

Oddi S, Dainese E, Sandiford S, Fezza F, Lanuti M, Chiurchiù V, Totaro A, Catanzaro G, Barcaroli D, De Laurenzi V, et al. (2012) Effects of palmitoylation of Cys(415) in helix 8 of the $\mathrm{CB}(1)$ cannabinoid receptor on membrane localization and signalling. Br J Pharmacol 165:2635-2651.

Oddi S, Stepniewski TM, Totaro A, Selent J, Scipioni L, Dufrusine B, Fezza F, Dainese $\mathrm{E}$, and Maccarrone M (2017) Palmitoylation of cysteine 415 of $\mathrm{CB}_{1}$ receptor affects ligand-stimulated internalization and selective interaction with membrane cholesterol and caveolin 1. Biochim Biophys Acta Mol Cell Biol Lipids 1862:523-532.

Oddi S, Totaro A, Scipioni L, Dufrusine B, Stepniewski TM, Selent J, Maccarrone M, and Dainese E (2018) Role of palmitoylation of cysteine 415 in functional coupling $\mathrm{CB}_{1}$ receptor to $\mathrm{G}_{\mathrm{i} 2}$ protein. Biotechnol Appl Biochem 65:16-20.

O'Dowd BF, Hnatowich M, Caron MG, Lefkowitz RJ, and Bouvier M (1989) Palmitoylation of the human beta 2-adrenergic receptor. Mutation of Cys341 in the carboxyl tail leads to an uncoupled nonpalmitoylated form of the receptor. J Biol Chem 264:7564-7569.

O'Hayre M, Eichel K, Avino S, Zhao X, Steffen DJ, Feng X, Kawakami K, Aoki J, Messer K, Sunahara R, et al. (2017) Genetic evidence that $\beta$-arrestins are dispensable for the initiation of $\beta_{2}$-adrenergic receptor signaling to ERK. Sci Signal 10:eaal3395.

Ohno Y, Kashio A, Ogata R, Ishitomi A, Yamazaki Y, and Kihara A (2012) Analysis of substrate specificity of human DHHC protein acyltransferases using a yeast expression system. Mol Biol Cell 23:4543-4551.

Ohno Y, Kihara A, Sano T, and Igarashi Y (2006) Intracellular localization and tissue-specific distribution of human and yeast DHHC cysteine-rich domaincontaining proteins. Biochim Biophys Acta 1761:474-483.

Olsen JV and Mann M (2013) Status of large-scale analysis of post-translational modifications by mass spectrometry. Mol Cell Proteomics 12:3444-3452.

Pagel O, Loroch S, Sickmann A, and Zahedi RP (2015) Current strategies and findings in clinically relevant post-translational modification-specific proteomics. $E x$ pert Rev Proteomics 12:235-253.

Paing MM, Johnston CA, Siderovski DP, and Trejo J (2006) Clathrin adaptor AP2 regulates thrombin receptor constitutive internalization and endothelial cell resensitization. Mol Cell Biol 26:3231-3242.

Paing MM, Stutts AB, Kohout TA, Lefkowitz RJ, and Trejo J (2002) beta -Arrestins regulate protease-activated receptor-1 desensitization but not internalization or Down-regulation. J Biol Chem 277:1292-1300.

Palczewski K, Kumasaka T, Hori T, Behnke CA, Motoshima H, Fox BA, Le Trong I, Teller DC, Okada T, Stenkamp RE, et al. (2000) Crystal structure of rhodopsin: a G protein-coupled receptor. Science 289:739-745.

Papoucheva E, Dumuis A, Sebben M, Richter DW, and Ponimaskin EG (2004) The 5-hydroxytryptamine(1A) receptor is stably palmitoylated, and acylation is critical for communication of receptor with Gi protein. J Biol Chem $\mathbf{2 7 9}$ 3280-3291.
Park M, Reddy GR, Wallukat G, Xiang YK, and Steinberg SF (2017) $\beta_{1}$-adrenergic receptor O-glycosylation regulates $\mathrm{N}$-terminal cleavage and signaling responses in cardiomyocytes. Sci Rep 7:7890.

Peeler JC, Schedin-Weiss S, Soula M, Kazmi MA, and Sakmar TP (2017) Isopeptide and ester bond ubiquitination both regulate degradation of the human dopamine receptor 4. J Biol Chem 292:21623-21630.

Peng J, Schwartz D, Elias JE, Thoreen CC, Cheng D, Marsischky G, Roelofs J, Finley D, and Gygi SP (2003) A proteomics approach to understanding protein ubiquitination. Nat Biotechnol 21:921-926.

Percher A, Ramakrishnan S, Thinon E, Yuan X, Yount JS, and Hang HC (2016) Mass-tag labeling reveals site-specific and endogenous levels of protein S-fatty acylation. Proc Natl Acad Sci USA 113:4302-4307.

Percherancier Y, Planchenault T, Valenzuela-Fernandez A, Virelizier JL, ArenzanaSeisdedos F, and Bachelerie F (2001) Palmitoylation-dependent control of degradation, life span, and membrane expression of the CCR5 receptor. J Biol Chem 276: 31936-31944.

Perroy J, Pontier S, Charest PG, Aubry M, and Bouvier M (2004) Real-time monitoring of ubiquitination in living cells by BRET. Nat Methods 1:203-208.

Persaud A, Alberts P, Mari S, Tong J, Murchie R, Maspero E, Safi F, Moran MF, Polo S, and Rotin D (2014) Tyrosine phosphorylation of NEDD4 activates its ubiquitin ligase activity. Sci Signal 7:ra95.

Petaja-Repo UE, Hogue M, Laperriere A, Bhalla S, Walker P, and Bouvier M (2001) Newly synthesized human delta opioid receptors retained in the endoplasmic reticulum are retrotranslocated to the cytosol, deglycosylated, ubiquitinated, and degraded by the proteasome. J Biol Chem 276:4416-4423.

Petaja-Repo UE, Hogue M, Laperriere A, Walker P, and Bouvier M (2000) Export from the endoplasmic reticulum represents the limiting step in the maturation and cell surface expression of the human delta opioid receptor. J Biol Chem 275: 13727-13736.

Petäjä-Repo UE, Hogue M, Leskelä TT, Markkanen PM, Tuusa JT, and Bouvier M (2006) Distinct subcellular localization for constitutive and agonist-modulated palmitoylation of the human delta opioid receptor. J Biol Chem 281:15780-15789.

Peterson YK and Luttrell LM (2017) The diverse roles of arrestin scaffolds in G protein-coupled receptor signaling. Pharmacol Rev 69:256-297.

Pitcher JA, Freedman NJ, and Lefkowitz RJ (1998) G protein-coupled receptor kinases. Annu Rev Biochem 67:653-692.

Pitcher JA, Payne ES, Csortos C, DePaoli-Roach AA, and Lefkowitz RJ (1995) The G-protein-coupled receptor phosphatase: a protein phosphatase type 2A with a distinct subcellular distribution and substrate specificity. Proc Natl Acad Sci USA 92:8343-8347.

Ponimaskin EG, Heine M, Joubert L, Sebben M, Bickmeyer U, Richter DW, and Dumuis A (2002) The 5-hydroxytryptamine(4a) receptor is palmitoylated at two different sites, and acylation is critically involved in regulation of receptor constitutive activity. J Biol Chem 277:2534-2546.

Ponimaskin EG, Schmidt MF, Heine M, Bickmeyer U, and Richter DW (2001) 5Hydroxytryptamine 4(a) receptor expressed in Sf9 cells is palmitoylated in an agonist-dependent manner. Biochem $J$ 353:627-634.

Prihandoko R, Bradley SJ, Tobin AB, and Butcher AJ (2015) Determination of GPCR phosphorylation status: establishing a phosphorylation barcode. Curr Protoc Pharmacol 69:2.13.11-12.13.26.

Qanbar R and Bouvier M (2003) Role of palmitoylation/depalmitoylation reactions in G-protein-coupled receptor function. Pharmacol Ther 97:1-33.

Raasi S and Pickart CM (2005) Ubiquitin chain synthesis. Methods Mol Biol 301 $47-55$

Radivojac P, Vacic V, Haynes C, Cocklin RR, Mohan A, Heyen JW, Goebl MG, and Iakoucheva LM (2010) Identification, analysis, and prediction of protein ubiquitination sites. Proteins 78:365-380.

Rahimi M, George J, and Tang C (2010) EGFR variant-mediated invasion by enhanced CXCR4 expression through transcriptional and post-translational mechanisms. Int $J$ Cancer 126:1850-1860.

Rands E, Candelore MR, Cheung AH, Hill WS, Strader CD, and Dixon RA (1990) Mutational analysis of beta-adrenergic receptor glycosylation. J Biol Chem 265: 10759-10764.

Reeves PJ, Callewaert N, Contreras R, and Khorana HG (2002) Structure and function in rhodopsin: high-level expression of rhodopsin with restricted and homogeneous $\mathrm{N}$-glycosylation by a tetracycline-inducible $\mathrm{N}$-acetylglucosaminyltransferase I-negative HEK293S stable mammalian cell line. Proc Natl Acad Sci USA 99: 13419-13424.

Reid HM and Kinsella BT (2007) Palmitoylation of the TPbeta isoform of the human thromboxane A2 receptor. Modulation of G protein: effector coupling and modes of receptor internalization. Cell Signal 19:1056-1070.

Reiter E and Lefkowitz RJ (2006) GRKs and beta-arrestins: roles in receptor silencing, trafficking and signaling. Trends Endocrinol Metab 17:159-165.

Reiter KH and Klevit RE (2018) Characterization of RING-between-RING E3 ubiquitin transfer mechanisms. Methods Mol Biol 1844:3-17.

Ren J, Wen L, Gao X, Jin C, Xue Y, and Yao X (2008) CSS-Palm 2.0: an updated software for palmitoylation sites prediction. Protein Eng Des Sel 21 639-644

Renner U, Glebov K, Lang T, Papusheva E, Balakrishnan S, Keller B, Richter DW, Jahn R, and Ponimaskin E (2007) Localization of the mouse 5-hydroxytryptamine(1A) receptor in lipid microdomains depends on its palmitoylation and is involved in receptor-mediated signaling. Mol Pharmacol 72:502-513.

Rinaldi L, Delle Donne R, Catalanotti B, Torres-Quesada O, Enzler F, Moraca F, Nisticò R, Chiuso F, Piccinin S, Bachmann V, et al. (2019) Feedback inhibition of cAMP effector signaling by a chaperone-assisted ubiquitin system. Nat Commun 10:2572

Robben JH, Kortenoeven ML, Sze M, Yae C, Milligan G, Oorschot VM, Klumperman J, Knoers NV, and Deen PM (2009) Intracellular activation of vasopressin V2 receptor mutants in nephrogenic diabetes insipidus by nonpeptide agonists. Proc Natl Acad Sci USA 106:12195-12200. 
Rohrer J, Bénédetti H, Zanolari B, and Riezman H (1993) Identification of a novel sequence mediating regulated endocytosis of the $G$ protein-coupled alphapheromone receptor in yeast. $\mathrm{Mol}$ Biol Cell 4:511-521.

Rondard P, Huang S, Monnier C, Tu H, Blanchard B, Oueslati N, Malhaire F, Li Y, Trinquet E, Labesse G, et al. (2008) Functioning of the dimeric GABA(B) receptor extracellular domain revealed by glycan wedge scanning. EMBO $J$ 27:1321-1332

Roth AF, Wan J, Bailey AO, Sun B, Kuchar JA, Green WN, Phinney BS, Yates JR III, and Davis NG (2006) Global analysis of protein palmitoylation in yeast. Cell 125: $1003-1013$

Rotin D and Kumar S (2009) Physiological functions of the HECT family of ubiquitin ligases. Nat Rev Mol Cell Biol 10:398-409.

Roy S, Perron B, and Gallo-Payet N (2010) Role of asparagine-linked glycosylation in cell surface expression and function of the human adrenocorticotropin receptor (melanocortin 2 receptor) in 293/FRT cells. Endocrinology 151:660-670.

Russo D, Chazenbalk GD, Nagayama Y, Wadsworth HL, and Rapoport B (1991) Sitedirected mutagenesis of the human thyrotropin receptor: role of asparagine-linked oligosaccharides in the expression of a functional receptor. Mol Endocrinol 5:29-33.

Sadeghi H and Birnbaumer M (1999) O-Glycosylation of the V2 vasopressin receptor. Glycobiology 9:731-737.

Sadeghi HM, Innamorati G, Dagarag M, and Birnbaumer M (1997) Palmitoylation of the V2 vasopressin receptor. Mol Pharmacol 52:21-29.

Salom D, Jin H, Gerken TA, Yu C, Huang L, and Palczewski K (2019) Human red and green cone opsins are $O$-glycosylated at an N-terminal Ser/Thr-rich domain conserved in vertebrates. $J$ Biol Chem 294:8123-8133.

Sanders SS and Hayden MR (2015) Aberrant palmitoylation in Huntington disease. Biochem Soc Trans 43:205-210.

Sato PY, Chuprun JK, Schwartz M, and Koch WJ (2015) The evolving impact of g protein-coupled receptor kinases in cardiac health and disease. Physiol Rev 95: 377-404.

Schaeuble K, Hauser MA, Rippl AV, Bruderer R, Otero C, Groettrup M, and Legler DF (2012) Ubiquitylation of the chemokine receptor CCR7 enables efficient receptor recycling and cell migration. J Cell Sci 125:4463-4474.

Schreiber RE, Prossnitz ER, Ye RD, Cochrane CG, and Bokoch GM (1994) Domains of the human neutrophil $\mathrm{N}$-formyl peptide receptor involved in $\mathrm{G}$ protein coupling. Mapping with receptor-derived peptides. J Biol Chem 269:326-331.

Schülein R, Liebenhoff U, Müller H, Birnbaumer M, and Rosenthal W (1996) Properties of the human arginine vasopressin V2 receptor after site-directed mutagenesis of its putative palmitoylation site. Biochem $J$ 313:611-616.

Seno K and Hayashi F (2017) Palmitoylation is a prerequisite for dimerizationdependent raftophilicity of rhodopsin. J Biol Chem 292:15321-15328.

Shenoy SK, McDonald PH, Kohout TA, and Lefkowitz RJ (2001) Regulation of receptor fate by ubiquitination of activated beta 2 -adrenergic receptor and betaarrestin. Science 294:1307-1313.

Shenoy SK, Modi AS, Shukla AK, Xiao K, Berthouze M, Ahn S, Wilkinson KD, Miller WE, and Lefkowitz RJ (2009) Beta-arrestin-dependent signaling and trafficking of 7-transmembrane receptors is reciprocally regulated by the deubiquitinase USP33 and the E3 ligase Mdm2. Proc Natl Acad Sci USA 106:6650-6655.

Shenoy SK, Xiao K, Venkataramanan V, Snyder PM, Freedman NJ, and Weissman AM (2008) Nedd4 mediates agonist-dependent ubiquitination, lysosomal targeting, and degradation of the beta2-adrenergic receptor. J Biol Chem 283:22166-22176.

Shukla A, Mylonas E, Di Cola E, Finet S, Timmins P, Narayanan T, and Svergun DI (2008) Absence of equilibrium cluster phase in concentrated lysozyme solutions. Proc Natl Acad Sci USA 105:5075-5080.

Sibley DR, Benovic JL, Caron MG, and Lefkowitz RJ (1987) Regulation of transmembrane signaling by receptor phosphorylation. Cell 48:913-922.

Skieterska K, Rondou P, Lintermans B, and Van Craenenbroeck K (2015) KLHL12 promotes non-lysine ubiquitination of the dopamine receptors $\mathrm{D} 4.2$ and $\mathrm{D} 4.4$, but not of the ADHD-associated D4.7 variant. PLoS One 10:e145654

Song L and Luo ZQ (2019) Post-translational regulation of ubiquitin signaling. $J$ Cell Biol 218:1776-1786.

Soto AG, Smith TH, Chen B, Bhattacharya S, Cordova IC, Kenakin T, Vaidehi N, and Trejo $J$ (2015) N-linked glycosylation of protease-activated receptor-1 at extracellular loop 2 regulates G-protein signaling bias. Proc Natl Acad Sci USA 112: E3600-E3608.

Soto AG and Trejo J (2010) N-linked glycosylation of protease-activated receptor-1 second extracellular loop: a critical determinant for ligand-induced receptor activation and internalization. J Biol Chem 285:18781-18793.

Sriram K and Insel PA (2018) G protein-coupled receptors as targets for approved drugs: how many targets and how many drugs? Mol Pharmacol 93:251-258.

Standfuss J, Edwards PC, D'Antona A, Fransen M, Xie G, Oprian DD, and Schertler GF (2011) The structural basis of agonist-induced activation in constitutively active rhodopsin. Nature 471:656-660.

Stanley P, Schachter H, and Taniguchi N (2009) N-Glycans, in Essentials of Glycobiology ( Varki A, Cummings RD, Esko JD, Freeze HH, Stanley P, Bertozzi CR, Hart GW, and Etzler ME eds), Cold Spring Harbor, New York.

Steentoft C, Vakhrushev SY, Joshi HJ, Kong Y, Vester-Christensen MB, Schjoldager KT, Lavrsen K, Dabelsteen S, Pedersen NB, Marcos-Silva L, et al. (2013) Precision mapping of the human O-GalNAc glycoproteome through SimpleCell technology. EMBO J 32:1478-1488.

Stone MJ, Hayward JA, Huang C, E Huma Z, and Sanchez J (2017) Mechanisms of regulation of the chemokine-receptor network. Int J Mol Sci 18:342.

Sullivan LJ, Makris GS, Dickinson P, Mulhall LE, Forrest S, Cotton RG, and Loughnan MS (1993) A new codon 15 rhodopsin gene mutation in autosomal dominant retinitis pigmentosa is associated with sectorial disease. Arch Ophthalmol 111:1512-1517.

Tanaka K, Nagayama Y, Nishihara E, Namba H, Yamashita S, and Niwa M (1998) Palmitoylation of human thyrotropin receptor: slower intracellular trafficking of the palmitoylation-defective mutant. Endocrinology 139:803-806.

Tanowitz M and Von Zastrow M (2002) Ubiquitination-independent trafficking of G protein-coupled receptors to lysosomes. J Biol Chem 277:50219-50222.
Tansky MF, Pothoulakis C, and Leeman SE (2007) Functional consequences of alteration of N-linked glycosylation sites on the neurokinin 1 receptor. Proc Nat Acad Sci USA 104:10691-10696.

Terrell J, Shih S, Dunn R, and Hicke L (1998) A function for monoubiquitination in the internalization of a G protein-coupled receptor. Mol Cell 1:193-202.

Thomsen ARB, Plouffe B, Cahill TJ III, Shukla AK, Tarrasch JT, Dosey AM, Kahsa AW, Strachan RT, Pani B, Mahoney JP, et al. (2016) GPCR-G protein- $\beta$-arrestin super-complex mediates sustained G protein signaling. Cell 166:907-919.

Tian X, Irannejad R, Bowman SL, Du Y, Puthenveedu MA, von Zastrow M, and Benovic JL (2016) The $\alpha$-arrestin ARRDC3 regulates the endosomal residence time and intracellular signaling of the $\beta 2$-adrenergic receptor. $J$ Biol Chem 291: 14510-14525.

Tiu AC, Yang J, Asico LD, Konkalmatt P, Zheng X, Cuevas S, Wang X, Lee H, Mazhar M, Felder RA, Jose PA, and Villar VAM (2020) Lipid rafts are required for effective renal D1 dopamine receptor function. FASEB $J$ 34:6999-7017.

Tobin AB, Butcher AJ, and Kong KC (2008) Location, location, location...site-specific GPCR phosphorylation offers a mechanism for cell-type-specific signalling. Trends Pharmacol Sci 29:413-420.

Torrecilla I, Spragg EJ, Poulin B, McWilliams PJ, Mistry SC, Blaukat A, and Tobin $\mathrm{AB}$ (2007) Phosphorylation and regulation of a $\mathrm{G}$ protein-coupled receptor by protein kinase CK2. J Cell Biol 177:127-137.

Trejo J, Connolly AJ, and Coughlin SR (1996) The cloned thrombin receptor is necessary and sufficient for activation of mitogen-activated protein kinase and mitogenesis in mouse lung fibroblasts. Loss of responses in fibroblasts from receptor knockout mice. J Biol Chem 271:21536-21541.

Trejo J and Coughlin SR (1999) The cytoplasmic tails of protease-activated receptor-1 and substance $\mathrm{P}$ receptor specify sorting to lysosomes versus recycling. $J$ Biol Chem 274:2216-2224.

Trejo J, Hammes SR, and Coughlin SR (1998) Termination of signaling by proteaseactivated receptor-1 is linked to lysosomal sorting. Proc Natl Acad Sci USA 95: 13698-13702.

Trester-Zedlitz M, Burlingame A, Kobilka B, and von Zastrow M (2005) Mass spectrometric analysis of agonist effects on posttranslational modifications of the beta-2 adrenoceptor in mammalian cells. Biochemistry 44:6133-6143.

Ullah S, Lin S, Xu Y, Deng W, Ma L, Zhang Y, Liu Z, and Xue Y (2016) dbPAF: an integrative database of protein phosphorylation in animals and fungi. Sci Rep 6: 23534

Uribe A, Zariñán T, Pérez-Solis MA, Gutiérrez-Sagal R, Jardón-Valadez E, Piñeiro A, Dias JA, and Ulloa-Aguirre A (2008) Functional and structural roles of conserved cysteine residues in the carboxyl-terminal domain of the follicle-stimulating hormone receptor in human embryonic kidney 293 cells. Biol Reprod 78:869-882.

van den Born LI, van Soest S, van Schooneveld MJ, Riemslag FC, de Jong PT, and Bleeker-Wagemakers EM (1994) Autosomal recessive retinitis pigmentosa with preserved para-arteriolar retinal pigment epithelium. Am J Ophthalmol 118:430-439. van Koppen CJ and Nathanson NM (1990) Site-directed mutagenesis of the m2 muscarinic acetylcholine receptor. Analysis of the role of N-glycosylation in receptor expression and function. J Biol Chem 265:20887-20892.

van Wijk SJ, Fulda S, Dikic I, and Heilemann M (2019) Visualizing ubiquitination in mammalian cells. EMBO Rep 20:e46520.

Villar VA, Cuevas S, Zheng X, and Jose PA (2016) Localization and signaling of GPCRs in lipid rafts. Methods Cell Biol 132:3-23.

Virion Z, Doly S, Saha K, Lambert M, Guillonneau F, Bied C, Duke RM, Rudd PM, Robbe-Masselot C, Nassif X, et al. (2019) Sialic acid mediated mechanical activation of $\beta_{2}$ adrenergic receptors by bacterial pili. Nat Commun 10:4752.

Walker KM, Urban L, Medhurst SJ, Patel S, Panesar M, Fox AJ, and McIntyre P (2003) The VR1 antagonist capsazepine reverses mechanical hyperalgesia in models of inflammatory and neuropathic pain. $J$ Pharmacol Exp Ther 304:56-62.

Wang J, Babcock GJ, Choe H, Farzan M, Sodroski J, and Gabuzda D (2004) N-linked glycosylation in the CXCR4 N-terminus inhibits binding to HIV-1 envelope glycoproteins. Virology 324:140-150.

Wang JR, Huang WL, Tsai MJ, Hsu KT, Huang HL, and Ho SY (2017) ESA-UbiSite: accurate prediction of human ubiquitination sites by identifying a set of effective negatives. Bioinformatics 33:661-668.

Wang T, Nakagawa S, Miyake T, Setsu G, Kunisue S, Goto K, Hirasawa A, Okamura $H$, Yamaguchi Y, and Doi M (2020) Identification and functional characterisation of N-linked glycosylation of the orphan G protein-coupled receptor Gpr176. Sci Rep 10:4429

Weber J, Polo S, and Maspero E (2019) HECT E3 ligases: a tale with multiple facets. Front Physiol 10:370.

Weinberg ZY, Crilly SE, and Puthenveedu MA (2019) Spatial encoding of GPCR signaling in the nervous system. Curr Opin Cell Biol 57:83-89.

Wheatley M and Hawtin SR (1999) Glycosylation of G-protein-coupled receptors for hormones central to normal reproductive functioning: its occurrence and role. Hum Reprod Update 5:356-364.

Wheatley M, Wootten D, Conner MT, Simms J, Kendrick R, Logan RT, Poyner DR, and Barwell J (2012) Lifting the lid on GPCRs: the role of extracellular loops. $\mathrm{Br}$ $J$ Pharmacol 165:1688-1703.

Whorton MR, Bokoch MP, Rasmussen SG, Huang B, Zare RN, Kobilka B, and Sunahara RK (2007) A monomeric G protein-coupled receptor isolated in a high-density lipoprotein particle efficiently activates its G protein. Proc Natl Acad Sci USA 104:7682-7687.

Wolfe BL, Marchese A, and Trejo J (2007) Ubiquitination differentially regulates clathrin-dependent internalization of protease-activated receptor-1. J Cell Biol 177:905-916.

Wu B, Chien EY, Mol CD, Fenalti G, Liu W, Katritch V, Abagyan R, Brooun A, Wells P, Bi FC, et al. (2010) Structures of the CXCR4 chemokine GPCR with smallmolecule and cyclic peptide antagonists. Science 330:1066-1071.

Wu H, Wacker D, Mileni M, Katritch V, Han GW, Vardy E, Liu W, Thompson AA, Huang XP, Carroll FI, et al. (2012) Structure of the human k-opioid receptor in complex with JDTic. Nature 485:327-332. 
Xiang Y, Rybin VO, Steinberg SF, and Kobilka B (2002) Caveolar localization dictates physiologic signaling of beta 2 -adrenoceptors in neonatal cardiac myocytes. $\mathrm{J} \mathrm{Biol}$ Chem 277:34280-34286.

Xiao K and Shenoy SK (2011) Beta2-adrenergic receptor lysosomal trafficking is regulated by ubiquitination of lysyl residues in two distinct receptor domains. $J$ Biol Chem 286:12785-12795.

Xie Y, Zheng Y, Li H, Luo X, He Z, Cao S, Shi Y, Zhao Q, Xue Y, Zuo Z, et al. (2016) GPS-Lipid: a robust tool for the prediction of multiple lipid modification sites. Sci Rep 6:28249.

$\mathrm{Xu}$ J, He J, Castleberry AM, Balasubramanian S, Lau AG, and Hall RA (2003) Heterodimerization of alpha $2 \mathrm{~A}$ - and beta 1-adrenergic receptors. $J$ Biol Chem 278: 10770-10777.

Xu J, Tan P, Li H, Cui Y, Qiu Y, Wang H, Zhang X, Li J, Zhu L, Zhou W, et al. (2019) Direct SUMOylation of M1 muscarinic acetylcholine receptor increases its ligandbinding affinity and signal transduction. FASEB J 33:3237-3251.

Xue Y, Zhou F, Zhu M, Ahmed K, Chen G, and Yao X (2005) GPS: a comprehensive www server for phosphorylation sites prediction. Nucleic Acids Res 33: W184-W187.

Yang S, Onigman P, Wu WW, Sjogren J, Nyhlen H, Shen RF, and Cipollo J (2018) Deciphering protein O-glycosylation: solid-phase chemoenzymatic cleavage and enrichment. Anal Chem 90:8261-8269.

Yu SM, Jean-Charles PY, Abraham DM, Kaur S, Gareri C, Mao L, Rockman HA, and Shenoy SK (2019) The deubiquitinase ubiquitin-specific protease 20 is a positive modulator of myocardial $\beta_{1}$-adrenergic receptor expression and signaling. J Biol Chem 294:2500-2518.

Zamah AM, Delahunty M, Luttrell LM, and Lefkowitz RJ (2002) Protein kinase A-mediated phosphorylation of the beta 2-adrenergic receptor regulates its coupling to Gs and Gi. Demonstration in a reconstituted system. J Biol Chem 277 31249-31256.

Zhang J, Liu Y, Jiang K, and Jia J (2017) SUMO regulates the activity of Smoothened and Costal-2 in Drosophila Hedgehog signaling. Sci Rep 7:42749.

Zhang Q, Xiao K, Liu H, Song L, McGarvey JC, Sneddon WB, Bisello A and Friedman PA (2018) Site-specific polyubiquitination differentially regulates parathyroid hormone receptor-initiated MAPK signaling and cell proliferation. $J$ Biol Chem 293:5556-5571.

Zheng H, Pearsall EA, Hurst DP, Zhang Y, Chu J, Zhou Y, Reggio PH, Loh HH, and Law P-Y (2012) Palmitoylation and membrane cholesterol stabilize $\mu$-opioid receptor homodimerization and G protein coupling. BMC Cell Biol 13:6.

Zheng N and Shabek N (2017) Ubiquitin ligases: structure, function, and regulation. Annu Rev Biochem 86:129-157.

Zhu JZ, Millard CJ, Ludeman JP, Simpson LS, Clayton DJ, Payne RJ, Widlanski TS, and Stone MJ (2011) Tyrosine sulfation influences the chemokine binding selectivity of peptides derived from chemokine receptor CCR3. Biochemistry 50:1524-1534.

Zuckerman DM, Hicks SW, Charron G, Hang HC, and Machamer CE (2011) Differential regulation of two palmitoylation sites in the cytoplasmic tail of the beta1adrenergic receptor. J Biol Chem 286:19014-19023. 